10. TEXT DES GLOSSARS FÜR LADISLAUS POSTUMUS (COD. PAL. GERM. 1787)

UND SEINER ABSCHRIFT (CVP 2945) 



$$
4^{\mathrm{ra}} 1^{r b}
$$

\begin{tabular}{|c|c|c|}
\hline ANgelus & Engil Engel & Andiel \\
\hline Archangel(us) & Archangil Archengel & Archandiel \\
\hline Anima & Sel Dusse & \\
\hline Aer & luft Powietrzi & \\
\hline Aqua & Wosser wasser & Woda \\
\hline Articulus & Gelid gelide ${ }^{\mathrm{c}}$ & Czlanek \\
\hline Amicus & Frunt freunt & Przitel pizitel ${ }^{\mathrm{d}}$ \\
\hline Amita & Müm müme ${ }^{\mathrm{e}}$ & Teta $^{f}$ \\
\hline Auus & Anherre & Died \\
\hline Avia & Anvrauwe ${ }^{g}$ anvra $(v) d e^{\mathrm{h}}$ & Babka \\
\hline Awunculus & Öme Óme h(er)lich ${ }^{\mathrm{i}}$ & Vgecz \\
\hline Amica & Ffrundin frewtdin & Przitelnicze przitelince \\
\hline Ancilla & Dirne diren & Diewka \\
\hline Antipedia & Furfüs furfus & Nartie \\
\hline Asinus & Esel Essel & Osel \\
\hline Agaso & Eselhyrt Esselhirt & Oslak \\
\hline Aries & Ster Stier & Beran \\
\hline Agnus Angnus & Lamp & Skopecz \\
\hline Aper & Ber & Kanecz \\
\hline Avea & Ganz Ganzs j & Hus \\
\hline \multicolumn{3}{|c|}{ a Abb. 7. Die Seite wurde auch faksimiliert in V. FLAJŠHANS, Jazyk, 265} \\
\hline \multicolumn{3}{|c|}{ b Abb. 36} \\
\hline \multicolumn{3}{|c|}{ c B: e nachträglich ergänzt } \\
\hline \multicolumn{3}{|c|}{ d die erste der vielen $r-i$ - Fehlschreibungen im tschechischen Teil von B. Vgl. dazu S. 45} \\
\hline \multicolumn{3}{|c|}{ e B ergänzt nachträglich das diakritische Zeichen und $e$} \\
\hline \multicolumn{3}{|c|}{ f B korrigiert aus leta } \\
\hline \multicolumn{3}{|c|}{ a A: ein kleines u mit Haarstrich über a geschrieben } \\
\hline \multicolumn{3}{|c|}{$\begin{array}{l}\text { h B: das Häkchen über dem } r \text { steht für } v \text { was der Überschreibung mit u in A entspricht. Der Kopist ha } \\
\text { dann das doppelstöckige } w \text { der Vorlage gründlich missverstanden. Dazu S. } 47\end{array}$} \\
\hline \multicolumn{3}{|c|}{ i B: das zweite Wort mit blasser Tinte ergänzt. Vgl. auch 75 } \\
\hline j B: $s$ ergänzt & & \\
\hline
\end{tabular}




$$
4^{v} 1^{v}
$$

\begin{tabular}{|c|c|}
\hline Anser & Ganzer Gan (n)sser \\
\hline Avis & Fogel \\
\hline Auceps & Fogeler Foler \\
\hline Ala & Flugel Fügel \\
\hline Aneta & enten entten \\
\hline Anetarius & Enthreich a entrich \\
\hline Alauda & leriche lerich \\
\hline Aquila & Adelar Adäler \\
\hline Accipiter & Habich ${ }^{\mathrm{c}}$ \\
\hline Aurum & Golt \\
\hline Argentum & Silber \\
\hline Arua & Feld \\
\hline Aleum & knobloch Knoblach \\
\hline Auena & haber ${ }^{d}$ \\
\hline Annona & Getreid Gtreid \\
\hline Asperiollus Asperiolus & Eychorn(n) Aychoren \\
\hline Angwilla Anwilla & $\mathrm{Ol} A l l$ \\
\hline Allec & Herink herinck \\
\hline Abicere & verwerfen ${ }^{\mathrm{f}}$ verweffen \\
\hline Abscondere & verpergen $^{g}$ \\
\hline \multicolumn{2}{|c|}{ a A: $i$ überschrieben } \\
\hline \multirow{2}{*}{\multicolumn{2}{|c|}{$\begin{array}{l}\text { b A: Orel etc vom Schreiber C nachgetragen. Vgl. S. } 33 \text { und Abb. } 16 \\
\text { c A: a nachträglich überschrieben }\end{array}$}} \\
\hline & \\
\hline \multicolumn{2}{|c|}{ d A: b aus w korrigiert } \\
\hline \multicolumn{2}{|c|}{ e in A wohl nachträglich mit dunklerer Tinte eingefügt } \\
\hline \multicolumn{2}{|c|}{ A: initiales $\mathrm{v}$ aus $\mathrm{w}$ korrigiert } \\
\hline \multicolumn{2}{|c|}{ A: initiales $\mathrm{v}$ aus $\mathrm{w}$ korrigiert } \\
\hline
\end{tabular}

Huser

Ptak ptack

Ptacznik Ptacznick

Krzidlo

Kaczicze

kaczer

Sskrziwanecz

Orlice Orel etc ${ }^{\mathrm{b}}$ Orlicze

orelicz

Gestrzab

Zlatto

Strzibro

Diedina

Czesnek

Owes

Obile

Wewerzicze

Vhorz

herynk e herýnk

zawrezy

Skryti 


\section{$5^{\text {r }} 2^{r}$}

\begin{tabular}{|c|c|c|}
\hline Abire & Hin gen hyn gen & Otgiti \\
\hline Abissus & Helle & Propast Peklo a \\
\hline Abluere & Waschn(n) waschenn & Oprati \\
\hline Abnegare & Verlouken verlaugen & Zaprziti \\
\hline Abreuiare & Churcen kurtzen & Vkratiti \\
\hline Absinthium Absintheum & wermut wermuet & Pelinek \\
\hline Absoluere & Erlosin erlosen & Rozhrziessiti \\
\hline Accede & Trither tritther & Przistup \\
\hline Accende & Zunde Zundenn (!) & Zazzi \\
\hline Acceptus & Genem Chenem & Zaczen \\
\hline Accipe & $\operatorname{nim}$ Nym & wezmi \\
\hline Accusare Acusare & Clagen clagenn & zalowati \\
\hline Acerbus & Pitter & horzky ${ }^{b}$ \\
\hline Acetum & Ezzig Essig & Oczet \\
\hline Acuere & Scherffen & Ostrziti \\
\hline Acus & nadel & Gehla \\
\hline Acutus & Sschorft Schorff c & Ostry Ostrï \\
\hline Adaquare & trenken ${ }^{\mathrm{d}}$ trencken & Napogiti \\
\hline Addere & Zugeben zwgeben & Przidati \\
\hline Adducere & Zubrengen zwfuren & prziwesti \\
\hline
\end{tabular}




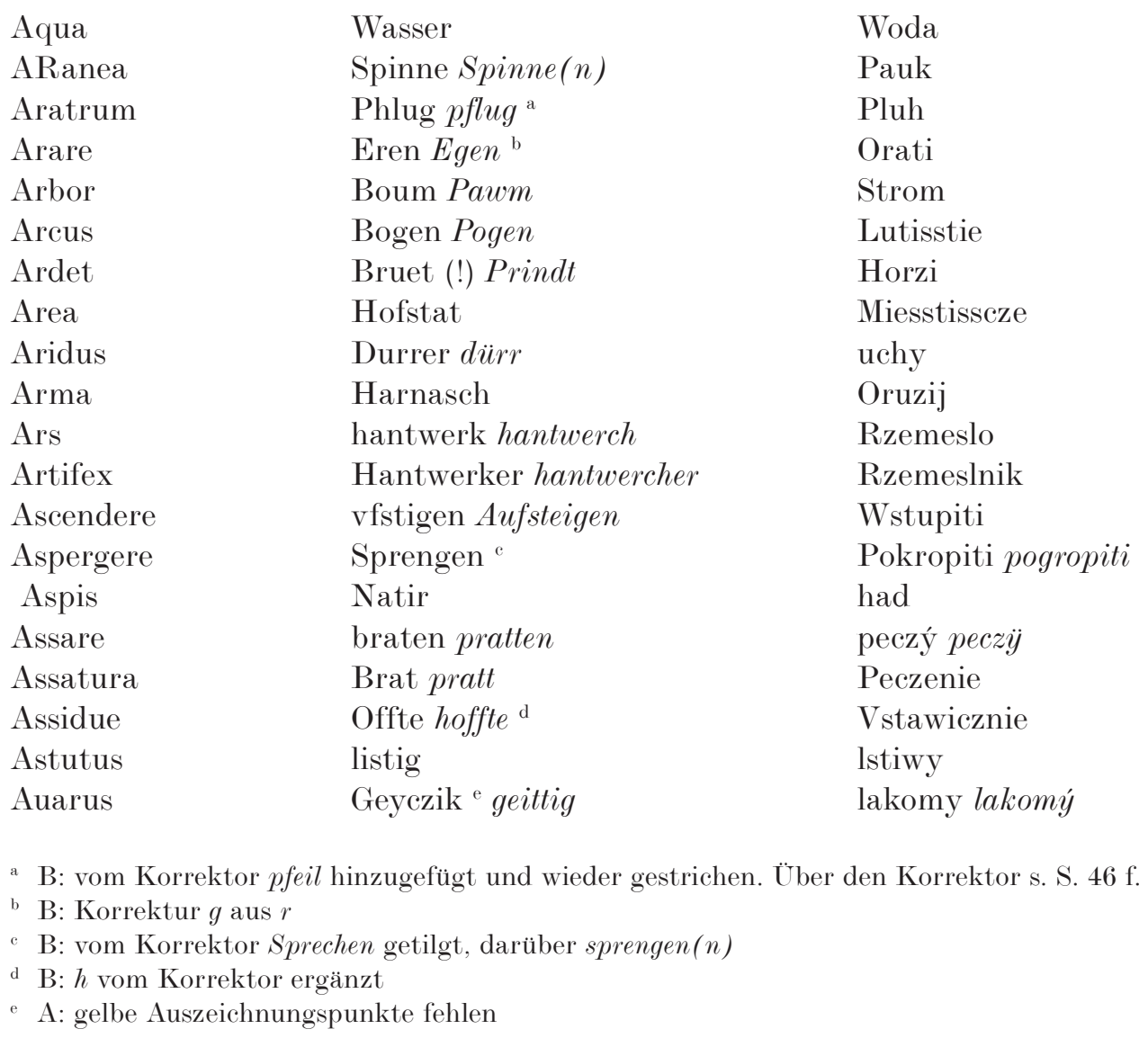


$6^{\mathrm{r}} 3^{\mathrm{r}}$

$\begin{array}{ll}\text { Audax } & \text { Chune } \\ \text { Audire } & \text { heren horen } \\ \text { Aufferre } & \text { nehmen nem }(m) \text { en } \\ \text { Aura } & \text { weter } \\ \text { Adequare } & \text { Ebin } \\ \text { Aderere (!) } & \text { Anhangen } \\ \text { Adiungere } & \text { Zuvugen zwfuegen } \\ \text { Adiuuare } & \text { Helfen helffen } \\ \text { Adolescens } & \text { Cnappe } \\ \text { Adorare } & \text { Anbeten Anpetten } \\ \text { Aduersarius } & \text { Fint veintt } \\ \text { Adulator } & \text { Zublezer Zütutler } \\ \text { Adulter } & \text { Ebrecher }{ }^{\mathrm{c}} \text { Eprecher } \\ \text { Aduocat(us) } & \text { Voit vogt } \\ \text { Affabilis } & \text { Mitsam Mittsam } \\ \text { Affirma } & \text { Veste pstett(n) } \\ \text { Affligere } & \text { Slahen Slahenn } \\ \text { Ager } & \text { Acker } \\ \text { Agere } & \text { Tun } \\ \text { Agilis } & \text { Resche } \\ \text { a A: dahinter se getilgt } & \\ \text { b A: sp(o)giti nachträglich ergänzt } \\ \text { a A: davor hurer getilgt } \\ \text { d B: voit vom Korrektor zu vogt korrigiert } \\ \text { e recte Role, vgl. Klaret } 727 \\ \end{array}$

Smiely

Slysseti

Odgiti

Powietrzi

przirownati

przidrzeti a $^{\text {a }}$

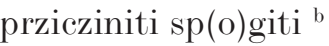

pomoczy

Ginoch

Modlitise

Protiwnik protiwirck

Pochlebnik pochlebrak

Czyzoloznik

Foit

Ochotny

Vtwrd

Biti

Bole $^{\text {e }}$

Cziniti

Rychly

20

a A: dahinter se getilgt

c A: davor hurer getilgt

e recte Role, vgl. Klaret 727 
$6^{\mathrm{v}} 3^{\mathrm{v}}$

$\begin{array}{lll}\text { Agitare } & \text { Jagen } & \text { Honiti } \\ \text { Agricola } & \text { Ackerman } & \text { Ratag } \\ \text { Alapa } & \text { Muleslac } & \text { policzek } \\ \text { Albugo } & \text { weisen weyssen } & \text { Bielmo } \\ \text { Albus } & \text { weis } & \text { Bily bilÿ } \\ \text { Alere } & \text { Ecin } & \text { krmiti } \\ \text { Aligenigena } & \text { Elende Ellende } & \text { Czyzozemecz } \\ \text { Alimentum } & \text { Speise Speis } & \text { Pokrm } \\ \text { Aliquando } & \text { Etwen Ettwen } & \text { Niekdy Niekdy } \\ \text { Aliquid } & \text { Etwaz Ettwas } & \text { Nieczo niezo } \\ \text { Aalius a Alius } & \text { Einander } & \text { Giny giny } \\ \text { Alter } & \text { Anders } & \text { Ginaky } \\ \text { Aleuiare } & \text { leichten } \text { Ringere(n) } & \text { Polehcziti } \\ \text { Aligare } & \text { Czubinden Zwpintten } & \text { Prziwazati } \\ \text { Alonge } & \text { Verre } \text { uerrer } & \text { Z daleka } \\ \text { Altare } & \text { Elter altär } & \text { Oltarz } \\ \text { Altus } & \text { Hoch } & \text { Wyssoky } \\ \text { Alcior } & \text { hohir hocher } & \text { Wyssi } \\ \text { Altissimus } & \text { Derhöst der hochst } & \text { Naywyssi } \\ \text { Alueus } & \text { Pach } & \text { Struha }\end{array}$

a A: Dopplung des Anfangsbuchstabens durch Mißverständnis zwischen Schreiber und Rubrikator 
$7^{r} 4^{r}$

\begin{tabular}{|c|c|c|}
\hline Aluus & Buch Puech & Brzicho \\
\hline Amor & Dy Lieb & Milost \\
\hline Amare & Liebhaben & Milowati \\
\hline Amarus & Bitter pitter & horzky \\
\hline Ambulare & Gen genn & Choditi - giti \\
\hline Amicus & Frunt frundt & przitel \\
\hline Amphora & Cruk krueg & Czban \\
\hline Angulus & winkel winckel & Kaut kynuti a \\
\hline Annuere ${ }^{a}$ & winken wincken & kynuti \\
\hline Annunciacio & Chundunge verku(n)dung & Zwiestowani \\
\hline Annus & Jore $j \ddot{a} r$ & Rok \\
\hline Antiqus (!) Antiquus & Alder man altter man & Stary \\
\hline Anulus & Vingerlin vingler ${ }^{\mathrm{b}}$ & Prsten \\
\hline Aperire & Vftun Auffthun & Otewrziti \\
\hline Apis & Bin Pyn & wezela \\
\hline Aparuit & Erschein Erscheine(n) (!) & zgewilo se zgwilose \\
\hline Appendere & Anhahen anhangen & Powiesyti \\
\hline Appetitus & pegerunge pegerung & Zadost \\
\hline Apponere & Czulegen czwlegen & Prziloziti \\
\hline Appreciare & Dingen & nagiti nagati nagiti \\
\hline
\end{tabular}




\section{$7^{\mathrm{v}} 4^{v}$}

\begin{tabular}{|c|c|c|c|}
\hline Appropin(que)re & Czunahen Zwnachent & Przibliziti & \\
\hline Avris & ore oren & Vcho Bcho & \\
\hline \multicolumn{4}{|l|}{ Avriga ${ }^{a}$} \\
\hline Avrum & Golt ${ }^{b}$ & Zlatto zlato & \\
\hline Awuncul(us) ${ }^{\mathrm{c}}$ & Ome ${ }^{\mathrm{c}}$ & Vgecz $^{\mathrm{c}}$ & 5 \\
\hline Auus $^{c}$ & anher Anherr ${ }^{\mathrm{c}}$ & Died $^{\mathrm{c}}$ & \\
\hline Auxilium(m) Auxilium & Hulfe hilffe & Pomocz & \\
\hline Axis & Achs & oy neb woy & \\
\hline Baculus & Knittel knettel & Kay Kä̈ & \\
\hline Baiulare & Tragen Tragenn & Nesti & 10 \\
\hline Balbus & Stamelder & Zagikawy Zagikaway & \\
\hline Balista & arbrust (!) armbrust & Samostrzil & \\
\hline Baptismus & Touf tauff & Krziest kiziest & \\
\hline Baptisare & Toufen tauffen & krztiti kizctiti & \\
\hline Barba Barbar (!) & Bart part & Brada & 15 \\
\hline Beatus & Heilig Heylig & Blahoslaweni & \\
\hline Bellum & Streit Streitt & Воу Вой & \\
\hline
\end{tabular}


Benedicere

Bene

Benignus

Bestia

Bibere

Bis

Bonus

Bos

Blandus

Breuis

Brucus

Buccina

Buccella

Bulit

Butirum

a B: $g$ überschrieben
Zegin geseghenn ${ }^{\mathrm{a}}$

$5^{r}$

Wol Woll

Williger guettig

Tire Tier

Trinkin trincken

Czwir zwir

Guttir guetter

Ochs

Senpht senffdt

Curcer Curtz

keuir

Blashorn(n)

Snite

walt

Puttir putter
Zehnati

Dobrzie Dobrizie
Dobrowolny
Howado
piti
dwakrat
Dobry
wul wull
lahodny lahodny
kratky krathy
Chraust
Trauba
Skyba
wrze
Maslo




\section{$8^{\mathrm{v}} 5^{v}$}

$\begin{array}{lll}\text { Cacabus } & \text { Sturcz } & \text { Pokliczka } \\ \text { Cadauer } & \text { Az As } & \text { Mrcha } \\ \text { Cadere } & \text { Vollen vallen } & \text { Vpadnuti } \\ \text { Calamus } & \text { Halm helm } & \text { Steblo stelbo } \\ \text { Calcare } & \text { Tretin tretten } & \text { Tlatiti } \\ \text { Calceus } & \text { Schuch Schuech } & \text { Trzewicz } \\ \text { Calciare } & \text { Schuen Schuechen } & \text { Obuti } \\ \text { Calefacere } & \text { wermin wirmen } & \text { Shrzieti } \\ \text { Calidus } & \text { Worm warm } & \text { Teply } \\ \text { Calix } & \text { Kelch kelich } & \text { Kalich } \\ \text { Calor } & \text { Hiczt hiecz } & \text { Horko } \\ \text { Caluus } & \text { Kal } & \text { Lysy } \\ \text { Caluicies } & \text { Glicee } & \text { lysyna } \\ \text { Camelus } & \text { Olbent } & \text { Welblud } \\ \text { Camera } & \text { kamer } & \text { Komora } \\ \text { Caminus } & \text { Vuermuer } & \text { komin } \\ \text { Campus } & \text { Velt } & \text { Pole } \\ \text { Canale } & \text { Rinne } & \text { Zlab } \\ \text { Cancer } & \text { Crebez Crebes } & \text { Rak } \\ \text { Candela } & \text { Luchte chirczen } & \text { Swicze }\end{array}$




$$
9^{\mathrm{r}} \boldsymbol{6}^{r}
$$

Candelabr(um)

Candidus

Cantare

Cancio

Canis

Canus

Captiuus

Capilli

Capra

Carbo

Carcer

Cardo

Caritas

Caro

Carus

Caseus

Castitas

Castrum

Cauda

Cauea
Luchter leuchter

Luchter liechter

Singen

Ein lit Einlit

Hunt hundt

Gra grab

Gefangin gefangen

har här

Czige gayss

kol

kerker Keychen ${ }^{\mathrm{b}}$

Ture angil Turangel

Libe lieb

Fleisch 'fleich (!)

lip lieb

kese ${ }^{\mathrm{d}}$ kess

kuscheit kewsch

Burg purck ${ }^{\mathrm{f}}$

Czogel zoglel (!)

Vogelhuz Vogehaus (!)
Swizcen

Swietly

Spiwati

Pisnie

Pes

5

Ssediwy Ssedwoy

popadeny neb wieczen ${ }^{\text {a }}$

Wlasy

Koza

Vhel

Zalarz zalaiz (!)

Stezege

laska

Masso

mily

Syr

Czistota ${ }^{\mathrm{a}}$

hrad

Oczas

kletcze

a A: neb wiezen ergänzt

b B: en aus er korrigiert

c A: s überschrieben

d A: finales e ergänzt

e A: s wohl nachträglich eingefügt

f B: perch zu purck korrigiert 


\section{$9^{\mathrm{v}} \boldsymbol{6}^{v}$}

\begin{tabular}{|c|c|c|c|}
\hline Caueas & Hute Hüett & Choway se Chowayse & \\
\hline Catena & Kethin khetten & Rzietiez & \\
\hline Cathedra & Sessil Sessel & Stolicze & \\
\hline Cecus & Blindir Blinder & Slepy & \\
\hline Celum & himel hym $(m) l$ & Nebe & 5 \\
\hline Cede & Stevor & Postup & \\
\hline Celarium(m) & Keller & Piwnicze & \\
\hline Celebrare & feirn(n) feyren & Swietiti & \\
\hline Cimentum & Kalch & Wapno & \\
\hline Cena & Abentessin a abentessen & weczerce beczerce & 10 \\
\hline Cera & Wachs wags & wosk ${ }^{b}$ & \\
\hline Certe & Gewislichen gewislich & Gistie & \\
\hline Cessa & Lasin lashin & Prziestan & \\
\hline Cete & Wolvisch & welryb welrÿb & \\
\hline Cibus & Spise Speis & krmie & 15 \\
\hline Cingulus & Gurtel & Pas & \\
\hline Circuire & Vmgen vmb gen & obgiti ${ }^{\mathrm{c}}$ & \\
\hline Circumcidere & Vmsniden vmb schneide( $n$ ) & Obrzezati & \\
\hline Citara & harfe Harpfen & husle & \\
\hline Cito & Snelle Snell & Brzo & 20 \\
\hline
\end{tabular}


$10^{r} y^{r}$

Ciuitas
Clama
Clauis
Claudus
Claude
Claudicare
Clibanus
Clipeus
Cocus
Coequare
Cophinus
Cogitacio
Cognatus
Cognoscere
Colasus
Coligere Colligere
Collum
Color
Columbus
Colu(m)ba
a B: aus glichin korrigiert
b B: vgl. S. 46
a recte Neffe
d A: aus Taumbin korrigiert

Stat

Ruf Rueff

Slussin Schluessl

lam

Tuczu thuezw

Hinken hincken

Ouin

Schilt

Choch

Glichin gleichen $^{\text {a }}$

korp kropff b

Gedanck gedanck

Nefte neste ${ }^{\mathrm{c}}$

Irkennen erkennen

Halsslak halsschlag

Ufcluben aufklaube( $n$ )

Hals

Fabe (!) farb

Taumber Tauben

Taumbe d Taubin
Miesto

wolay

klicz

belhawy

zawrzi

kleczeti

Pecz

Sstit

Kucharz

Zrownati zrowonati

10

koss

Missleni

rodicz

poznati

possigek

zbierati

Hrdlo

barwa

Holub

holubicze

20 
$10 \times y^{v}$

Columna

Combustus

Commedere

Commendare

Comiscere

Communis

Comunica(r)e ${ }^{b}$

Comutare commitare (!)

Compassio

Componere

Comprim(er)e

Contencio

Concubina

Conculcare

Concupiscencia

Concupiscie( $n$ ) cia

Conferre

Confidere

Confirmare

Confessio

Confortat(us)
Sule

verbrant verprinen

Essen

Loben

mischin mischen

Gemein gemayn

Gmeinschaft gemayschaft (!) b

wechsil wechsll

Erbarmen erparmen

Czusamlegen zwsamlegen

Druggen

kryg krieg

Slafwip Schlafbeib

Petretin

Gerunga geru(n)g

Zamsprechen zamsprechn(n)

Hoffen

Pfesten bestatten

Beicht

Gesterk gesterckn (n)
Slup

Zhorzal

Gisti

Chwaliti

Smiesseti

Obeczny Obeczowati a

Obczowati promieniti (!) ${ }^{b}$

Promieniti

Slitowanie

Sloziti

Stisknuti

Swar

Zenina

Potlatiti

Zadost

Spolu mluwiti

Spolumluwiti

$\checkmark$ fati

15

Spowied

Posylen

a B: zweites $a$ getilgt

b B: Zeile hinter Confessio $10^{\vee}$ Z. 19. Am Beginn der Zeile setzte der Korrektor ein communio 
$11^{\mathrm{r}} 8^{r}$

Conbitumina(r)e

Cong(re)gare

Consang(u)ine(us)

Consciencia

Consecracio

Consilium

Consolacio

Constans

Consuere

Consuetudo

Contempt(us)

Contradice(re)

Contristatus

Conueni(r)e

Conuersio

Conuiuiu(m) Conuium (!)

Conuocare

Cooperire

Cor

Corea
Zleimin

Sammen

Frunt

Gewisunge Gewisung

Weiunge beichung

Rath Ratt

Trost

Stete Statig

Nen náen

Gewonheit

Virsmeheit vnschmachait (!)

widersagen

Betrubt betruebt

Czamkumen Zamkum (m) en

Bekerunge becheru( $n) g$

Enkwas ${ }^{a}$

Czomruffen zamRueffen

bedecken

Hercz $^{b}$

Tancze
Sekliti

Sebrati

Rodicz

Swiedomi

Poswieczeni

Rada

Vtiessieni

Vstawiczný

Ssiti

Obyczey Obiczeý

Zhrzeny Zhrzený

odpowiedieti

Zarmuczen

Sgiti se

Obraczenie Obraczanie

15

kwas

Swolati

przikrziti

Srdcze

Tanecz ${ }^{\mathrm{c}}$

a A: wohl nachträglich eingefügt. Gelbe Auszeichnungspunkte fehlen

b B: darüber irrtümlich noch ein er-Kürzel

c B: der restliche Text im Abschnitt C fehlt, vgl. dazu S. 43 
$11^{\mathrm{v}}$

\begin{tabular}{lll} 
Corigium & Rumen & Rzemen \\
Corrigere & Besseren & oprawiti \\
Corripere & Straffen & Tresktati \\
Cornu & Horn & Roh \\
Corpus & leichnam & Tielo \\
Cortex & Rinde & kura \\
Cortina & Vmhang & opona \\
Coruus & Rabe & hawran \\
Costa & Rippe & zebro \\
Cottidie & Altage & Nawssakyden \\
Cras & Morgen & Zaytra \\
Craticula & hurt & lesa \\
Creator & Schepper & Stworzitel \\
Creatura & dycreature & Stworzeni \\
Crebro & Dike & Czasto \\
Credo & Geloub & Wierzim \\
Crepusculu $(m)$ & Obent & Sumrak \\
Crescere & Wachsen & Rosti \\
Cribrum a & Sippe & Rzesseto \\
Crimen & Sunde & hrzich \\
a i aus e korrigiert & & \\
\hline
\end{tabular}


$12^{\mathrm{r}}$

$\begin{array}{ll}\text { Crinis } & \text { Har } \\ \text { Crocus } & \text { Zafren } \\ \text { Crispus } & \text { Cruspe } \\ \text { Crudelis } & \text { Grimmic } \\ \text { Crux } & \text { Creuce } \\ \text { Cubiculu(m) } & \text { Schpanbet a } \\ \text { Culpa } & \text { Scholt } \\ \text { Cubitus } & \text { Elbogen } \\ \text { Culex } & \text { Mucke } \\ \text { Cupio } & \text { beger } \\ \text { Cura } & \text { Zorge } \\ \text { Currere } & \text { leufen } \\ \text { Curia } & \text { hofe } \\ \text { Custos } & \text { Huter } \\ \text { Custodire } & \text { huten } \\ \text { Cutis } & \text { haut }\end{array}$

Wlasy

Ssafran

kaderzawy

Vkrutny

krziz

lozcze

wina

Loket

komar

Zadam

pecze

Bezeti

Dwuor

Strazcze

Strziczy

15

kuoze

a A: nachträgliche Ergänzung ohne Auszeichnungspunkt 
$12^{\mathrm{v}} 8^{v}$

Dabo

Damnu(m)

Dampnatus Damnat(us)

Debilis

Debilitas

Debitor

Debitum

Decem

Decima ${ }^{\mathrm{b}}$ DEecima ${ }^{\mathrm{C}}$

Decepcio

Decet

Decolare

Deprimere

Depellere

Deducere

Denudare

Deformis

Defraudatus

Defunctus
Ich geb $i c h$ gib

Schode Schadt

Ferloren verloren

Crank kranck

Crankeit kranchait

Gelder geltter

Schult Schuldt

Czehen Zehen

Czehent Zehent

Trugeheit treugnus

Czimp Zim

Enteupten enhauppen

Virdrucken vnd(er) rucken (!)

Virtreiben vertreiben

Geleite gelayten

Enplozen enplossen

vngestalt

betrogen

begraben begrabenn
Dam li dam

Sskoda

ztraczny ztraczwy (!)

Medly, mdly a

Mdloba

Dluznik Dluznick

Dluh

Deset

Desatek

Oklamanie

Slussi

Stiti

Stisknuti

Sehnati

Prowodit

15

a A: mdly ergänzt

b A: Decima als eigene Zeile irrtümlich wiederholt, vgl. S. 31

c B: $E$ vom Rubrikator getilgt

neyasny neyaswij (!)

Obelstieny

Pohrzebeny 
$13^{\mathrm{r}}$

Deiectus

Abgewofen (!) Abgeworffnn

Swrzeny

\section{$\boldsymbol{g}^{r}$}

Deglutire

Delere

Delibe(r)are

Delicatus

Delicie

Delictum ${ }^{c}$

Demonstrare

Denarius

Dens

Depilare

Depingere

Deponer

Deportare

Deprecacio

Deprehensus

Deprope

Derelinquere Delinquere

Deridere

Descendere

Virslinden verslindenn

Abtun

Betrachten erlosen a

eliczart man eliczzartman ${ }^{b}$

wirtsheft wirtschefft

Sult Schuld ${ }^{\mathrm{C}}$

Weisen weysenn

Phennink Pfenni(n)g

Czan zand

Raufen Rauffen

Malen

Abzeczen

Entragen

Engebet ein gepet

Begriffen begrieffen

Nahen

losen $v($ er )lassen

Virspattin verspotten

Absteigen
Pozrzieti

Zahladiti zahbatiti

Rozmyslyti

Rozkossny

Rozkossi Roskossi

wina ${ }^{c}$

pokazati

peniz

Zub

10

Rwati

Malowati

Sloziti

Donesti

Prozba

15

Zastupen

Zblizka

Ostawiti

Posmiewati se

Stupiti

a B: DUCANGE setzt deliberare mit redimere gleich

b recte ein czart man, wohl im Sinn von „,weichlich, wollüstig“, vgl. GRIMM XV, 285 bzw. tschechisch rozkošné, JUNGMANN 3, 885

- B: diese Zeile nach $13^{\text {r }}$ Z. 19 Deridere 
$13^{\mathrm{v}}$

Deserere Virlosen verlassen Opustiti

Deseruire

Desiderare

Desiderabilis

Desine

Desideratus

Desolatus

Desponsatus

Destruere

Desuper

Detegere

Detiner

Detrahere

Deterius

Deturpare

Deuiare

Deuorare

Deuote

Dextera

Diccio $\boldsymbol{9}^{v}$

Virdien (!) widerdiene $(n)$
begern begeren
Wnsam wunsam
Ablas
begert
elende ellendt
Vorlobter ${ }^{\text {a }}$ verlobter
Virterben verderbn $(n)$
Darobir Daruber
entecken endencken (!)
Vfhalden auffhalden
Enczien enziehen
Bozer pöser
Vurschamen ${ }^{b}$ Vuerschamen
Irren
fresen fressen
Andachtig
Recht hant
Wort

Zasluziti

zadati

Zadostiwy zadostiwoy

Przestan

5

zadany

zpustly

zasnubeny

zkazyti

zhuory zhuorij

odkryti odkriti

zdrzeti

Strhnuti

Horssi

ohyzditi

Bluditi

Seżrati Sezrati

Naboznie

Prawicze

Slowo

a A: Auszeichnungspunkte fehlen

b A: $r$ überschrieben 
$14^{\mathrm{r}}$

Dicere

Dies

Differre

Difficile

Digerere

Digitus

Dignus

Dilatare

Dileccio

Diluculum

Diluuium

Dimidium

Dimittere

Diminuere Diminure

Dirigere

Discalciare

Discedere

Disciplina

Disciplinatus
Sprechen Sprechen(n)

Rzeczy

$10^{r}$

Hab gesprochn(n)

abgesprochn(n) (!)

Tag

Vfczihen Vfziehenn

Swer swar

Deuuen deuen

ffinger vinger

Wirdik wirdig

Breiten praitten

Liebe

Taget

Flut flus

Halp halb

lasen lassen

Minneren Mynder(n)

Senden

Enschuen Endschuechn(n)

hingen

Czucht zucht

Wolgeczogen wolgezogen ( $n$ )
Rziekl sem Rzieklsein (!)

Den

Odloziti

Nesnadno Mesnadno

pożiti poziti

Prst

dostoyny

Rozssirziti Rossicziti

Milost

10

Switanie

Potopa

Polowicze

Pustiti

Vmenssiti

Poslati

15

zzutise zutise

odgiti

kaze'n kazen

Kazany 
$14^{\mathrm{v}}$

Discrecio

Discipulus

Discordia

Discoopertus

Discurrere Discurre (!)

Discus

Dispenssator Dispensator

Dispersit

Dissensio

Dissipare

Dissoluc (i)o

Distribuere Distribure (!)

Distinccio

Ditare

Diuicie

Diuersu

Diuininitas (!)

Diuidere

Diu

Diuulgare

a zu mhd. enbloezen

b B: $t$ eingeflickt

c B: $s$ zu $z$ verbessert
Bescheid(en)heit

geschmeydikait

$10 v$

Junger

Czweiunge enzwaiu(n)g

Enplacz ${ }^{a}$

Vmlaufen vmb lauffen

einkar

Schaffer

Verteilit vertayligt (!)

Streit Streitt

Streuwen

Vnstetikeit Vnstätikait

Teilen taylenn

Teilunge taylung

Richen Reichenn

Reichtum Reichtu(n)g

Manig(er)lei Manig(er)lay

Gotheit Gotthaitt

Teilen taylen

lange lang

Kunden
Rozom

Vezedlnik vizedlnik

Rozdrzenie

Odkryty

haleti

5

Okrzin

Sapharz

Rozptitel rozsipal

Roznicze

Rozptylel

Rozpusstienie

Rozdawati

Rozdiel

Obohatieti

Bohatstwi $^{b}$

15

Rozliczne

Bostwi

Rozdieliti ${ }^{\circ}$

dluho

oznamiti 
$15^{\mathrm{r}}$
Docere
Leren lernen
Veziti

$11^{r}$

$\begin{array}{ll}\text { Doctus } & \text { Gelerit gelert } \\ \text { Dolabrum } & \text { Bart pratt }{ }^{\text {a }} \\ \text { Dolare } & \text { Czimmiren Czimmraren (!) } \\ \text { Dolor } & \text { Smercze Smerczhn(n) } \\ \text { Doleo } & \text { Tut mirwe Thuet mir we } \\ \text { Dolosus } & \text { Listiger } \\ \text { Domare } & \text { Czeumen zamme(n) } \\ \text { Dominus } & \text { Herre herr } \\ \text { Domus } & \text { Huz haws } \\ \text { Domesticus } & \text { huzman hawsman } \\ \text { Donum } & \text { Gabe gab } \\ \text { Dormire } & \text { Sloffen Schlaffen } \\ \text { Dormitare } & \text { Nepczen }{ }^{b} \\ \text { Dorsum } & \text { Rucke Rücke } \\ \text { Dos } & \text { Morgengobe Morgengab } \\ \text { Dubium } & \text { Czwiuil zweyfell } \\ \text { Ductor } & \text { furer } \\ \text { Ducere } & \text { furen } \\ \text { Ducenti } & \text { Czweihundert Czwayhundert } \\ & \\ \text { a mhd. barte „Beil“ } & \text { b mhd. nafzen „schlummern “ } \\ \end{array}$

Vezeny

Bradaticze

Tesati

Bolest

Boli mne

Lstiwy Lstiwiy

Vkrotiti

Pan

duom

10

domovnik domownik

Dar

Spati

Drziemati

Chrzbet

wieno

negisto

wudcze

wezti westi

Dwiestie

mhd. barte „Beil“ 
$15^{\mathrm{v}}$

Dulcis Suse Suess Sladky

$11^{v}$

$\begin{array}{lll}\begin{array}{l}\text { Duo } \\ \text { Duodecim } \\ \text { Duplum }\end{array} & \text { Czwey Zway } & \text { Dwa } \\ \text { Durum } & \text { Czweilef Zwelff } & \text { Dwanaczte } \\ & \text { Herte hiert } & \text { dwogene } \\ \text { Eadem } & \text { Dazselbe dassebig (!) } & \text { Twrde } \\ \text { Ebdomada } & \text { Woche wochen } & \text { Tez } \\ \text { Ebrius } & \text { Trunken Truncken } & \text { Tyden } \\ \text { Ebur Ebor } & \text { Helfenbein helffe }(n) \text { pain } & \text { Opily Opyly } \\ \text { Ecce } & \text { Sich Siech } & \text { Slonowa kost } \\ \text { Ecclesia } & \text { Kirchen Kirchenn } & \text { hled } \\ \text { Ebulire } & \text { Vbersiden Vber sieden } & \text { kostel } \\ \text { Edere } & \text { Essen } & \text { Wykpieti } \\ \text { Edictum } & \text { Dasgesprochen } & \text { Gisti } \\ & \text { das gsprochn(n) } & \text { wypowied } \\ \text { Edificare } & \text { baun pawen } & \\ \text { Edificium } & \text { hus gebude haus paue(n) (!) } & \text { Stawieti } \\ \text { Educere } & \text { Vorfuren Verfuren } & \text { Staweni } \\ \text { Efferre a } & \text { Auztragen Austrage(n) } & \text { wywesti } \\ \text { Effodere } & \text { Auzgraben ausgraben } & \text { Wynesti } \\ \text { Effugare } & \text { Voriagen vergagen } & \text { Wykopati } \\ & & \text { wypuditi }\end{array}$

Kirchen Kirchenn

Vbersiden Vber sieden

Essen

Dasgesprochen

das gsprochn $(n)$

baun pawen

hus gebude haus paue(n) (!)

Vorfuren Verfuren

Auzgraben ausgraben

wypuditi

a A: eine ursprüngliche e-Dopplung entsprang einem Mißverständnis zwischen Schreiber und Rubrikator. Der Schreiber erkannte dies und tilgte sein initiales e. 
$16^{\mathrm{r}}$

Effundere

Auzgisen Ausgiessen

$12^{r}$

Effugere
Egens
Ego
Egredi
Egregius
Egrotus
Eicere Eicire (!)
Elatus
Electus
Elemosin
Elephans
Eleuatus
Elongatus
Eloquens
Emana
Emarcuit
Emendare
Emere
Emittere

Enphlien enphilen (!)

$\operatorname{Arme} \operatorname{Arm}(m)$

Ich

Ausgen

Geslach

kranke kranck

hynwerfen hynwerffen

hoffertik hochfertig

einerweltir auserwelter

Almusen almuessen

Elefant

Dirhebter erhebter

Gelenget gelengert

Gesprech gesprachig

Auzfluset ausfliesset

Durret

Besseren

keufen kauffen

Auzlossen auslossen
Wyliti

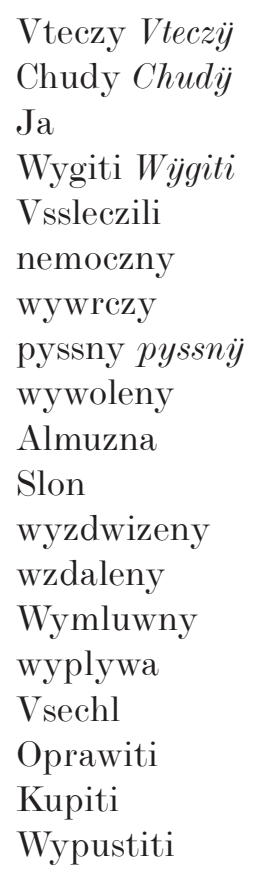


$16^{\mathrm{v}}$

Emptor Emtor

Keufer kauffer

Kupecz

$12^{v a}$

\begin{tabular}{|c|c|c|}
\hline Emulari & Nochvolgen ${ }^{b}$ nachuolgen & Nasledovati ${ }^{\mathrm{b}}$ Nasledowati \\
\hline Emundare ${ }^{\mathrm{c}}$ & Reinen erleiwtern( $n)$ d & vezstiti \\
\hline Euacuare & Auzbeduten ${ }^{\mathrm{e}}$ ausleiten $(n)^{\mathrm{f}}$ & wyprazniti ${ }^{\mathrm{g}}$ wyprazniti \\
\hline Enatare & Auzswimmen Ausswimmen & wyplynuti wylypnuti \\
\hline Eneus & Mesigen Messigen ${ }^{\mathrm{h}}$ & mosazny mosacznÿ \\
\hline Enutritus & Gespeiset & Vkrmeny Vkrmenÿ \\
\hline Episcopus & Bischof Bischolf & Biskup \\
\hline Epulari & wulleben wolleben & hodowati \\
\hline Equales Equalis & Gleicher geleich $(e) r$ & Rowny Rowný \\
\hline Equaliter & Geleich & Rownie \\
\hline Equitas & Rechtikeit pillikait) ${ }^{\mathrm{i}}$ & Sprawedliwost Sprwedliwost \\
\hline Equs Equus & Ros & kuoň kuon \\
\hline Erectus & Aufgericht erhebt ${ }^{\mathrm{j}}$ & Zprostieny Zprostienÿ \\
\hline Ericius & Igel Igël & Gezek \\
\hline Erga & Neben & Podle \\
\hline Ergo & darumme darvmb & proto \\
\hline Eripere & Auznemen ausnemnien (!) & Wyniti \\
\hline Errare & Irgen Irren & Bluditi \\
\hline Erubescere & Sschemen Schemen ${ }^{\mathrm{k}}$ & Stydieti se Stydietise \\
\hline
\end{tabular}

a Abb. 37

b A: deutsch-tschechische Kolumne vertauscht

c A: i zu e korrigiert

d B: reinen vom Korrektor getilgt, darüber erleiwtern ( $n)$

e A: darüber ledigen

f B: Ausbetutten und darüber ledigen getilgt, darüber vom Korrektor ausleiten(n)

g A: korrigiert aus wyprawiti

$\mathrm{h}$ recte wohl Messingen

i B: über Rechtigkeit schreibt der Korrektor pillikait

j B: Aufgericht getilgt, darüber vom Korrektor erhebt

k $\mathrm{B}$ : $e$ eingefügt 
$17^{\mathrm{v}}$

Euocare

Auzrufen Ausrueffen

Wywolati

$13^{v}$

Exaltatus ${ }^{a}$
Examinare
Exacerbare ${ }^{\mathrm{b}}$ Excercebare (!)
Exasperare
Exaudire
Excecare
Excelsus
Excessus
Excipere
Excidere
Excitare
Excusare
Excutere ${ }^{\mathrm{d}}$
Exemplum
Exemplar ${ }^{\text {e }}$ Exempla
Exercitus ${ }^{\text {exercitus }}$ Exere
Exibere Exhibere
Exire

Gehoht Erhocht

Vorsuchen versuechen

czReisen ZwReisen

Scherfen Scherffen

Irhoren Erhoren

Irblenden Erblenden

der höch Erhocht

Vbertreten Vbertretten

Auznemen ausnemmen

Auzsniden auschneiden

wecken wecken

Euschulden (!) Enschuldigen

Auzslan

Einbilde Ebenpild

bilder bildar

Einher

biten bitten

Auz gen ausgen
Powyssen

Zkusyti

Roztrhati

wybrusyti

Vslysseti Vslyssety

Oslepiti

wysoky

przestupeny przestupený

wyniti

Wyrzezati wirzezati

zbuditi

Omluwiti

Wytrzisti witizisti

Prziklad

15

idem

Zastup

wydati

Wygiti Wytigi

a B: die nächsten neun Zeilenanfänge zu je dreien mit einer Initiale E zusammengefaßt

b A: Exacerbare in eigener Zeile wiederholt, vgl. S. 31

c B: $c$ überschrieben, vielleicht missverstandenes (er)wecken

d B: diese Zeile nach Exutacio 18¹8. Der Schreiber markierte seinen Irrtum vor den Zeilen Excusae bzw. Excutere mit $b$ bzw. $a$

e A: die e-Dopplungen entspringen einem Mißverständnis zwischen Schreiber und Rubrikator

f B: davor witig getilgt. Die nächsten 3 Zeilen noch auf $13^{\mathrm{v}}$ 
$18^{\mathrm{r}}$

$\begin{array}{lll}\text { Exordium } & \text { Anvank Anvanck } & \text { Poczatek } \\ \text { Expandere } & \text { Breiten praitten } & \text { Rozpostiti a } \\ \text { Expllere (!) expellere } & \text { Auztreiben Austreyben } & \text { Wyhnati }\end{array}$

$14^{r}$

$\begin{array}{lll}\text { Exponere } & \text { Auzlegen Aus legen } & \text { Wylozity } \\ \text { Exportare } & \text { Auztragen Aus tragen } & \text { Wynesti } \\ \text { Exprimere } & \text { Auzdrucken Ausdrucken } & \text { Wytisknuti } \\ \text { Exprobrare }{ }^{\text {b }} & \text { Virsm(eck)en verschmechn(n) } & \text { Porokowati } \\ \text { Expungnare (!) } & \text { Auzfechten Ausvechten } & \text { Wyboiowati } \\ \text { Exsuffiare Ex sufflare }{ }^{\text {c }} & \text { Auzblasen Aus blassn(n) } & \text { wyduti } \\ \text { Extendere } & \text { Recken } & \text { Zprostiti } \\ \text { Extingwere } & \text { Virleschen verleschen } & \text { zhasiti zhasyti } \\ \text { Extirpare } & \text { Auzbrechen ausprechen } & \text { wykorzeniti } \\ \text { Extrahere } & \text { Auzczihen aus ziechn( } n) & \text { wytahnuti } \\ \text { Extollere } & \text { hoen } & \text { Powyssiti } \\ \text { Extraneus } & \text { Fremde } & \text { Czyzy } \\ \text { Extremus } & \text { Leczte } & \text { Posledni } \\ \text { Extrinsecus } & \text { Vzwendig auswendig } & \text { zewnitrz zewnitiz } \\ \text { Exutacio (!) } & \text { Freude } & \text { Radost } \\ \text { Exuere } & \text { Auzczhen (!) ausziechen } & \text { Swieczy Swleczy d }\end{array}$

a B: $s$ zu $z$ gebessert

b B schreibt zunächst richtig Exprobare und verschlimmbessert durch überschriebenes $r$

c B: davor fla getilgt

d B ergänzt in einer weiteren Zeile $17^{ }$Z. 12 und setzt ein Merkzeichen $b$ 
$18^{\mathrm{v}} 14^{v}$

\begin{tabular}{|c|c|c|}
\hline Faba & Bon ${ }^{a}$ & Bob ${ }^{\text {a }}$ \\
\hline Faber & Smit Schnidt (!) & Kowarz \\
\hline Fafricare Fabricare & Smiden Schmiden & Kowati \\
\hline Fabula & Mer & Base'n Basen \\
\hline Fasilis (!) b & Ringe & Snadny Snadnì \\
\hline Facinus & Sunde & Hrzich \\
\hline Facere & Tun Thun & Veziniti \\
\hline Facies & Antlucz Antlichz (!) & licze Twarz \\
\hline Falx & Sichil Sichel & Srp \\
\hline Fallax & Listiger & lstiwy lstiwÿ \\
\hline Falsum & Volsch valsch & Neprawe \\
\hline Fama & Gutnam lob & Powiest \\
\hline Fames & Hunger & hlad \\
\hline Famelicus & hungerig hungriger & Laczny lacznÿ \\
\hline Famelicus (!) Famulus & Knecht & Pacholek \\
\hline Familia & Gesind & Czeled ${ }^{\mathrm{c}}$ \\
\hline Familiaris Familiarius & heimlicher haymlich (e)r & powolny \\
\hline Farina & Mel Mell & Muka \\
\hline Fasciculus & Gärbe Gärb & Snopek \\
\hline Fastus & kundikeit kundigkait & hrdost \\
\hline
\end{tabular}


$19^{\mathrm{r}} 15^{r}$

$\begin{array}{ll}\text { Fatigatus } & \text { Müde Mude } \\ \text { Febris } & \text { Daz kalde das kalde } \\ \text { Fedus } & \text { Gelübde Gelübe } \\ \text { Femina } & \text { weip Beib(er) (!) } \\ \text { Femur } & \text { Huf Huff } \\ \text { Fenum } & \text { Hey } \\ \text { Fenestra } & \text { Fenster } \\ \text { Ferculum } & \text { Gericht } \\ \text { Feretrum } & \text { Bar Barr } \\ \text { Ferire } & \text { Slahen schlagenn } \\ \text { Fermentum } & \text { Jerb Jerbn(n) a } \\ \text { Feces } & \text { hewen } \\ \text { Ferum Ferrum } & \text { Eyzen eïssen } \\ \text { Fera } & \text { Tir } \\ \text { Feruor } & \text { hicze } \\ \text { Ferre } & \text { Tragen } \\ \text { Festinare } & \text { Eylen } \\ \text { Festum } & \text { hohczeit hochzeit } \\ \text { Festuca } & \text { Ast Ost } \\ \text { Fetus } & \text { Geburd }\end{array}$

Vstal

Zymnicze

Slib

Zena

Bedra

Seno

Okno

krmie

Nosydlo

Vderziti

kwas

kwasnicze

zelezo

Zwierz zwiercz

wedro

Nesti

Chwatati

Swatek

Suk

Plod

a mhd. gërwe, vgl. SCHMELLER 1, 934-935 
$19^{\mathrm{r}} 15^{v}$

\begin{tabular}{|c|c|c|}
\hline Fetor & Stank Stanck & Smrad \\
\hline Ficus & Feige feÿgen & Fik ${ }^{a}$ \\
\hline Fidelis & Getreue getrewer & wierny wiernÿ \\
\hline Fideiussor Fideiusor & einburge ${ }^{\mathrm{b}}$ Einburge & Rukoymie \\
\hline Fiducia & Hofnunge hoffnu(n)g & Vfanie \\
\hline Fiat & werde werd & bud \\
\hline Fingere & Stechen & Busti \\
\hline Figulus & Toppher haffner & Hrnczirz \\
\hline Figura & Einbilde eben (n)pild & Obliczey Obliczey \\
\hline Filius & Sun & Syn \\
\hline Filia & Tochter & dczera \\
\hline Fimbria & Zeum & Podolek \\
\hline Fimus & Mist & hnuoy hnиой \\
\hline Finis & Ende Endt & konecz \\
\hline Finitus & volendet vollenden & Skonan Skonam \\
\hline Firmus & Feste fest & Twrdy \\
\hline Fiscus & Darme darm & Trzewo \\
\hline Fixus & Gestochen Gestochenn & Vklany Vklanÿ \\
\hline Flos & blume plum & kwiet \\
\hline Florere & bluen pluen & kwisti \\
\hline
\end{tabular}


$20^{\mathrm{r}} 16^{r}$

Flagellum
Flagicium
Flamen
Flatus
Flectere
Fletus
Fluit
Flumen
Fluius Fluuius
Fodere
Folium
Fons
Foramen
Forpices
Forma
Formosus
Formare
Formica
Formidolosus
Fornax

Geisel Gaissel

Zunde

Flamen flamenn

Weunge

Neigen Naygen

weiunge waiunge (!)

Rinnet Rindt

Bach pach

Bachlein pachlein

Graben Grabenn

Blat platt

Brunne prun

Loch

Einczang Ein Zang

Schene Schon

wolgestalt

Schicken

Ameiz Amais

Forchtig

Ein owen Offen
Bicz

hrzich

Plamen

Dutie

Nakloniti

Placz

Tecze

Rzeka

Potok

kopati

10

list

Studicze (!) Studicze(n)

Diera

klesstie

Twarz

15

Twarzny twarznÿ

zposobiti

Mrawenecz

Strassliwy

kamna

20 
$20^{\mathrm{v}} 16^{v}$

$\begin{array}{ll}\text { Fornicator } & \text { Hürer hurer } \\ \text { Forum } & \text { Markt Marckt } \\ \text { Fortitudo } & \text { Sterke Sterck } \\ \text { Fortis } & \text { Stark Starck } \\ \text { Forte } & \text { leicht } \\ \text { Fortuna } & \text { Glucke Gluck } \\ \text { Fortunatus } & \text { Glukzelig glucklich } \\ \text { Fossa } & \text { Eingrub (!) Eingraben } \\ \text { Fouea } & \text { Eingrub } \\ \text { Fossores } & \text { Graber } \\ \text { Frangere } & \text { Brechen Prechenn } \\ \text { Fragmenta } & \text { Bozem prossen }{ }^{\text {a }} \\ \text { Frater } & \text { Bruder Brueder } \\ \text { Fraus } & \text { List } \\ \text { Frenum } & \text { Czaum zam } \\ \text { Frequenter } & \text { Dick } \\ \text { Frigus } & \text { kalt klatt (!) }{ }^{\text {b }} \\ \text { Frigidus } & \text { kelder } \\ \text { Frons } & \text { Stirn } \\ \text { Fructus } & \text { Frucht } \\ & \\ \text { a mhd. brozem } & \\ \text { b B: vgl. S. } 48 & \end{array}$

Smilnik

Trh

Syla

Sylny

Snad

Sstiesti

Ssczastny Ssczatnï (!)

Jama

Duol

Kopaczi

zlamati

Otrusky Otruskiy

Bratr

lest

Vzda

Czasto

Zyma züma

Studeny

Czelo

Plod, owocze
5 
$21^{\mathrm{r}} 1 \mathrm{y}^{\mathrm{r}}$

Fruges Frugus
Frumentum
Frustra
Frutex
Fugere
Fugare
Fulcire
Fulgur
Fumus
Funda
Fundus
Fundamentu(m)
Fundere
Funis
Furiosus
Fur
Furatus
Fuscus
Fubula
Fusale

Sat Sátt

Getrad getraid

Vmsust Vmbsunst

Gerten

Flihen flichen

voriagen vorigan (!) b c

Vmsteken Vmbsteken ${ }^{\mathrm{b}}$

Blicze

Rauch

Grunt Gruntt

badem

Gruntfest Grundfest

Gisen Giessen

Strick

Czornig zornig

dipp diepp

virstalen gestolen

Brune praw (!)

ol Oll

Czwekholez ${ }^{\mathrm{d}}$ czweckholz
Oseni

Obile

na darmo a

Prut prutt

Vteczy

za puditi

Ohraditi

Bliskot Bliskott

Dym

Prak

10

Dno

Zaklad

liti

Powraz

Hniewiwy

15

Zlodiey

vkradl

Smiedi

Ssidlo

Brslen

20

a B: aus nar darmo korrigiert

b B: die beiden nächsten lateinischen und deutschen Lemmata vertauscht. Zur Kennzeichnung des Irrtums setzte der Schreiber vor und nach den tschechischen Entsprechungen ein $b$ und $a$

c über vorigan irrtümliche or-Kürzung

d A: Zierpunkte fehlen 
Galea

Gallus

Galina

Gaudium

Gelu

$\operatorname{Gem}(\mathrm{m}) \mathrm{a}$

Gemelli

Gemitus

Gene

Generacio

Generalis

Generator

Generare $^{b}$

Genua

Germanus

Gestare

Gesta

Giga

Glacies

Gladius
Helm

han

Henne henn

Freude frewd

Reif Reyff

Perle perl

Czweiling Czwayling

Zufzung Zussrung (!)

Wank Wang

Geburt gepurd

Gemein gemayn

Gebere (!) geperer

Geberen geperen ${ }^{\mathrm{b}}$

Knie knye

Bruder brueder

Tragen tragn $(n)$

Tat

Rizs Riss

Ize eizs Eiss

Swert
Helm

kokot

Slepicze

Radost

Mraz ${ }^{a}$

Perla

Blizenczy Blizenczy

lkani

Jahodeze

Narod

Obeczny Obeczny

Roditel Roditi (!)

Roditi ${ }^{b}$

kolena koleno

Bratr

Nosyti nossity

Skutky Skutï

Obr

led

Mecz mecss

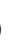

a B: Mraz vom Rubrikator unterstrichen

b B: Zeile nach $21^{\mathrm{V}} \mathrm{Z}$. 20 Gladius 
Globus Glounis a

Gloria

Gluten Glutenn

Grabatum

Gracia

Gracias age(re)

Gradus

Graditur

Grandi

Granum

Gratis

Gratus

Grauis

Gressus

Grex

Grossus

Gustum d

Gustare

Guttur

Gula
Kule ${ }^{b}$ keule

Lop $l o b$

Leim

Bet

Gnad Genad

Danken Dancken

Treppe

Geth

Gros

koren $\operatorname{korn}(n)$

Sust Sunst

Genem genam

Swer

Gank Ganck

her hertt

Dicke gros

Beise $^{\mathrm{e}}$

Kosten

kele kelle

Geiczickeit (!) Frashait
Chule b ${ }^{b}$ keule $(n)$

Slawa

kley klë̈

Loze

Milost

5

Diekowati

Schod

Chodi

weliky

Jadro, zrno Jardo zrno ${ }^{\circ}$

10

Darmo

Wraczen

Tiezky tiezk $\ddot{y}$

Chod

Stado

15

Tlusty

kus

okusyti

hrdlo

Obzerstwi

20

a B: recte glomis, vgl. S. 45

b A: deutsches mit tschechischem Lemma vertauscht

- B: keine Interpunktion, zrno vom Rubrikator unterstrichen

d B: aus gustus verbessert

e wohl Weise 
Habere

Habitus

Habitare

Habitacio

Habundanter Habundare (!)

Hamus

Harundo

Hasta

Haurire

Hereditas

Heremus

Heremita

Heret

Hereticus

Herodius

Herba

Hesitare

Hiems

Hibaris ${ }^{a}$

Hircus

a recte Hilaris
Haben Habenn

Cleider Klayder

Wonen wonenn

wonunge wanunge

Wolliclichen

Ein angil

Ror

Sper

Schefen Schepfen

Erbe Erbschafft

wust wuest

Einsidel Einsidl

haft

ketczer keczer

Blafuz

wurez

Czweiuil

Winter wintter

Vrolicher

Bok pock
Mieti

Rucho

Prziebywati

Przibytek

Hoynie

Vdicze

Trest

Kopi

Nawaziti Nabaziti

diedicztwi

Pusstie

Pustenik

wiezy

kaczyerz

Raroh

15

korzen

Rozpakowati Rospakowati

Zyma

wesely

kozel

20 
$23^{r} 19{ }^{r}$

Hodie

Heute Hewt

Dnes

Homo

Mensch

Czlowiek

Homicida Homicidia

Manslechtig Manschlechtig

Wrazedlnik

Honestus

Honor

Ersam

Cztny Catiný

Ere

Czest

Honus

Burde burd

Brziemie

Hhora Hora ${ }^{\text {a }}$

Stund

Horeum

Horror Horor

Schuwe ${ }^{b}$

hodina

Forcht

Stodola

hruoza

Horribilis

Grausem grausam

Hrozny

Hordeum

Gersten Gerstenn

Geczmen

Hospicium

Herberg

Gast,wirt Gastwirt

hospoda

Hospes

vint veindt

host. hospodarz ${ }^{\mathrm{c}}$

Hostis

Ture Tür

Neprzitel

Hostium

Hostiari(us)

Torwarter Turwartter

dwerzi

Huc

her

Humanitas

Menschheit Menschait

Wratny wratny

Sem

Humerus

Aksil

Czlowieczenstwie

Ramie

Humilis

demutig diemuettig

Pokorny

a A: initiale Doppelschreibung durch ein Mißverständnis zwischen Schreiber und Rubrikator

b recte Schuwer, vgl. mhd. schiuwer „Scheuer"

c B: Interpunktion fehlt 
$23^{\mathrm{v}} 19 v$

$\begin{array}{lll}\text { Humus } & \text { Erde } & \text { Zemie } \\ \text { Iacere } & \text { Ligen } & \text { Lezeti } \\ \text { Ianua } & \text { Tur } & \text { wrata } \\ \text { Ibidem } & \text { Dasalbest daselben } & \text { Tudiez } \\ \text { Ictus } & \text { Enslag Einschlag ain wurff a } & \text { Rana } \\ \text { Idiota } & \text { Envngelert } & \text { Nedouka } \\ \text { Idoneus } & \text { Wirdig } & \text { Dostoyny } \\ \text { Iecur } & \text { Leber } & \text { Jatry Jatri } \\ \text { Ieiunium } & \text { Fast fasten } & \text { Pust } \\ \text { Ignis } & \text { Feuer fewer } & \text { Ohe'n Ohen } \\ \text { Ignile } & \text { Feuereisen } & \text { Ohniwo } \\ \text { Ignobilis } & \text { Vnedel } & \text { nesslechetny } \\ \text { Ignorare } & \text { vnwissen } & \text { Neumieti } \\ \text { Ignoscere Ignoscer (!) } & \text { Virgaben vergaben } & \text { Odpustiti } \\ \text { Illaqueare } & \text { Virstricken verstricken } & \text { Osydliti } \\ \text { Illico } & \text { Czuhant zwhant } & \text { Ynhed Ynhet } \\ \text { Illicitum } & \text { Vmmuglich vnmugelich un erlich }{ }^{b} & \text { Neslussno } \\ \text { Illusio } & \text { Trugenheit trugenhait } & \text { obluda } \\ \text { Illuminare } & \text { Irleuchten Erleuchtenn } & \text { Oswietiti }\end{array}$

a B: vom Korrektor Einschlag getilgt, darüber ain wurff

b B: un erlich vom Korrektor ergänzt 
$24^{r} 20^{r}$

\begin{tabular}{|c|c|}
\hline Illustris Illustrus (!) & Durchluchter durchleichtig(e)r \\
\hline Imago & Bilde pild \\
\hline Imitari & Nochfolgen Nochvolgen \\
\hline Immensus & Anmas \\
\hline Immolare Im molare & Oppheren opheren \\
\hline Inmundus & Vnrein vn Rain \\
\hline Inpaciens & Vngeduldig \\
\hline Inpedire Impedire & Irren hindern Irren hinder (!) \\
\hline Inpeditus Impetitus & Vnmusik vnmuessig \\
\hline Imperator & Keiser kayser \\
\hline Imperare & Gebiten Gepietten \\
\hline Impetrare $^{\mathrm{a}}$ & Biten Bitten erlangen a b \\
\hline Imperitus ${ }^{\text {a }}$ & vngelernt a vngelert \\
\hline Impius & Vngnedik Vngenadik \\
\hline Inponere Imponere & Einlegen Ein legen \\
\hline Inpugnare & Anfechten \\
\hline Implere & Fullen fuellen \\
\hline Inprobus & Vnfrum \\
\hline Improperare & Virweizin $^{\mathrm{c}}$ \\
\hline Incantator & Czeuberer \\
\hline
\end{tabular}

Oswieczeny Oswieczenÿ

Obraz

Nasledowati

Nesmierny Nesmierny

Obietowaty

Neczisti

Netrpeliwy

Przekazeti

Neprazdny Neprazdnï

Cysarz

10

Przikazati

Vprosity $^{\text {a }}$

Neuczeny Neuczen $\ddot{y}^{\text {a }}$

Nemilostivy

Wloziti

Boboyowati (!)

Naplniti

Necztny

Porokowati

Czarodieynik 


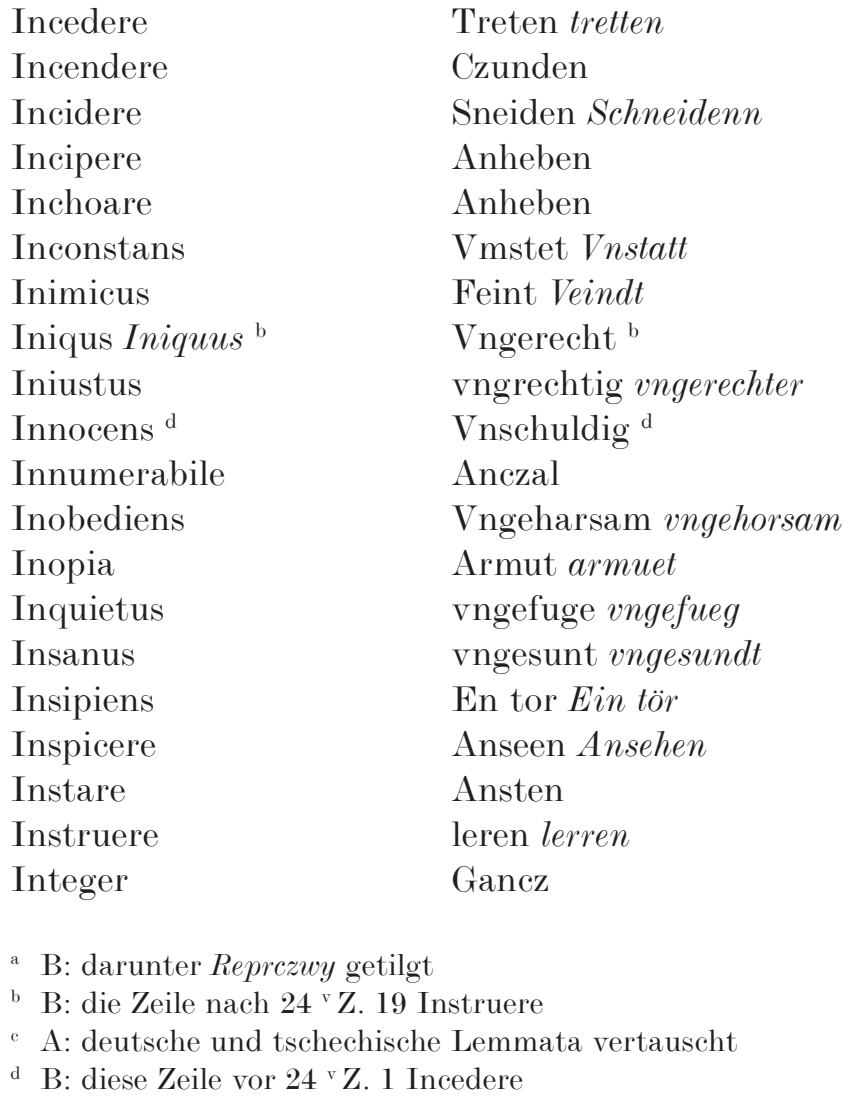

Incedere

Incidere

Incipere

Inconstans

Inimicus

Iniustus

Inobediens

Inopia

Insanus

Instruer

B: diese Zeile vor $24^{\vee} \mathrm{Z} .1$ Incedere
Stupati

Zaswititi

Narzezati

Pocziti

Pocziti

Neustawiczny

Neprzitel Reprzitel (!) a

Neprawy Nepraw ${ }^{b}$

Nesprawedliwy ${ }^{\circ}$

Newinny newinniy ${ }^{\mathrm{d}}$

Beztisla Bestizla

Neposlussny Neposlussnÿ

Chudoba

Nepokoyny

nezdrawy

Nemudry Nemudrï

hledieti

Nastati

Veziti viziti

Czely Czelý 
$25^{\mathrm{r}} 21^{r}$

\begin{tabular}{|c|c|c|}
\hline Intellectus & Vernuft & Rozom \\
\hline Inferior & Niderst Nyderst & Niderst Nissi ${ }^{a}$ \\
\hline Interficere & Töten Tötten & Zabiti \\
\hline Intercedere & Vorbiten & prosyti \\
\hline Interpretari & Bedeuten beteutten & wyprawiti \\
\hline Interpre & vursprech(er) b vorsprech & Rzecznik \\
\hline Interrrogare & Fragen fragenn & Tazati \\
\hline Intestina & Darm & Trzewa \\
\hline Intingere & Eintunken eintuncken & Omocziti \\
\hline Intueri & Ansehen & opatrziti \\
\hline Interius & Inwendik Inwendich & wnitrz \\
\hline Inutilis & Vnnucze vnnuecz & Nevziteczny \\
\hline Invenire & Vinden & Naleznuti \\
\hline Intus & Inwendik inwendig ${ }^{c}$ & wnitrz wintrz \\
\hline Incumbere & der ligen derligen & Przilezi \\
\hline Incuruare & Crummen & Nakrziwiti \\
\hline Inclinare & Eneigen & Nakloniti \\
\hline Includere & Einslisen einSchliessen & Zawrziti \\
\hline Incredulus & Inglabiger vngelaubig & Newierny \\
\hline Increpare & Schelden & lati \\
\hline
\end{tabular}

a A und B setzen niderst irrtümlich auch in die tschechische Kolumne. Der Rubrikator von B suchte den Fehler aber durch ein Häkchen zu kennzeichnen.

b A: aus vursprechn(n) korrigiert

- B: vom Korrektor aus inwendick verbessert 
$25^{\mathrm{v}} 21^{v}$

$\begin{array}{lll}\text { Indicare } & \text { Ceigen Zeigenn } & \text { Pokazati } \\ \text { Indigencia } & \text { Durfur Durfen }{ }^{\text {a }} & \text { Potrzeba } \\ \text { Indignari } & \text { Czuren (!) } & \text { hnewatise } \\ \text { Indisciplinat(us) } & \text { vngeczogen } \text { vngezohen }^{\text {Indoctus }} & \text { Nekazany } \\ \text { Inducere } & \text { Engelert } & \text { Neuczeny } \\ \text { Induere } & \text { Anlegen } & \text { Vwesti } \\ \text { Indulgencia } & \text { Ablas } & \text { Obleczy Oblecznÿ } \\ \text { Induratus } & \text { Herter hertter } & \text { Odpustek } \\ \text { Infelix } & \text { Vnselik Vnsalig } & \text { Zatwrzeny } \\ \text { Inferre } & \text { Eintragen } & \text { Nessczastny } \\ \text { Infernus } & \text { helle } & \text { wnesti } \\ \text { Infidelis } & \text { Vngetrauer } & \text { Peklo } \\ \text { Infimus } & \text { der minst } & \text { Newierny } \\ \text { Infirmus } & \text { krank kranck } & \text { Naynissi } \\ \text { Infu(n)dere } & \text { Eingisen Eingiessen } & \text { Nemoczny } \\ \text { Inflatus } & \text { Czuswollen Czvswollen } & \text { Naliti } \\ \text { Infringere Infrangere } & \text { Czubrechen Czwprechn(n) } & \text { Naduty } \\ \text { Ingenium } & \text { Sin Synn } & \text { Przelomiti } \\ \text { Ingens } & \text { dergroze } & \text { Wtib }\end{array}$

a B: aus Durfer korrigiert, zu mhd. durfen, durft 
$26^{r} 2^{r}$

$\begin{array}{ll}\text { Ingredi } & \text { Eingen } \\ \text { Infans } & \text { Ein kind Ein kint } \\ \text { Investigare } & \text { Irfolgen } \\ \text { Invidia } & \text { Neit neyd } \\ \text { Inuitatus Invitatus } & \text { Geladener geladner } \\ \text { Iocundus } & \text { Vrolicher frolicher } \\ \text { Ita } & \text { Alzo a } \\ \text { Iter } & \text { Wek weck } \\ \text { Iubilare } & \text { Vreuen sich vreuensich } \\ \text { Iudeus } & \text { Jude Jud } \\ \text { Iudex } & \text { Richter } \\ \text { Iudicium } & \text { Gericht } \\ \text { Iugulare } & \text { Wurgen } \\ \text { Iugum } & \text { Ein Joch } \\ \text { Iumentum } & \text { Fieh } \\ \text { Iungere } & \text { Czufugen Czwfuegen } \\ \text { Iurare } & \text { Sweren } \\ \text { Iurgium } & \text { Krik } \\ \text { Iussit } & \text { heisit haisset } \\ \text { Iustus } & \text { Ein rechter Ein gerechter } \\ \end{array}$

Wniti

Dietie

dostihnuti

Zawist

Pozwany

Wesely

Tak ${ }^{\text {a }}$

Czesta

Radowati se Radowatise

Zid

Richtarz. Sudi ${ }^{b}$

Sudi

Vdawiti

Gho

Skot

Seziniti

Przisahati

Swar

kazal

Prawy Prawý

20

a A: deutsche und tschechische Lemmata vertauscht, in B vor Tak ein al vom Rubrikator getilgt

b B: keine Interpunktion. 
$26^{\mathrm{v}} 22^{v}$

$\begin{array}{lll}\begin{array}{l}\text { Iusticia } \\ \text { Iuuenis }\end{array} & \begin{array}{l}\text { Rechtikeit gerechtigkait } \\ \text { Jung a Junger } \\ \text { Juuentus }\end{array} & \begin{array}{l}\text { Sprawedlnost } \\ \text { Mlady }\end{array} \\ \text { Labia } & \text { Lebs } & \text { Mladost } \\ \text { Labor } & \text { Orbeit arbait } & \text { Rty } \\ \text { Lac } & \text { Milich } & \text { Visle Dielo Vysle dielo } \\ \text { Lacerta } & \text { Eudechs } & \text { Mleko } \\ \text { Lacerare } & \text { Reisen Reissen } & \text { Gessczerka } \\ \text { Lacus } & \text { Ze } & \text { Drati } \\ \text { Lacrima } & \text { Zaher } & \text { Rybnik Rybnick } \\ \text { Lagena Lagna } & \text { Legel Lagel } & \text { Slza } \\ \text { Laycus } & \text { Leige } & \text { lawicze layk }{ }^{b} \\ \text { Lamentum } & \text { Wein } & \text { layk } \\ \text { Lambere } & \text { Lecken } & \text { Placz } \\ \text { Lamina } & \text { Plech } & \text { lizati } \\ \text { Lampas } & \text { lampp lamppen } & \text { Plech } \\ \text { Lancea } & \text { Sper } & \text { lampa } \\ \text { Lana } & \text { Wolle } & \text { kopie } \\ \text { Langor } & \text { Sichtum } & \text { Wlna } \\ & & \text { Nemocz }\end{array}$

a A: er getilgt

b B: der Kopist hat fälschlich layk aus der nächsten Zeile übertragen, diese Zeile dann aber ausgelassen 


$\begin{array}{lll}\text { Lapis } & \text { Stein Stain } & \text { Kamen } \\ \text { Lapidare } & \text { Steinen Stainnen } & \text { Kamenowati } \\ \text { Lapsus } & \text { Vallen } & \text { Pad } \\ \text { Laqueus } & \text { Strik Strick } & \text { Osydlo } \\ \text { Largus } & \text { Milde Mild } & \text { Ssczedry } \\ \text { Lasciuus } & \text { Geil Gail } & \text { Smilny } \\ \text { Lassus } & \text { Mude Muede } & \text { vstal } \\ \text { Later } & \text { Czigel Ziegel } & \text { Czyhla } \\ \text { Latitare Latigare (!) } & \text { Bergen sich Bergensich }{ }^{\text {a }} & \text { Skryti se } \\ \text { Llatus }{ }^{b} \text { Latus } & \text { Breit Breitt } & \text { Ssiroky } \\ \text { Llatro }{ }^{b} \text { Latro } & \text { Dip. loter Dieb.lotter }{ }^{\text {e }} & \text { lotr } \\ \text { Laudare } & \text { loben } & \text { Chwaliti } \\ \text { Lauare } & \text { Woschen waschenn } & \text { Vmiti } \\ \text { Lebes } & \text { Reinel } & \text { Rendlik } \\ \text { Lectus } & \text { Beth } & \text { loze } \\ \text { Ledere } & \text { Wetun Bethun } & \text { vrazyti vraziti } \\ \text { Legere } & \text { lesen } & \text { Czisti } \\ \text { Leuis } & \text { Geringe } & \text { lehky lehk } \ddot{~}\end{array}$

Leo

Lepus lewe

Haze Hass lew

Zagicz

a vgl. dazu S. 32

b A: initiale Dopplung, weil Schreiber und Rubrikator l setzten

c B: Interpunktion vom Rubrikator 
$27 \mathrm{v}$

$\begin{array}{lll}\text { Lepra } & \text { Auzseczik Ausseczick } & \text { Malomoczenstwi } \\ \text { Leticia } & \text { Freude frewde } & \text { wesele } \\ \text { Letificare } & \text { Irfreuen Erfreydenn } & \text { Weseliti } \\ \text { Leua } & \text { link hant } & \text { lewicze } \\ \text { Leuare } & \text { Aufheben } & \text { Zdwihnuti } \\ \text { Lex } & \text { Ee } & \text { Zakon } \\ \text { Libenter } & \text { Gerne } & \text { Rad } \\ \text { Liber } & \text { Buch puech } & \text { Knihy } \\ \text { Liberare } & \text { lözen lozen } & \text { zbawiti } \\ \text { Libido } & \text { Begerunge } & \text { Zadost } \\ \text { Licencia } & \text { Vrloup } & \text { Odpussczeni } \\ \text { Licet } & \text { Czimet zimet } & \text { Slussi } \\ \text { Ligare } & \text { Binden } \text { pynden } & \text { Swazati } \\ \text { Lignum } & \text { holcz } & \text { Drzewo } \\ \text { Ligua Ligwa (!) } & \text { Czunge Czung } & \text { Jazik } \\ \text { Linire } & \text { Smeren } & \text { Mazati } \\ \text { Linum }{ }^{a} & \text { Fflachs } & \text { len a } \\ \text { Linteamen } & \text { leiloch Lleiloch } & \text { Prostiradlo } \\ \text { Lira } & \text { lire }{ }^{b} \text {, forch } & \text { brazda }\end{array}$

Literatus

Gelert

Vezeny

a B: die Zeile fehlt

b s. dazu S. 34 
$28^{\mathrm{r}}$

\begin{tabular}{|c|c|}
\hline Litigare & Krigen kriegen \\
\hline Littus & Vber \\
\hline Locus & Stat Stat $(t)$ \\
\hline Locuples & Reich \\
\hline Locusta & Heuschrek Heuscherck (!) \\
\hline Longus & Lank lang \\
\hline Longeuus & lenger ewik Le(n)ger. Ewick a \\
\hline Loquela Loqula (!) & Rede Redt \\
\hline Loquitur & Redt redt \\
\hline Lorica & Pancer panczer \\
\hline Lubricus & Slipset ${ }^{b}$ \\
\hline Lucrum & Gwin Gewin \\
\hline Lucet & leucht leicht \\
\hline Luctus & Weinuge \\
\hline Ludere $^{d}$ & Spilen \\
\hline Lumen & Licht Liecht \\
\hline Luna & Man \\
\hline Lupus & Wolf wolff \\
\hline Lutum & kot kott \\
\hline Lux ${ }^{e}$ & $\operatorname{licht}^{\mathrm{e}}$ \\
\hline \multicolumn{2}{|c|}{ 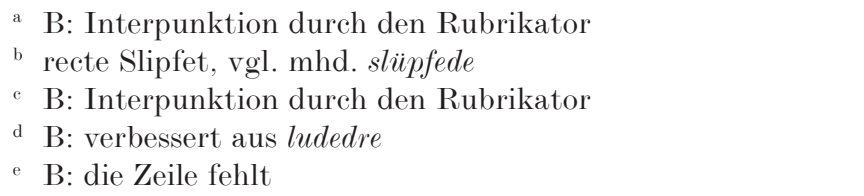 } \\
\hline
\end{tabular}

Waditise

Brzeh

Miesto

Bohaty

Kobylka Kobilka

Dluhy

Dluhoweczný Dluhowczny (!)

Rzecz

Mluwi

10

Panczyerz

Plzky

Zisk

Switise

Placz placet.placz ${ }^{\mathrm{c}}$

hrati

Swietlo

Miesycz

wlk

Blato

20

5

Swietlo ${ }^{\mathrm{e}}$ 


$\begin{array}{ll}\text { Malus } & \text { Boser Pösser } \\ \text { Malicia } & \text { Bosheit Poshait } \\ \text { Maior } & \text { Gresser Grossen (!) } \\ \text { Macilentus } & \text { Mager } \\ \text { Machina } & \text { Bleide } \\ \text { Mactare } & \text { Morden } \\ \text { Macula } & \text { Mackl Mayll } \\ \text { Maculare } & \text { Vnfletiken Mayligen } \\ \text { Magister } & \text { Meister Maister } \\ \text { Magnus } & \text { Groser Gros(s) } \\ \text { Maledicere } & \text { Schelten Scheltten } \\ \text { Maleus } & \text { Hamer } \\ \text { Mandare } & \text { Gebeten pietten } \\ \text { Mamilla } & \text { Tuttel Tuetten } \\ \text { Manducare } & \text { Essen Essenn } \\ \text { Mane } & \text { Frufrue } \\ \text { Manere } & \text { Bleiben peleyben } \\ \text { Manifestare } & \text { Offenbar } \\ \text { Manswetus } & \text { Mesik } \\ \text { Manus } & \text { Hant Hantt } \\ & \\ \text { a: Interpunktion durch den Rubrikator }\end{array}$

Zly

zlost

Wietssi

Suchy

Prak

Mordowati

Poskwrna poskwati

Zmazati

Mistr

Weliky

lati

Kladiwo

Kazati kaziti

Czeczek

Giesti

Rano

Bydliti. ostati Byliti.ostati ${ }^{\text {a }}$

Zgewiti

Tichy

Ruka
5 
$29^{r} 25^{r}$

$\begin{array}{lll}\text { Manica } & \text { Ermel Ermel } & \text { Rukaw } \\ \text { Mantica } & \text { wotsak watsack } & \text { Tlumok } \\ \text { Mare } & \text { Mer } & \text { Morze } \\ \text { Maritus } & \text { Man } & \text { Muż Mocz } \\ \text { Masculus } & \text { knechtelein knechtlein } & \text { Samecz } \\ \text { Mater } & \text { Muter Muetter } & \text { Matie } \\ \text { Matrimoniu(m) } & \text { he (!) } & \text { Manzelstwo } \\ \text { Matertera } & \text { Stifmuter Stiefmuetter } & \text { Maczecha } \\ \text { Matutinum } & \text { Metten } & \text { Gitrznie } \\ \text { Maxilla } & \text { Wanle (!) Wang } & \text { licze } \\ \text { Maximus } & \text { Allergroser (!) Der allergrost } & \text { Naywietssi } \\ \text { Mecum } & \text { Mitmir } & \text { Semnu } \\ \text { Medicus } & \text { Arczt } & \text { Lekarz } \\ \text { Medium } & \text { Halbes } & \text { Prostrzedek } \\ \text { Meditacio Metidacio (!) } & \text { Gedank Gedanck } & \text { Myssleni } \\ \text { Medula } & \text { Schedel Schaydtel (!) } & \text { leb } \\ \text { Mel } & \text { honik honig } & \text { Med } \\ \text { Melior } & \text { Besser pesser } & \text { Lepssi } \\ \text { Memoria } & \text { Gedechtnus Gedancknus } & \text { Pamiet } \\ \text { Membrum } & \text { Glid } & \text { Vd }\end{array}$

Allergroser (!) Der allergrost

Arezt

Semnu

Prostrzedek

ysslen

Glid

20 


Mendacium
Mendicus
Mens
Mensa
Mensis
Mensur
Mentiri
Mercator
Merces
Meretrix Meritrix
Meror
Mergere
Meridies
Messis
Messores
Metiri
Metus
Mille
Milicia
Miles

Lugen liegenn

Lez

Betler Petl(e)r

Zebrak

Gedank Gedanck

Mysl

Tisch

Stul

Man Manad

Miesycz

Mas

Miera

Ligen

Keufman Kauffman

Lhati

lon lan

Kupecz

hur huer

Mzda

Weinen wainen

Trenken Trencken

Kurwa

Placz

hruzeti

Mittag

Snit Schnitt

Poledne

Sniter Schnitter

Zěn zen

Messen

Zenczy Zencz

Mierziti

Furcht forcht

Strach

Tusent Taussent

Tisycz

Ritterschaft Ritterschafft

Rytirstwo Rytirstiwo (!)

Rytter Ritter

Rytierz 


$\begin{array}{ll}\text { Miliare } & \text { Ein Meil Ein meyl } \\ \text { Miluus } & \text { weige Geyer } \\ \text { Minari } & \text { Dreuen } \\ \text { Minister } & \text { Diner dienner } \\ \text { Minor } & \text { Minner Mynder } \\ \text { Minimus } & \text { Derminst } \\ \text { Minorare } & \text { Minneren Myndern(n) } \\ \text { Minuere Minure (!) } & \text { lasen lassen } \\ \text { Mirari } & \text { Wudern(n) wündern (n) } \\ \text { Mirabilis } & \text { wuderlich wunderlich } \\ \text { Miserere } & \text { Erbarmen erparmen } \\ \text { Misericordia } & \text { Baremh(er)czikeit Barmhe(r)czigkait } \\ \text { Miser } & \text { Durftik arm } \\ \text { Miseria } & \text { Vnselikeit } \\ \text { Misterium } & \text { heimlikeit Haymlichkait } \\ \text { Mittere } & \text { Senden } \\ \text { Mitigare } & \text { enstillen a) } \\ \text { Mitis } & \text { Senfter } \\ \text { Miscere } & \text { Mischen Mischenn } \\ \text { Modicum } & \text { Weninck wenick } \\ & \\ \text { a recte wohl e(i)nstellen, vgl. GRIMM III, 310 }\end{array}$

Mile

lunyak

hrozyti

Sluha

Menssi

Naymenssi

Vmenssiti

Pusstieti

Diwitise

Diwny

10

Smilowatise

Milosrdenstwi Milorsdenstwi

Hubeny

Bida

Tagemstwi

15

Poslati

Vkrotiti

Tichi

Misseti

Malo

20 
$30{ }^{\mathrm{r}} 26^{v}$

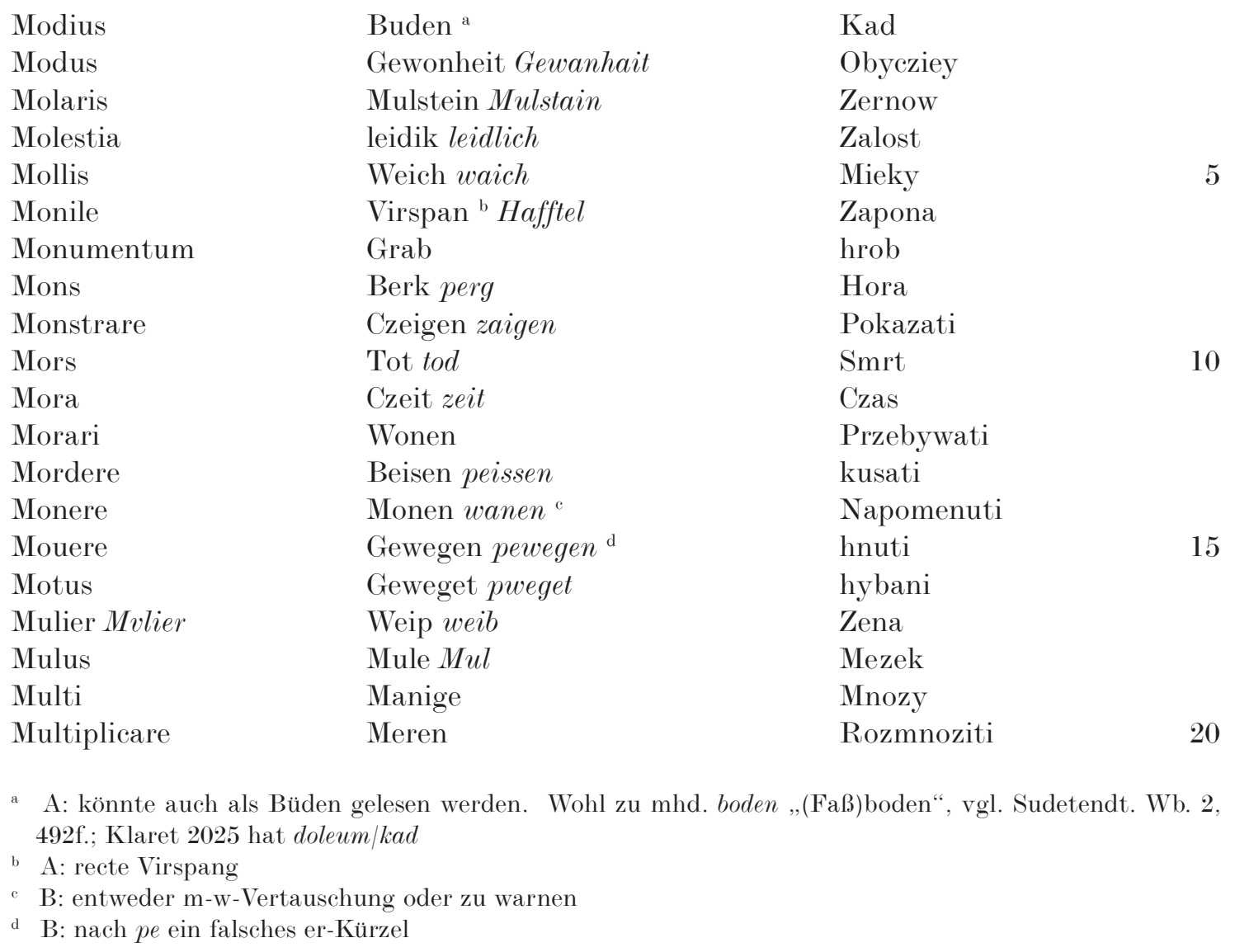


$31^{\mathrm{r}} 2 \mathbf{2}^{r}$

\begin{tabular}{|c|c|c|c|}
\hline Mundus & Rain ${ }^{a}$ werled Rain werlt & \multicolumn{2}{|l|}{ Czysty Swiet Czysty Swiett } \\
\hline Munir & Bewaren Bebaren & \multicolumn{2}{|l|}{ Ohraditi } \\
\hline Murus & Muwer Mawer & \multicolumn{2}{|l|}{ Zed } \\
\hline Municio & Manung & \multicolumn{2}{|l|}{ Ohrada } \\
\hline Mures & Meuze Meize & \multicolumn{2}{|l|}{ Myssi } \\
\hline Murmurare & Murmulen Murlenn & \multicolumn{2}{|l|}{ Reptati } \\
\hline Mutuare & wekselen weckseln(n) & \multicolumn{2}{|l|}{ Promieniti Mutare idem b } \\
\hline Mutus & Stumme ${ }^{c}$ Stum & \multicolumn{2}{|l|}{ Niemy } \\
\hline Nares & Nazlecher Naslocher & \multicolumn{2}{|l|}{ Chrzipi } \\
\hline Nates & lenden & ledwi lewi & 10 \\
\hline Nacio & Geburth Gepurd & \multicolumn{2}{|l|}{ Rod Roth.rod d } \\
\hline Narrare & Sagen Sagenn & \multicolumn{2}{|l|}{ Prawiti } \\
\hline Natura & Die nature natür & \multicolumn{2}{|l|}{ Przirozeni przwozeni } \\
\hline Nauigare & Schiffen & \multicolumn{2}{|l|}{ Plauiti } \\
\hline Nauta & Schifman Scheffman & \multicolumn{2}{|l|}{ Przewoznik przewoznick } \\
\hline Nebula & Nebel & \multicolumn{2}{|l|}{ Mhla } \\
\hline Necare & Derslaen derschbergen (!) & \multicolumn{2}{|l|}{ Zabiti } \\
\hline Necessitas & Durftikeit durftigkait & \multicolumn{2}{|l|}{ Potrzeba } \\
\hline Negare & widerzogen widersagenn & \multicolumn{2}{|l|}{ Zaprziti } \\
\hline \multicolumn{4}{|c|}{$\begin{array}{l}\text { B: Mutare idem außerhalb der Zeile angefügt. Vom Rubrikator mit Punkt und Strich als Ergänzung } \\
\text { gekennzeichnet. } \\
\text { c A: t überschrieben }\end{array}$} \\
\hline
\end{tabular}


$31^{\mathrm{v}} 29^{v}$

\begin{tabular}{|c|c|c|}
\hline Negligere & Virzeumen Versaum(m)en & Zmeskati \\
\hline Nnegocium a Negocium & Durft & Potrzeba \\
\hline Nemo & Niment & Nizadny Nizadnü \\
\hline Nemus & walt, pusch & hay \\
\hline Nepos & Swestersun & Sestrzenecz wnuk \\
\hline Nequam & Schalk ${ }^{\mathrm{b}}$ Schlack (!) & Zlosyn Zlosýn \\
\hline Neruus & einader & Zila \\
\hline Nescio & Ich kan(n)ycht ich kannich & Newim \\
\hline Nidus & Ein nest & hnizdo \\
\hline Niger & Swarcz & Czerny \\
\hline Nimium & Czufil zwiul & Prziliss \\
\hline Nix & Sneh Schne & Snih \\
\hline Nobilis & Edel & Sslechetny \\
\hline Nocere & Schaden & Sskoditi \\
\hline Nolo & Ichwilnicht & Nechezy \\
\hline Nomen & Namen & Gmeno \\
\hline Nominatus Nominati(us) (!) & Genant & Gmenowany \\
\hline Noscere & Irkennen Erkenne(n) & Znati \\
\hline Nouaculum & Schermesser & Brzitwa \\
\hline Nouus & Neuwe Newe & Nowy Now $\ddot{y}$ \\
\hline
\end{tabular}

a A: Nn-Schreibung durch Mißverständnis zwischen Schreiber und Rubrikator. Gilt auch für die weiteren n-Dopplungen dieser Art in A und B

b A: aus Schakk verbessert 
$32^{r} 28^{r}$

\begin{tabular}{|c|c|c|}
\hline Nouissimus & Derleczt Der newist ${ }^{\text {a }}$ & Posledni \\
\hline Nox & Nacht & nocz \\
\hline Noxius & Schedlich & Pakostiwy \\
\hline Nubes & wolken wolckhn(n) & Oblak \\
\hline Nudus & Nakter nackvnder & Nahy \\
\hline Nudatus & Enplozet enplassen & Obnazeny \\
\hline Numerare & Czelen zelenn & Poczitati \\
\hline Nnum(m)us Numus & Phennig & Peniz \\
\hline Nummulari Numulary ${ }^{b}$ & Mincer Minsser ${ }^{\mathrm{b}}$ & Minczerz ${ }^{b}$ \\
\hline Nuncciare & Enpiten enpietten & zwiestowati \\
\hline Nundine & Jarmark Jarmarck ${ }^{c}$ & hody hodÿ \\
\hline Nunquid & vnd.ist vndist & zdalit \\
\hline Numquam Nunquam & Nimmer nymer & Nikdy niki \\
\hline Nunc & $\mathrm{Nu}$ nün & Nynie \\
\hline Nupcie & hochezet hochzat & Swadba \\
\hline Nutrix & Amme & Chowaczka \\
\hline Nutrire & Eczen neren & krmiti \\
\hline Nutrimentum & Speise Speissen & Pokrm d \\
\hline Nux & Nus & Orzech \\
\hline Nodulus & kneyfel kneyffel & Knoflik \\
\hline
\end{tabular}


Obicere

Obitus

Oblacio

Obediencia Oobediencia ${ }^{\text {a }}$

Obligatus Oobligatus

Oblitus Ooblitus

Obscurus Oobscurus

Obsecro $^{\mathrm{c}}$

Obserua Oobserua

Obsequium Oobsequium

Obstruere Oobstruere ${ }^{\text {e }}$

Obtemperare Oobtemperare

Obtinere Oobtinere

Obuiare Oobuiare

Obvmbrare Oobvmbrare

Ooccasio

Ooccidere Occidere

Occurrere

Ooccultum Ocultum

Ociosus
Entwerfen entberffen

Dertod Der tod

Opfer Oppher

Gehorsam

Schuldiger

Virgessen vergessen

Vinster vinster ain scharffer ${ }^{b}$

Ich bite $i c h$ pitt ${ }^{\mathrm{d}}$

Behalde Behalden

Dinst Ein dienst

Virschiben Verschybenn

Demutigen diemuettigen

Behalden Pehalden

Begein pegegen

Verhaben

Enczuldung Enschuldung

Toten Totten

kegen gen gegen gen

Teugen

Musyk
Nawrezy

Vmrzeni

Obiet

Poslussenstwi

Powinen Powinem

zapomenul

Temny Temny ${ }^{\mathrm{c}}$

Prosy d

Zachoway

Sluzba Sluzwa

Zahraditi

Przehowieti

Obdrzeti

Potkati

Zasloniti

Omluva Omluwa

Zabiti

Potkati

Tayne

Prazdny Prazdni

a AB: diese und die folgenden initialen oo-Schreibungen sind Mißverständnisse zwischen Schreiber und Rubrikator

b B: vinster getilgt, darüber vom Korrektor ain scharffer

c B: möglicherweise aus lemny korrigiert, Längezeichen über $y$ vom Korrektor

d B: die folgende Zeile am Schluß der Seite hinter 32 Z. 20 Ociosus. Der Schreiber suchte seinen Irrtum durch ein $a$ vor der Zeile Obligatus $32^{\vee} \mathrm{Z} .5$ bzw. ein $b$ vor der Zeile Obsecro $32^{\vee} \mathrm{Z} .8$ zu markieren

e B: erstes $r$ eingeflickt 
$33^{r} 29^{r}$

\begin{tabular}{|c|c|c|}
\hline Occupatus & Bekummert & Neprazdny Neprazdnÿ \\
\hline Ocree Ocre & Stiveln(n) Stiual & Sskornie \\
\hline Octo Oocto & Acht & Osrn \\
\hline Octuaginta & Achczik & Ossmdesat \\
\hline Oculi & Augen & Oczy \\
\hline Odium & has & Nenawist \\
\hline Odor & Smak Smach a & Wunie \\
\hline Offendere & wetun Behuetten (Be)laydign(n) b & Vrazyti \\
\hline Officium & Ammecht $A m p t$ & Vrzad \\
\hline Officiales Officialis & Amtleute Amptlewt amptman ${ }^{c}$ & Vrzedniczy \\
\hline Oleum & Ole Olle & Oley \\
\hline Olus & kreut & Zele \\
\hline Olla & Topf heffn $(n)$ d & Hrnecz \\
\hline Omnes & Alle $A l l$ & Wsseczkni \\
\hline Ompnipotens $O m(n i)$ potens & Almechtig(er) al Mächtiger ${ }^{\mathrm{e}}$ & Wssemohuczy \\
\hline Onus & Burde purde & Brziemie Vrzienie \\
\hline Operimentu(m) & Decklachen Decklachen( $n$ ) & Przikrow \\
\hline Operari & Erbeiten Erbeitten & Dielati \\
\hline Opes & Reichtum & Bohatstwie \\
\hline Oportet & Mus mues & Musy \\
\hline $\begin{array}{l}\text { a: aus Smack korrigiert } \\
\text { b } \\
\text { B: vom Korrektor Behuetten ge } \\
\text { c } \text { B: Amptlewt vom Korrektor ve } \\
\text { d } \text { B: vom Korrektor Topf getilgt } \\
\text { e } \text { B: al vom Korrektor ergänzt }\end{array}$ & $\begin{array}{l}\text { ilgt, darüber (Be)laydign (n) } \\
\text { bessert zu Amptman } \\
\text { darüber kursiv heffn( } n)\end{array}$ & \\
\hline
\end{tabular}




$\begin{array}{ll}\text { Opprimere } & \text { Virdrucken verdrucken } \\ \text { Opponere } & \text { Widersten } \\ \text { Optimus } & \text { Allerbest } \\ \text { Opulentus } & \text { Reich } \\ \text { Oracio } & \text { Gebeth } \\ \text { Oratorium } & \text { Bethauz }{ }^{\text {a Bethaus }} \\ \text { Orbis } & \text { werld } \\ \text { Ordeum } & \text { Gersten } \\ \text { Ordo } & \text { orden } \\ \text { Organa } & \text { Orgeln } \text { orgeln }(n) \\ \text { Oriens } & \text { vfgank auffganck } \\ \text { Oritur } & \text { vfget aufget }{ }^{b} \\ \text { Ornatus } & \text { Czirheit } \\ \text { Orphanus } & \text { Enweiz Erweiz (!) }{ }^{\text {c }} \\ \text { Oreum } & \text { Stadel } \\ \text { Ortus } & \text { Garten Gartten } \\ \text { Osculum } & \text { Kuz kusz } \\ \text { Os } & \text { Munt Mundt } \\ \text { Ossa } & \text { Bein Pain } \\ \text { Ostendere } & \text { Czeigen }\end{array}$

Vtisknuti

Protiwitise

Naylepssi

Hoyny

Modlitba Modlitha

Modlitebnicze

Swiet

Geczmen

Rzad. Swieczeni

warhany

wychod

wschodi

ozdobeny

Sirotek

Stodola

Zahrada

Polibenie

Vsta

kosti

Vkazati

20

a A: deutsche und tschechische Lemmata vertauscht

b B: aufganck korrigiert zu aufget

c vgl. S. 79 
$34^{r} 30^{r}$

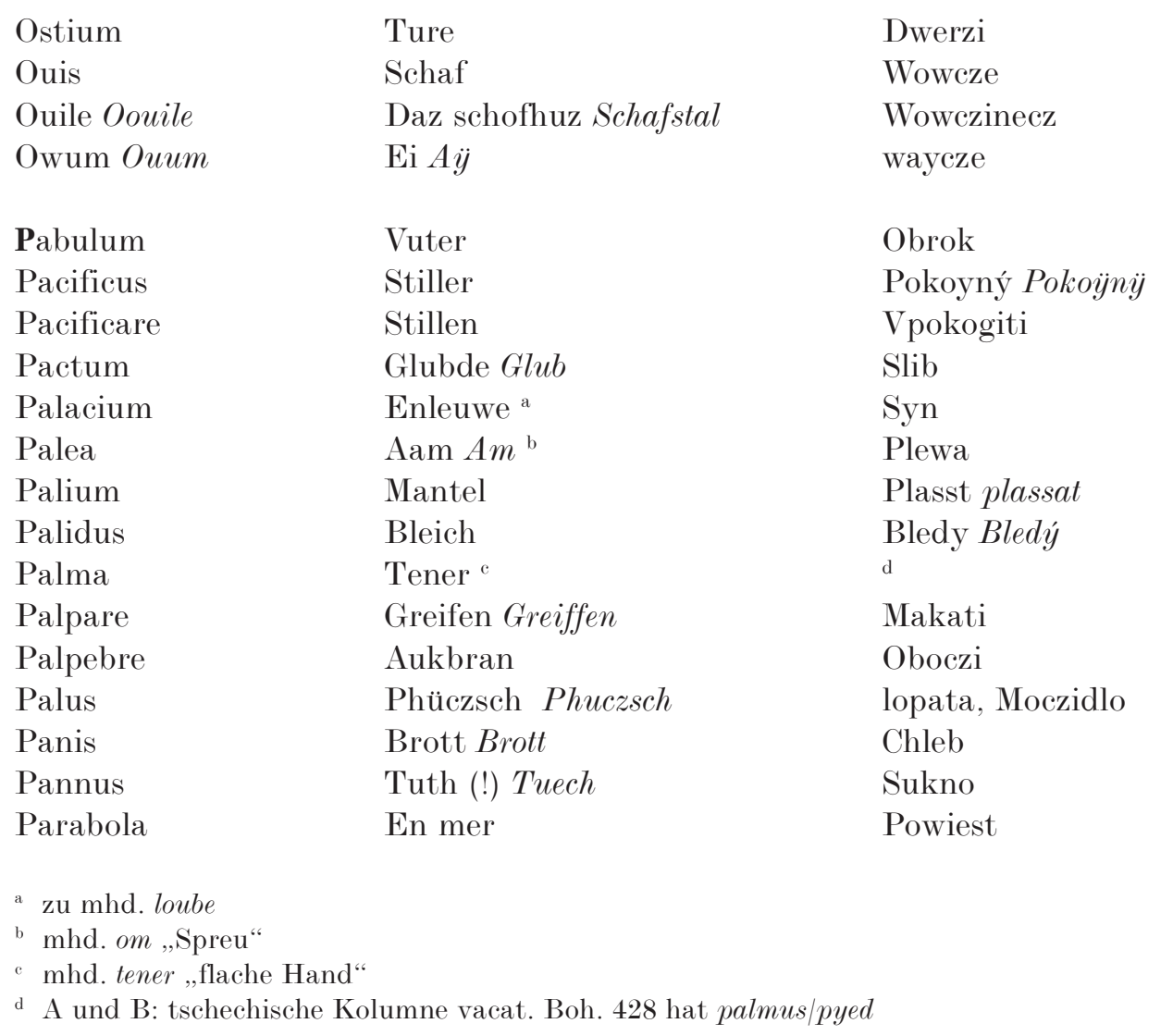


$34^{\mathrm{v}} 30^{v}$

\begin{tabular}{|c|c|c|c|}
\hline Paradisus & Paradiz Paradeys & Ray & \\
\hline Parare & Machen & Cziniti & \\
\hline Parcere & Virgeben vergeben & Otpustiti & \\
\hline Parere & Geberen Geperen & Vroditi & \\
\hline Pariter & Mit einand(er) Miteinand(e)r & Spolu a & 5 \\
\hline Paries & Enwant wandt & Stiena & \\
\hline Pars & enteil ayntayl & Strana & \\
\hline Particeps & Teilhoftik tailhafftig & Vezasten & \\
\hline Parum & wenik wenig & Malo & \\
\hline Paruus & Wenige & Maly Malï & 10 \\
\hline Pascha & Ostern Ostern $(n)$ & Welika nocz Welikanocz & \\
\hline Pascua & weide waid & Pastua & \\
\hline Pastor & Enhirt hiert & Pastirz & \\
\hline Passus & Erliden erlitten & Trpiel & \\
\hline Patera & mazer ${ }^{b}$ & Rziepicze & 15 \\
\hline Pater & Voter vatter & Otecz & \\
\hline Patria Ppatria ${ }^{\mathrm{C}}$ & Ein lant ain lantt & wlast & \\
\hline Patibulum Ppatibulu(m) & Der Galge & Ssibenicze & \\
\hline Paucus Ppaucus & Cleine klayne & Maly & \\
\hline PAuor & vorchte vorcht & Strach & 20 \\
\hline
\end{tabular}


$35^{\mathrm{r}} 31^{r}$

$\begin{array}{lll}\text { Paulatim } & \text { Melich } & \text { Lehky } \\ \text { Pauper } & \text { En Armer Ein armer } & \text { Chudy } \\ \text { Pax } & \text { Fride frid } & \text { Pokoy } \\ \text { Peccatum } & \text { Sunde Sündt } & \text { Hrzich } \\ \text { Pectus } & \text { Brust prust } & \text { Prsy } \\ \text { Peccator } & \text { Sundiger } & \text { Hrzissnik hrzifrak } \\ \text { Peccunia Pecunia } & \text { Gelt } & \text { Penize } \\ \text { Pecora }{ }^{a} & \text { Vich }{ }^{\text {a }} & \text { Dobytek. Skot dobydek, Skott }{ }^{\text {a }} \\ \text { PEdes } & \text { Ffuse fües } & \text { Nohy Noby } \\ \text { Peior Peyor } & \text { Der boste Der poste } & \text { Horssi } \\ \text { Pellis } & \text { En hüte Ein haut } & \text { Kuze } \\ \text { Peluis } & \text { Enbecken Ein peche } & \text { Medenicze } \\ \text { Pellicium } & \text { Enpellicz Ein pelcz } & \text { Kozich } \\ \text { Pena } & \text { Peine pein } & \text { Muka } \\ \text { Penitencia } & \text { Enbuze Ein puess } & \text { Pokanie } \\ \text { Pendet Pendett } & \text { hanget } & \text { Wisy } \\ \text { Penetrare Pennetrare } & \text { Durchvare Durchfaren } & \text { Progiti } \\ \text { Penitus } & \text { Gar Gárr } & \text { Owssem } \\ \text { Penna } & \text { Feder } & \text { Pero } \\ \text { Pensare } & \text { Wagin } \text { wagen } & \text { Waziti }\end{array}$

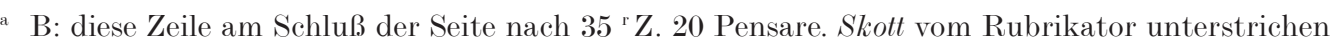




$\begin{array}{lll}\text { Pera } & \text { Tasche } & \text { Tobolka } \\ \text { Percutere } & \text { Slan Schlagn(n } & \text { Biti } \\ \text { Perdere Pedere (!) } & \text { Wirlizen verliessen } & \text { Ztratiti } \\ \text { Perducere } & \text { Durchvuren durchfuren } & \text { Przewezti przeweti (!) } \\ \text { Peregrinus } & \text { Ein pilgrem Ein pilgrain } & \text { Putnik putrack } \\ \text { Perficere } & \text { Volenden } & \text { Dokonati } \\ \text { Perfectus } & \text { Volkumend(er) vollkum }(m) \text { en } & \text { Dokonali } \\ \text { Perflare } & \text { durch plazen durchplasen } & \text { Produti } \\ \text { Perforare } & \text { Durch barn durchporen }{ }^{\text {a }} & \text { Prowrtati } \\ \text { Pergere } & \text { Voren fueren } & \text { Geti } \\ \text { Periculum } & \text { Schade Schád } & \text { Nebezpeczenstwi } \\ \text { Perire } & \text { Virterben verderben } & \text { Zahynuti } \\ \text { Permanere } & \text { Bleiben peleyben } & \text { Ostati } \\ \text { Permittere } & \text { verhenken verhengen } & \text { Dopustiti } \\ \text { Perpetrare } & \text { Tum }(!) \text { thuen } & \text { Cziniti } \\ \text { Perpetuus } & \text { Ewik Ewig } & \text { Weczny Wecznÿ } \\ \text { Persecutor } & \text { Volger volger betrieger }{ }^{b} & \text { Nasledownik nasledowruck } \\ \text { Perseuerare } & \text { vrharen verharren } & \text { Setrwati } \\ \text { Perspicere } & \text { durch sen durch sechn }(n) & \text { Prozrzieti } \\ \text { Perteritus } & \text { Erschrecken } & \text { Przestrasseny przesstrasseny }\end{array}$

a B: ch vom Korrektor eingefügt, $a$ zu $o$ korrigiert

b B: volger, dazu vom Korrektor ergänzt betrieger, danach v(er)rate( $r)$ getilgt 
$36^{r} 32^{r}$

\begin{tabular}{|c|c|c|}
\hline Pertinet & Czugehorte zwgehoren & Przislussi Praslussi \\
\hline Peruenit & komen ist $k u m(m)$ en ist & dosslo \\
\hline Peruertir (!) Peruertit(us) & Virkert verkert & Przewratil \\
\hline Pestilencia & Sterben & Mor \\
\hline Pessimus Ppessimus & Allerbost & Nayhorssi \\
\hline Petere Ppettere & Bitten pitten & Prosyti \\
\hline Petra & kyslink vels & Skala \\
\hline Pictus & Gemal Gemalt & Malowany \\
\hline Piger & Treg & Leni \\
\hline Pius & Gutik guettig & Milostiwy Milostiwy \\
\hline Pigmentum & Salb & Mast \\
\hline Pignus & Phant phantt & Zaklad \\
\hline Pilus & En har Einhar & wlas \\
\hline Pila ${ }^{a}$ & En bal ein pal ab & Micz $^{a}$ \\
\hline $\operatorname{Pi}(\mathrm{n})$ guis Pingwis ${ }^{\mathrm{c}}$ & Veist faist & Tuczny \\
\hline Pirum & En birne pirenn & hrusska \\
\hline Piscis & En visch Visch & Ryba \\
\hline Piscator & Fischer Vischer & Rybarz Rybars \\
\hline Pix & Bech peck & Smola \\
\hline Placet & Beheit geuelt & libise \\
\hline
\end{tabular}


$36^{\mathrm{v}} 32^{v}$

$\begin{array}{lll}\text { Placitum } & \text { Lib } & \text { Libost } \\ \text { Placenta } & \text { Mazancze } & \text { Mazanecz } \\ \text { Plaga } & \text { Enslag EinSchlag } & \text { Rana } \\ \text { Planctus } & \text { Weinung Waynu }(n) g & \text { Placz } \\ \text { Planum Pplanu }(m)^{\text {a }} & \text { Gleich } & \text { Rowne Rowe } \\ \text { Plantar } & \text { Phlanczen } & \text { Sscezpowati } \\ \text { Platea } & \text { Gasse } & \text { Vlicze } \\ \text { Plaudere } & \text { Schrecken Screcken }(!) & \text { Plesati } \\ \text { Plaustrum } & \text { Wagen } & \text { wuoz } \\ \text { Plebs } & \text { En volk Ein volck } & \text { lid } \\ \text { Plectere } & \text { Czuvugen } & \text { Plesti } \\ \text { Plenus } & \text { Vol voll } & \text { Plny } \\ \text { Plorat } & \text { weint waintt } & \text { Placz } \\ \text { Plumbum } & \text { Bley pley } & \text { Olowo } \\ \text { Plus } & \text { Mer } & \text { Wicze } \\ \text { Pluma } & \text { Bete } & \text { Perzina } \\ \text { Poculum } & \text { Trank Tranck } & \text { Napoý } \\ \text { Polenta } & \text { gezlicz }{ }^{b} & \text { Kyselicze }{ }^{b} \\ \text { Polire Poliren }(!) & \text { Cziren } & \text { Vhladiti } \\ \text { Pollex } & \text { Daum } & \text { Palecz } \\ \text { a: Dopplung durch Mißverständnis zwischen Schreiber und Rubrikator } \\ \text { b }\end{array}$


$37^{\mathrm{r}} 33^{r}$

\begin{tabular}{|c|c|c|c|}
\hline Pollicitus & Gelopt Gelobt oder versprochn( $n$ ) a & Slibil & \\
\hline Pollutus & Gevnrei(n)t Gewren (!) & 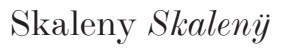 & \\
\hline Pomum & En Aphel Einaphel & Jablko & \\
\hline Pomeri(um) & Baumgarten paumga(r)tte(n) & Sad & \\
\hline Pomposus & Hofertik hochfertig & Hrdy Hrdÿ & 5 \\
\hline Pondus & Gwicht. Búrd purd. gwicht & waha. Brzimie & \\
\hline Ponere & legen & Poloziti & \\
\hline Pons ${ }^{b}$ & Bruck pruck & Most & \\
\hline Pontifex ${ }^{b}$ & Bischaf Bischalf & Biskup & \\
\hline Pontus & En mer zmier (!) & Morze & 10 \\
\hline Populus & volk & Lid & \\
\hline Porcus & Varck & Prase & \\
\hline Porrigere & Reichen Reichen(n) & Dosyhnuti & \\
\hline Portus & Czuvart Czuuart & Priwoz & \\
\hline Porta & Entor Ein tor & Brana & 15 \\
\hline Portulanus & Entorwertel torwertel & Branny Branný & \\
\hline Portare & Tragen Tragenn & Nesti & \\
\hline Porcio & Enteil aintayl & Diel & \\
\hline Poscere $^{c}$ & Begeren & Zadati & \\
\hline Possum & Ich mag & Mohu & 20 \\
\hline
\end{tabular}




$\begin{array}{lll}\text { Posessio (!) Possessio } & \text { Besiczunge Besiczung } & \text { Osazeni } \\ \text { Posidere (!) } & \text { Besiczen } & \text { wladnuti a }{ }^{2} \text { saditi Wladnuti } \\ \text { Post } & \text { Darnach } & \text { Potom } \\ \text { Postea } & \text { Parnach } & \text { Potom } \\ \text { Potis } & \text { Schwel } & \text { Posledni } \\ \text { Postremus } & \text { Der leczte } & \text { Zadati } \\ \text { Postulare } & \text { Begern(n) Begeren } & \text { Napoý Napoy } \\ \text { Pocio } & \text { Trank Tranck } & \text { Mocz } \\ \text { Potencia } & \text { Macht } & \text { Obied } \\ \text { Prandium } & \text { Morgenessen } & \text { Zle } \\ \text { Prawm Ppranu }(m){ }^{\text {b }} & \text { boze } & \text { Vchowati se vchowatise } \\ \text { Precauere } & \text { Vorhuten sich vorhueten sich } & \text { Prozba } \\ \text { Preces } & \text { Gebet } & \text { Przedgiti } \\ \text { Precedere } & \text { vorgen } & \text { Przikazani } \\ \text { Preceptum } & \text { Geboten } & \text { Obrzezati } \\ \text { Precidere } & \text { Obsniden Obsnidn(n) } & \text { Opasati } \\ \text { Precingere } & \text { Vmgurten vmbgurtten } & \text { Stroziti } \\ \text { Precipitare } & \text { Abstazen } & \text { Lupiti } \\ \text { Predari } & \text { Rawbn(n) Rawbenn } & \text { Lupeznik } \\ \text { Predo } & \text { Rauber } & \end{array}$

a A: davor Osaditi getilgt

b B: Dopplung durch Mißverständnis zwischen Schreiber und Rubrikator 
$38^{\mathrm{r}} 34^{r}$

$\begin{array}{lll}\text { Predicare } & \text { Predigen } & \text { Kazati } \\ \text { Prelium } & \text { Sreit Streitt } & \text { Boy } \\ \text { Premere } & \text { Drucken } & \text { Tisknuti Tiknuti (!) } \\ \text { Preparare } & \text { Bereiten peraitten } & \text { Prziprawiti } \\ \text { Presens } & \text { Kegenwertig gegn }(n) \text { wurtig } & \text { Przitomny } \\ \text { Presepe } & \text { Crippe } & \text { Gesle Gessle } \\ \text { Presbiter }{ }^{\text {a }} & \text { Enbriste (!) priester } & \text { kniez } \\ \text { Presidium } & \text { hulfe hilffe } & \text { Pomocz } \\ \text { Presumpcio } & \text { Turstikeit Turstikait } & \text { Smielost } \\ \text { Prestare } & \text { Geben } & \text { Dati } \\ \text { Preire }{ }^{b} & \text { Vbirgen vber Gebenn } & \text { Przegiti } \\ \text { Precium } & \text { Lon } & \text { Mzda } \\ \text { Preciosus } & \text { Teuer } & \text { Drahy } \\ \text { Preualere } & \text { Vbirkommen Vberkum }(m) \text { en } & \text { Przemoczy } \\ \text { Procella } & \text { Envüde Envude } & \text { Wlna } \\ \text { Procul } & \text { Verre verrer } & \text { daleko } \\ \text { Prolongare } & \text { Erlengen } & \text { Prodleti } \\ \text { Promittere } & \text { Geloben } & \text { Slibiti }\end{array}$

a B: erstes $e$ eingeflickt

b B: erstes $e$ überschrieben

c Mißverständnis, vgl. mhd. vluot bzw. JUNGMANN 5, 136-137 wlna = fluctus

d hier setzt der Rubrikator von B noch irrtümlich eine P-Initiale 
$38^{\mathrm{v}} 34^{v}$

$\begin{array}{lll}\text { Quercus } & \text { En eich Ein Eiche }(n) & \text { Dub } \\ \text { Quem } & \text { welchem } & \text { Koh (!) Roh } \\ \text { Quatuor } & \text { Fir vier } & \text { Cztyrzi } \\ \text { Quadraginta } & \text { Firczik furzig (!) } & \text { Ctyrzdczed a } \\ \text { Quamdiu } & \text { Wilang wielang } & \text { Jak dluho } \\ \text { Quantum } & \text { Wivil wieuil } & \text { Jakmnoho } \\ \text { Quantus } & \text { Wigros wiegros } & \text { koliky } \\ \text { Quare } & \text { warm (!) warvmb } & \text { Procz } \\ \text { Quasi } & \text { Alz also } & \text { Jako } \\ \text { Querere } & \text { Suchen Suechen } & \text { hledati } \\ \text { Quia } & \text { darum darvmb } & \text { Nebo } \\ \text { Quinqu(e) } & \text { Funf } & \text { Piet } \\ \text { Quid } & \text { waz was } & \text { Czo } \\ \text { Quies } & \text { Rue Rüre } & \text { Odpoczinutie Odpocznutie } \\ \text { Quiescere } & \text { Ruwen Rueen } & \text { Odpocziwati } \\ \text { Quis } & \text { Wer } & \text { kto } \\ \text { Quo } & \text { wohin } & \text { kam } \\ \text { Quousque } & \text { wiver wieuer } & \text { dokud } \\ \text { Qociens Quociens } & \text { wioff wieoff } & \text { Kolikrat } \\ \text { Quocumq(ue) } & \text { Wonorthin b } & \text { Kamzkoli } \\ \text { B: davor Cztyrzi vom Rubrikator getilgt } & \\ \text { b bei A vermutlich nachträglich eingefügt, recte wohl wonochhin } & \end{array}$


$39{ }^{\mathrm{r}} 35^{r}$

\begin{tabular}{|c|c|}
\hline Quomodo & Wi Wie \\
\hline Quondam & Etwenne etwennet \\
\hline Quot & Wimaniger wimanigerder a \\
\hline Remissio & Virgebunk vergebunk \\
\hline Repellere & Virtreiben vertreybenn \\
\hline Repente & Snelle \\
\hline Remunerare & Begaben \\
\hline Reperire & Vinden \\
\hline Reple(ne)re Repellere (!) & Vullen \\
\hline Reponere & widerlegen \\
\hline Reportare ${ }^{b}$ & widerbre(n)gen widergebe $(n)^{b}$ \\
\hline Reprehender & $\operatorname{Straffn}(\mathrm{n}) \operatorname{stroffn}(n)$ \\
\hline Rreputare Reputare & wenen wenen $(n)$ \\
\hline Requiescere & Rue Ruen \\
\hline Res & Endink Eindinck \\
\hline Residuus & Vbirbleiben vberbleiben \\
\hline Resina & Horczt Harcz \\
\hline Resistere & widersten \\
\hline Resonet & Clincet \\
\hline \multicolumn{2}{|c|}{ B: wohl aus wimanigerdir verbessert } \\
\hline \multicolumn{2}{|c|}{${ }^{\mathrm{b}}$ B: diese Zeile nach $39^{\text {r }}$ Z. 19 Resonet } \\
\hline \multicolumn{2}{|c|}{ B: davor ge getilgt } \\
\hline \multicolumn{2}{|c|}{ d B: vgl. ${ }^{\circ}$ wyra „Geldstrafe, Wehrgeld“, JUNGMANN 5,109 } \\
\hline \multicolumn{2}{|l|}{ A: czi überschrieben } \\
\hline f B: davor wiw vom Rubrika & getilgt \\
\hline
\end{tabular}

Wi Wie

enne etwennet

Kterak

Niekdy

koliko

Odpussczenie

Odehnati

Nahle

Obdarziti

Naleznuti

Naplniti

Zasepoloziti

10

Zaseprzinesti ${ }^{b}$

winiti wirati ${ }^{\mathrm{d}}$

Prziczitati ${ }^{\text {e }}$

Odpoczinuti

Wiecz $^{f}$ ostaly

Pryskyrzicze

Odporen byti odporenbyti wzni Wzra (!) 
$399^{\mathrm{v}} 35^{v}$

Respicere

Responsum

Restituere Restiture ide(m) (!)

Resuscitare

Retardare Redartare (!)

Recte

Retinere

Refugium

Rapere

Recedere

Recens

Recipere

Recitare

Recumbere

Reconciliare Reconsitiare

Recordare

Redarguere

Reddere

Redimere

Redire

a B: zweites $o$ überschrieben

b $B$ : erstes $i$ überschrieben
Anseen ansehen

Atwort anttwurt

widergeben widergebn $(n)$

Erwecken erweckn( $n$ )

werzamen $v(e r)$ samme $(n)$

Recht

Behalden

Czuflucht

Czucken

Wek gen wech gen

ffrisch frisch

Nehmen ne $(m)$ e $(n)$

Vf sagen aufsagen

ligen

Vrsunen

Gedenken Gedenckn(n)

Schtrofen Starffn(n) (!)

Widergeben widergebn ( $n$ )

Irlozen Erlossen

Widerkummen
Zrzieti

Odpowied a $^{\text {a }}$

Nawrati (!) Nabrati

Zkrzisyti

Obmesskati

Prawie

Zachowati

Vtoczisscze

vehwatiti

Odgiti

Vdatny

Wryti

Wyprawiti

lezeti

Smierziti b

Spomenuti

Tresktati

Nawratiti Nabratiti

wykupiti

wrati se wratise

20 
$40^{r} 36^{r}$

$\begin{array}{ll}\text { Redolet } & \text { Smecket Smechet } \\ \text { Referre } & \text { Sagen } \\ \text { Refrigerare } & \text { Külen kulen } \\ \text { Regere } & \text { Verwezen } \\ \text { Rex } & \text { Kunig } \\ \text { Regina } & \text { Kunigin kuniging (!) } \\ \text { Regnum } & \text { Reych Reich } \\ \text { Religiosus a } & \text { Geistlich } \\ \text { Reliquie } & \text { heilittum hellitum (!) } \\ \text { Remanere } & \text { Bleiben peleiben } \\ \text { Respuere } & \text { Virsmen versmeen } \\ \text { Reserare } & \text { Aufschlisen aufschliessn(n) } \\ \text { Racio } & \text { Sin } \\ \text { Racionabilis } & \text { Vstandiger } \\ \text { Radere } & \text { Scheren Schern(n) } \\ \text { Rasor } & \text { En scherer Scherrer } \\ \text { Radix } & \text { En wurcze wurcz } \\ \text { Radius } & \text { Schein } \\ \text { Ramus } & \text { Enczwike astt } \\ \text { Rana } & \text { En krote Einkrot } \\ & \\ \text { a B: li überschrieben } & \\ \text { b A: ein zweites sta getilgt } & \end{array}$

Wonie

Prawiti

Vstuditi

Zprawowati

Kral

Kralowna kralowati (!)

Kralowstwi

Duchowni dwchowni

Swatosti

Ostati ${ }^{\mathrm{b}}$ Ostatati

Zhrzeti

Odmeknuti

Rozom

Rozomny

holiti

15

Holicz

korzen

Paprslek

Ruozka

Zaba

a B: li überschrieben 


$\begin{array}{ll}\text { Raphanus } & \text { Rettich Raichtig a } \\ \text { Retrahere } & \text { widerczihen widerziehn }(n) \\ \text { Retribucio } & \text { lon } \\ \text { Reuelare } & \text { künden kunden } \\ \text { Reuereri } & \text { Eren } \\ \text { Reuertere } & \text { widerkumen widerkum }(m) \text { en } \\ \text { Reus } & \text { Suldik Schuldig } \\ \text { Reuocare } & \text { widerrufen widerrueffn }(n) \\ \text { Ridere } & \text { Lachen lachn }(n) \\ \text { Rigare } & \text { Begisen pegiess }(n) \\ \text { Rippa } & \text { bach pach } \\ \text { Riuulus } & \text { Bechlein peichlein }(!) \\ \text { Rixa } & \text { Krig krieg } \\ \text { Robustus } & \text { Stark Starck } \\ \text { Rogo } & \text { Bitte pitten } \\ \text { Ros } & \text { Entaw tawb } \\ \text { Rota } & \text { Rat } \\ \text { Rotundus } & \text { Scheiblik Schemp }(\text { er }) \text { lich }(!) \text { b } \\ \text { Rubicundus } & \text { Rot Rott } \\ \text { Rubigo } & \text { Rost }\end{array}$

Rzedkew ${ }^{a}$

Odtrhnuti

Odplata

Zgewiti

Teztiti

Obrati (!)

winny

Odolati (!)

Smiti se Smitise

Polewati

Brzieh

Potuczek

Swar

Moczny Mocznÿ

Prosym Prosÿm

Rosa

Kolo

Okruhly

Czrweny

Rez

a B: deutsches und tschechische Lemma vertauscht

b B: vgl. DIEFENBACH 345 sinwelich 
$41^{r} 3 y^{r}$

\begin{tabular}{|c|c|c|}
\hline Rubus & Pusch & Kerz \\
\hline Ruffus & Rotfüchsichter a Rotschuchtige(r) (!) & Rysslawy \\
\hline Ruina & Val vall & Vpad \\
\hline Ruptutus (!) & Czubrechen czubrechn(n) & Zlamany \\
\hline Rursum & czuandrmal czwand(er)mal & Opiet \\
\hline Raxum ${ }^{b}$ & Enstein & Camen \\
\hline Scabellu(m) & Fusschamel fuescham $(m) l$ & Podnocz. Stoliczka ${ }^{\mathrm{c}}$ \\
\hline Scabies & Rudik Reidich & Chrasty Chrastÿ \\
\hline Sca(n)dalu(m) & Schant & hanba \\
\hline Scapula & Schulde Schultter & Plecze \\
\hline Scandere & Steigen & wlezti. wstupiti d \\
\hline Scelus & Sund Sundt & hrzich \\
\hline Scire & künnen kunnen & Vmieti \\
\hline Sciencia & Künst kunst & Vmieni \\
\hline Scindere & Spalden & Rozedrziti \\
\hline Scopa & Bezem & Chwosstiscze \\
\hline Scorpio & Schkorp Schorp & Sczir \\
\hline Scortum & Bözewip Bozewip(er) (!) & Newiestka \\
\hline Scribere & Schreiben ${ }^{\mathrm{e}}$ schreibenn & Psati \\
\hline Scriptura Scriptum & Schrift Schrifft & Pismo \\
\hline \multicolumn{3}{|c|}{ 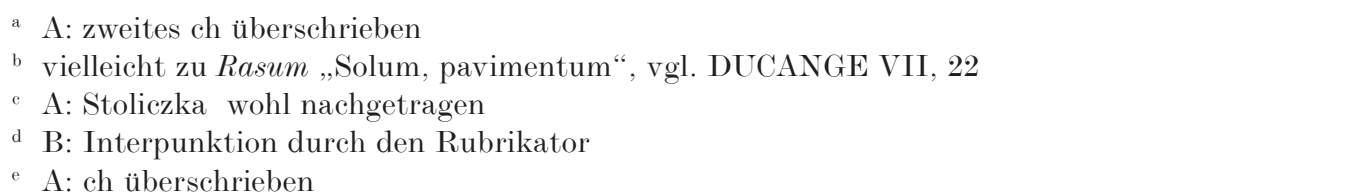 } \\
\hline
\end{tabular}


$41^{\mathrm{v}} 39^{v}$

\begin{tabular}{|c|c|c|}
\hline Scrutari & $\operatorname{Ervarn}(n)$ & Ztazatise \\
\hline Sculpere & Graben & Ryti \\
\hline Scutum & Schilt Schlitt (!) & Sczit Szitt \\
\hline Seccare & Hauen & Sekati \\
\hline Secedere & Hingen ${ }^{a}$ & Odgiti ${ }^{a}$ \\
\hline Seculum & Werld & Swiet \\
\hline Secularis & Wertlich weltlich ${ }^{\text {a }}$ & Swietsky ${ }^{a}$ \\
\hline Secundum & Dazander das ander & Druhe \\
\hline Secus & Bei pey & Podle podke (!) \\
\hline Securis & hack & Sekera \\
\hline Securus & Sicher ${ }^{b}$ & Bezpeczny vezpeczny ${ }^{\mathrm{b} c}$ \\
\hline Secretum & heimlikeit haimlich & Tagemstwi \\
\hline Sectari & Nachvolgen nachvolgn ( $n$ ) & Nasledowati \\
\hline Sedare & Stillen & Vpokogiti \\
\hline Sedes & Stul Stuel & Stolicze \\
\hline Sedere Sesdere (!) & Ziczen Siczen & Sedieti \\
\hline Sedicio & Krig krieg & Swada \\
\hline Seducere & Obvuren obuurn(n) & Swezti \\
\hline Sella & Satel & Sedlo \\
\hline Semel Semell & En mal Ainmal & Gednu Sednu (!) d \\
\hline
\end{tabular}

a A: tschechisches vor deutschem Lemma

b B: deutsches und tschechisches Lemma vertauscht

- B: vzpaz getilgt, darüber vezpeczny

d B: vgl. S. 48 
$42^{r} 38^{r}$

$\begin{array}{lll}\text { Semen } & \text { Same Same }(n) & \text { Symie } \\ \text { Seminare } & \text { Seen Seheen } & \text { Syti } \\ \text { Semita } & \text { Steg } & \text { Stezka } \\ \text { Semper } & \text { Allczeit alzeit } & \text { wzdyczky a } \\ \text { Sempitern(us) } & \text { Ewig } & \text { wieczny } \\ \text { Senex } & \text { Alt } & \text { Stary } \\ \text { Sentire } & \text { Phülen Emphinde(n) } & \text { Cziti }{ }^{\text {b }} \\ \text { Sensus } & \text { Sin Syn } & \text { Smysl } \\ \text { Sensatus } & \text { Sinniger Synniger } & \text { Smyslný Smyslny } \\ \text { Seorsum } & \text { Sunderlich } & \text { Oblasscze } \\ \text { Separare Seperare } & \text { Scheiden } & \text { Odlucziti } \\ \text { Sepe } & \text { Oft Offt } & \text { Czasto } \\ \text { Seps } & \text { Czaume zawn } & \text { Plot plott } \\ \text { Sepelire }{ }^{\text {c }} & \text { Begraben pegraben } & \text { Pohrabati } \\ \text { Septem } & \text { Ziben Sybenn } & \text { Sedm } \\ \text { Sabatum } & \text { Zunnabent Sambstag } & \text { Sobota } \\ \text { Sacerdos } & \text { Prister priester } & \text { Kniez } \\ \text { Saciatus Saccatus } & \text { Gesetigt } & \text { Nasyczen } \\ \text { Saccus } & \text { Sak Sack } & \text { Pytel pytek } \\ \text { a B:y vor ky getilgt } & & \\ { }_{\text {b recte wohl Czisti }} \text { A wiederholt darunter irrtümlich Sepelire, vgl. S. 31 } & \\ & & \end{array}$


42

Sagita

Saltus

Saluator

Salus

Saluatus

Sambucus

Sanus

Sanctus

Sanctificare

Sanguis Sagwis (!)

Sanguisuca

Sapiencia

Sarcina

Satis

Satum

Septuaginta

Sepulcrum

Sequitur

Sericum
Schtral Stral

$38^{v}$

Zalcz Salcz

Ensprunk einSpru(n)g

Heilant Haylant

Heil Hayl

Geheilik Geheyligt

Holunder Holler

Gesund

Heilig heylig

heiligen heyligen

Blut pluett

Egel

Weyzheit Weyshait

Wotsack ${ }^{a}$

Gnuk Genug

Sat Satt

Zibenczik siczbe $(n)$ czik (!) ${ }^{\mathrm{b}}$

Grab

Volgt

Zeiden Seyden
Strzela

Sul

Skok

Spasytel

Zdrawi

Spaseny

Bez

Zdrawy

Swaty

Swietiti

Krew

Pigawicze

Mudrost

Tlumok a Tlumock

Dosti

Osenie

Sedmdesat

Hrob

Nasleduge

Hedwabi

a A: tschechisches vor deutschem Lemma

b B: vgl. S. 48 
$43^{\mathrm{r}}$

Sermo

Red Redt

Rzecz

$39^{r}$

\begin{tabular}{|c|c|c|}
\hline Sero & Obent abent & w noczy, weczer a \\
\hline Serpens & Natir Nater & had \\
\hline Seruare & Behalden & Schowati \\
\hline Seruus & Knecht & Pacholek \\
\hline Seuerus & $\operatorname{Grim}(\mathrm{m}) \mathrm{ik} \operatorname{Grim}(m)$ ich & Lity \\
\hline Sex & Sechs & Ssest \\
\hline Sexaginta & Zechczik & Ssedesat \\
\hline Sexcenti & Zechshundert Sexhundert & Ssedtset ${ }^{b}$ Ssedset \\
\hline Sedecim & Zechsczehen zechszehn( $n)$ & Ssestnast \\
\hline Sexus & Geschlecht geschlacht & Plod \\
\hline Siccus & Durrer & Suchy \\
\hline Sicut & Alzo Also & Jako \\
\hline Sidus & Stern Stern $(n)$ & Hwiezda \\
\hline Sigillum & Sigel Sigell & Peczet \\
\hline Signum & Enczeichen ainzaichn(n) c & Znameni \\
\hline Signare & Czeichen zaichn $(n)^{\mathrm{c}}$ & Znamenati \\
\hline Siliques & Treber & Mlato \\
\hline Silere & Sweigen & Mlczeti \\
\hline Silex & Kislink kislinck & krzemen \\
\hline
\end{tabular}


$43^{\mathrm{v}}$

Silua Wald Les

$39 v$

Similis

Simulare

Simul

Simplex

Sincerus

Sine

Sinistra

Sinus

Sobrius

Socer $^{\mathrm{a}}$

Socius ${ }^{b}$

Socrus ${ }^{b}$

Sol

Solacium

Solempnitas

Solicitudo

Solium

Soluere

Solitus
Gleich geleich

Sweigen sweign( $n$ )

Mitnander Mitainand(e)r

Enfeldig ainfeltig

Rein

An

lenkhant denckhant

Schos

Nuchter Nuechter

Sweher

Gesel Gesell ${ }^{\mathrm{b}}$

Swiger b

Zunne Sun

Trost

hochczeit hochczat

Zarge Sarg

En Stul ein Stul

Gelten geltn ( $n$ )

Gewon
Podobny

Mlezeti

Spolu

Sprostný

Czisty

Bez

Lewicze

luno

Strzi (!)

Swagr Swekr

Towaryss ${ }^{b}$

Swekr Swek ${ }^{b}$

Sluncze

Vtiesseni

15

Hody

Pecze

Stolicze

Zaplatiti

obwykly

20

a B: ein anschließendes cer vom Rubrikator getilgt

b B: beide Zeilen nach $43^{\vee}$ Z. 19 Soluere 
$44^{\mathrm{r}}$

Solus

Selber allain

Sam

$40^{r}$

$\begin{array}{lll}\text { Sompnus } & \text { Slaf Schlaff } & \text { Se'n Sen } \\ \text { Sonus } & \text { klank klanck } & \text { Zwuk Zwuck } \\ \text { Sordes } & \text { Vnflat Vnflatt } & \text { Sspina } \\ \text { Soror } & \text { Schwester swester } & \text { Sestra } \\ \text { Sospes } & \text { Gesunt Gesundt } & \text { Zdrawy } \\ \text { Spargere } & \text { Streiwen Streyen } & \text { Rozsypati } \\ \text { Spacium } & \text { Kraume stat Raumestat } & \text { Prostranemiesto } \\ \text { Spelunca } & \text { Hol hól } & \text { Peless } \\ \text { Spes } & \text { Hofnunge Hoffnu(n)g } & \text { Nadiege } \\ \text { Spernere } & \text { Virsmen V }(\text { er }) \text { smehn }(n) & \text { Zhrzeti } \\ \text { Speciosus } & \text { Schön Schon } & \text { Krasny } \\ \text { Sponsa } & \text { Braut prawt } & \text { Newiesta } \\ \text { Spica } & \text { Eher }{ }^{\text {a }} & \text { klas } \\ \text { Spina } & \text { Endorn dórren } & \text { Trn } \\ \text { Spiritus } & \text { Geist } & \text { Duch } \\ \text { Spirare } & \text { seufftcen } & \text { bichati } \\ \text { Spiritualis } & \text { Geistlich } & \text { Duchowni } \\ \text { Splendet } & \text { Scheinet } & \text { Sktwi se Sktwise } \\ \text { Spoliare } & \text { Raben Rauben } & \text { lupiti } \\ \text { a B: davor vom Rubrikator heer getilgt } & \\ \text { b A: deutsche Übersetzung fehlt, tschechisches Lemma in deutscher Kolumne } & \end{array}$


$44^{\mathrm{v}}$

Spondere

Glóben Glúben ${ }^{\mathrm{a}}$

Slibiti

40

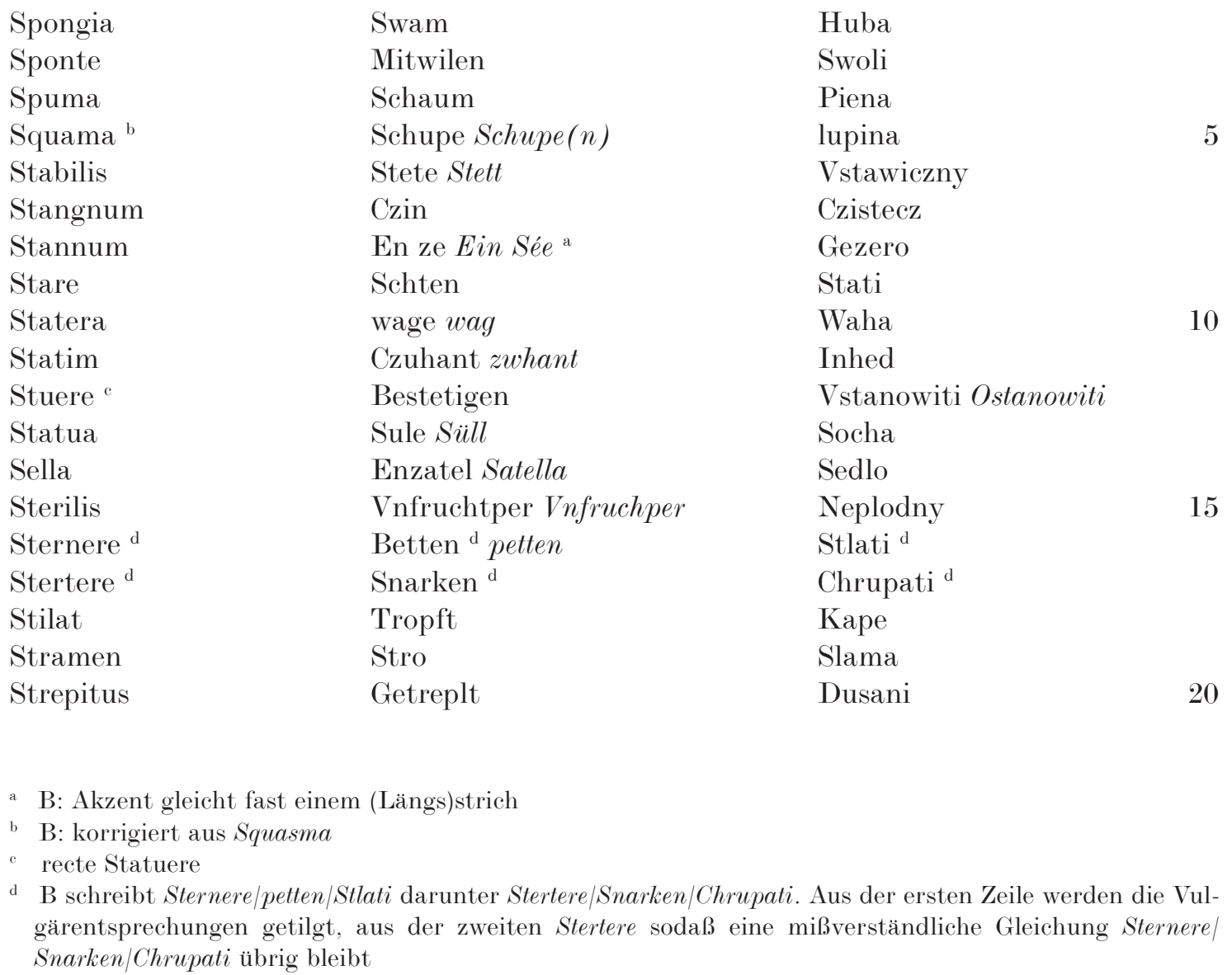


STrenuus

$41^{r}$

Stringere

Studere

Stultus ${ }^{\text {a }}$

Stuba ${ }^{a}$

Stuppa

Stupor

Suauis

Suadere

Subuertere

Subter

Succendere

Suber

Succidere Succedere

Succrescit

Sufficit

Sufflare

Suffocare

Sulfur

Sumere Sum(m)ere
Kün Kun

Czwingen Zwingen
Leren lerren
Entor Ain Tor a
Enstube Ain Stubn(n) a
Werk
Vorcht
Semft Senft
Roten Ratten
Vmkeren vmbKeren
Vnder
vnd(er)czunden vnd(er)zunde(n)
Enbost Einporst
vnd(er)schniedn(n)
vnd(er)wechst
Ist gnuk Ist gnuck
Blazen plasen
Dirwirgen de( $r) b u r g e n$
Schwebil Swebel
Nehmen nem(m)en

Vdatny

Suziti

Vezitise

Blazen ab

Gizba a c

Kudele

Hruoza

Sladky

Raditi

Przewratiti

10

Pod

Podnititi

lyko

Podrzezati

Podruosta

15

Dosti gest Dostigest

Duti

Zadawiti

Syra

Wzyeti

20

a B: beide Zeilen vertauscht

b B: davor vom Rubrikator Tba getilgt

c B: davor vom Rubrikator Blazen getilgt 
SVm(m)us Sumus

Der Hoberst der obrist

$41^{v}$

Superior

Supremus

Superius

Super

Superare

Supplere

Superponere

Surdus

Surge

Sursum

Supra

Sus

Suscipere

Sustinere

Suscitare

Suspendere

Suspicari

Suspirari

Suspirrare Susurrare
Höchst hochst

Allerhöhst allerhochst

Vben(!) a

Vber

Vbirwiden vberwinde( $n$ )

Fullen

Auflegen auflegn( $n$ )

Taup

Schtandauf Stantauf

V́ff auff a

Auff

Schwein Swein

Entphan Enphaen

Virtragen vertragen

wecken

Hahen

Wen

Drzüfczen a drzufczen

Runen
Swrchni

Wyssi

Naywyssi Nawïssi

Nahorze Nahorse

$\mathrm{Na}$

Przemoczy

Naplniti

Naloziti

Hluchy

Wstăn wstan

Wzhuru. nahoru ${ }^{b}$

Nahoru

Swynie

Przigiti

Snesti

Zbuditi

Obiesyti

Domniwatise

Wzdychati

Sseptati ' Ssptati

20

a A: keine Zierpunkte

b A: e eingeflickt

c B: Interpunktion des Rubrikators 
$46^{\mathrm{r}} 42^{r}$

Taberna

Tabula

Tacere

Tabernac(u)l(u)m

Talamus

Talentum

Talis

Taliter

Talus

Tangere

Tantum

Tanquam (!)

Tartarus

Tarde

Taurus

Taxare

Tectum

Tedet

Tedium

Tegula
Kreczem taffern( $n$ )

En Tafel Eintaffel

Sweigen Sweign(n)

Engeczelt a einzelt

Beth

Phunt phuntt

Zulcher Sollich(e)r

Alzo Also

Enkel enckel

Rüren Rurren (!)

Alzvil als vill

Alzo

Helle

Schpet Spadt

Schter Stir

Schacze (!)

Dach Tach

Vrdreist

Trageit tragkayt

latt
Krezma

Desstka

Mlczeti

Stanek

Loze

Funt

Taky

Tak

hnat

Dotknuti

10

Tak mnoho Takmnoh

Jakozto

Peklo pekho

Pozdie

Byk

15

Ssaczowati Sslaczowati (!)

Strzecha

Mrzy

Tesknost

lat

20

a A: Zierpunkte fehlen 
$46^{\mathrm{v}} 42^{v}$

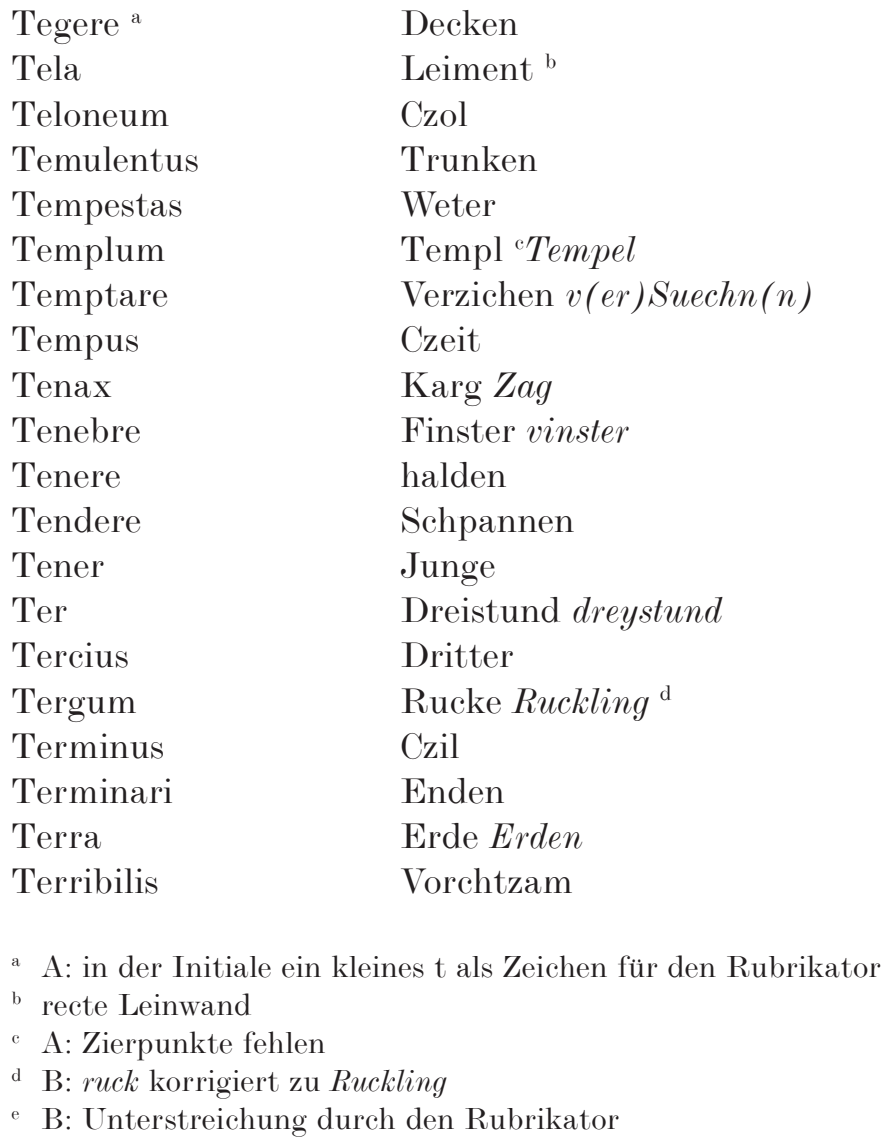

Przikryti

Platno

Mýto Myto

Opily

Powietrzi

Chram

Pokusseti

Czas

Skupy

Tma

Drzeti

Napnuti

Mlady

Trikrat

Trzeti

Zadek

Czyl

konati

Zemie

Hrozny

20 
$47^{\mathrm{r}} 43^{r}$

Tesaurus

Testa

Testamentu(m)

Testimoniu(m)

Testis

Texere

Tibia

Tibi

Timor

Timpanum

Tingere

Tinea ${ }^{\mathrm{b}}$ Tine (!)

Tirannus

Tollerare (!)

Tollere

Tonat

Tonitru Tonitrui

Tondere

Torcular
Schacz

Enschirbe einscherb

Geschaft geschafft

Geczugnis zeugnus

Geczeuge zeug

Wirken a wurcken

waden $^{\text {a }}$

Dir

Vorcht

En Pauke einpauck

Eintunken Eintunckn(n)

Mol ${ }^{c}$

Gvaldiger Gwaldiger

leiden

Aufheben Auffhebn(n)

Donert

Doner

Scheren Scherren

Pres
Poklad

Skerzepina

Poruczenstwi

Swiedecztwi

Swiedomie

Tkati

Lytka

Tobie

Bazen

Buben

10

Omocziti

Mole

Vkrutny

Trpieti

Zdwihnuti

hrzima

hrom

Strziczy

Pres

a A: ohne Zierpunkte. Möglicherweise nachträglich eingetragen

b A: Tinea darunter irrtümlich wiederholt, vgl. S. 31

c Diefenbach 584 tinea/mot. Vielleicht also eine Verschreibung 
$47^{\mathrm{v}}$

Torquere

Czwingen Zwingen

Suziti

$43^{v}$

$\begin{array}{ll}\text { Torrens } & \text { flis }^{\text {a }} \\ \text { Torta } & \text { Kuche } \\ \text { Totum } & \text { Alz als } \\ \text { Trabs } & \text { Enbalk a } \\ \text { Tradere } & \text { Vrroten V(er)ratten } \\ \text { Traditor } & \text { Vrreter verretter } \\ \text { Trahere } & \text { Czihen ziehenn } \\ \text { Transferre } & \text { Vbertragen } \\ \text { Transgressus } & \text { vbertretung } \\ \text { Transire } & \text { Vbergen } \\ \text { Tra(n)slatus } & \text { Vbertragen } \\ \text { Tranquillum } & \text { Schtil } \\ \text { Tremit } & \text { Czitert } \\ \text { Tres } & \text { Drei Drey } \\ \text { Tribulacio } & \text { Angest Angst } \\ \text { Tribuere } & \text { Geben } \\ \text { Tribunal } & \text { GrichtSchtul richt(er) Stull } \\ \text { Tristis } & \text { Treurik Trawrig }{ }^{\text {b }} \\ \text { Triticum } & \text { Weicz }\end{array}$

Praud

Kolacz ${ }^{\text {a }}$

Wssecko Wsseczk (!)

Tram

Zraditi

Zradeze

Tahnuti

Przenesti

Przestupeni

Przegiti

Przieneseny

Ticho

Trzese se Trzesese

Trzi

Zamuczený Zamuczenye

Dati

Sudiho stolice Sudiho stolicze Smutny

Pssenicze

a A: Zierpunkte fehlen

b B: erstes $r$ überschrieben 
$48^{\mathrm{r}}$

Tritum Gebent Trzene

$44^{r}$

Tritulare

Truncus

Trucidari

Tuba

Tugurium

Tumescit

Tumultus ${ }^{a}$

Tumulus

Tunica

Turba

Turbari

Turbo

Turibulum Turribulu(m)

Turpis

Turris

Thus

Turtur

Tuus

Tutus
Dreschen Treschn(n)

Schok Stock

Irschlaen

Blazhorn Blazhorn (n)

Einrigel Ein Rigel

Enplest sich

$\operatorname{Gesüm(m)e~} \operatorname{Gesum}(m) e^{\text {a }}$

En grab Engrab

Rok Rock

Schare Schar

Betruben

betrube

Rauchvas

Greulich Grevlich

Ein turm Einturen

Weirouch weyrach

Turkeltaube gurtteltaub tawb

Dein

Zicher
Mlatiti

Spalek

Vbiti

Truba

Zawora

5

Nadyma se Nadymase

Hluk ${ }^{\text {a }}$

Hrob

Suknie

Zastup Zastug

10

Zamutiti se Zamutitise

Mutieni

Kadilnicze

Sskaredy Ssrkaredý ${ }^{\mathrm{b}}$

Wieze

15

Kadidlo

Hrdliczka c)

Twoy

Bezpeczen

a B: diese Zeile nach $48^{\text {r Z }} 19$ Tutus

b B: korrigiert aus Ssraaredy

c B: aus Platzmangel greift tawb in die tschechische Kolumne über. Entsprechend ragt hrdliczka über den Zeilenrand und ist vom Rubrikator zur Verdeutlichung unterstrichen 
$48^{\mathrm{v}} 44^{v}$

\begin{tabular}{|c|c|}
\hline Uacca & Enku kuee \\
\hline Uacuus Uaccuus & Lere lerre \\
\hline Uacare & ledigen \\
\hline Uadium & Enphant Ein pfandt \\
\hline Uade & Ge Gee \\
\hline Uagina & Enscheide Einschayde \\
\hline UAgus & Missikge(n)ger Muesgender \\
\hline Ualatus & Beranter ${ }^{b}$ \\
\hline Ualde & Gar \\
\hline Ualet & Taugt \\
\hline Uallis & Tal Tall \\
\hline Ualua & Entor \\
\hline Uanus & Vmsister Schnodt \\
\hline Uas & Vas \\
\hline Uastauit & Dirschtigen ${ }^{c}$ \\
\hline Ubi & wo \\
\hline Uelare & beDecken ${ }^{\mathrm{d}}$ bedecken \\
\hline Uelamen & Eindecke Ein decke \\
\hline Uelox & Sneller Schneller ${ }^{\mathrm{f}}$ \\
\hline Uelum & Vmhang vmbhang \\
\hline $\begin{array}{l}\text { B: keine Interpun } \\
\text { b } \\
\text { zu mhd. berennen } \\
\text { c vgl. mhd. erstigen } \\
\text { d A: be ergänzt } \\
\text { e A: przi ergänzt } \\
\text { f: } \\
\text { B } \text { A: Korberschriebe } \\
\text { A: Korrektur aus }\end{array}$ & $\begin{array}{l}\text { n“" } \\
\text { en“ }\end{array}$ \\
\hline
\end{tabular}

Krawa

Prazdný Prazdny

Prazdniti

Zaklad

Gdi

Noznicze

Biehun,Tulak ${ }^{\text {a }}$

Obehnan

Welmi

hodise

Vdol

Brana

darebný

Sud

Zlezl

kde

przi kriti

Przikrywadlo

Rychly ${ }^{g}$ Rykhly

Opona 
$49^{r} 45^{r}$

\begin{tabular}{|c|c|c|}
\hline Uelud & $\mathrm{Alz} A l s$ & Jakzto \\
\hline Uena & Ein Ader einader & Zila \\
\hline Uenator & Ein Jeger ein jager & Lowecz \\
\hline Uenari Veneri ${ }^{\text {a }}$ & Jagen & lowiti \\
\hline Uendere & verkaufen $v($ er $)$ kauffen & Prodati \\
\hline Uenia & Genod genad & Milost \\
\hline Ueni & Kum & Pod \\
\hline Uenerabilis & Ersam & Cztny \\
\hline Uenter & Buche Pauch & Brzicho \\
\hline Uentus & wint & Witr \\
\hline Uerus & Rechter & Prawý Prawy \\
\hline Ueritas & Worhei (!) warhait & Prawda \\
\hline Uerberare & Schlaen Schlagen & Biti \\
\hline Uerecundia & Scham & Stud \\
\hline Uerte & Umker & obrat \\
\hline Uertex & Húbel & Wrch \\
\hline Uertigo & Schesind (!) Schwindl & Zawrat \\
\hline Uescitur & Erschpeizet sich Erschperzetsich (!) & Krmise \\
\hline Uesica & Blaze Blater ${ }^{\mathrm{C}}$ & Miechyrz \\
\hline Uespera & Wesper Vesper & Nesspor \\
\hline
\end{tabular}


$49^{\mathrm{r}} 45^{v}$

\begin{tabular}{|c|c|c|}
\hline Uester & Euwer Ewer & Wass \\
\hline Uestigium a & Fustrit a & Slaplege ${ }^{a}$ \\
\hline Uestimentum & Cleit klaid & Rucho \\
\hline Uetus & Alt & Stary \\
\hline Uexillum & En van fane ${ }^{b}$ & Koruhew \\
\hline Uia & En wek weg & Czesta \\
\hline Uicinus & Nochgbure Nachtpawer & Sused \\
\hline Uicium & Zind lastter & hrzich \\
\hline Uictima & Oppher & obied (!) \\
\hline Uidere & Zeen Sechen & widieti $^{c}$ \\
\hline Uidua & Witwa witib & Wdowa \\
\hline Uigilare & Wachen wachn(n) & Bditi \\
\hline Uiginti & Czwenczik & Dwadczeti \\
\hline Uilla & Dorf darff d & Wes \\
\hline Uillicus & Amptmann ein paw(e)r $r^{\mathrm{e}}$ & Wladarz wladars \\
\hline Uilis & Grawsem Grausam & Mrzky \\
\hline Uincere & Vbirwunden vberwinden & Przemocz (!) \\
\hline Uinculum & Bant fancknüss ${ }^{\mathrm{f}}$ & Swazek \\
\hline Uindicare & Rechen Rechenn & Pomstiti \\
\hline Uinea & Weingarte & Winicze \\
\hline $\begin{array}{ll}\text { a } & \text { B: diese Zeile f } \\
\text { b } & \text { B: vom Korrek } \\
\text { c } & \text { B: di eingefügt } \\
\text { d } & \text { B: abschließen } \\
\text { e } & \text { B: vom Korrek } \\
\text { f } & \text { B: vom Korrek }\end{array}$ & $\begin{array}{l}\text { getilgt, darüber ein paw (e)r } \\
\text { lgt, darüber fancknüss }\end{array}$ & \\
\hline
\end{tabular}


$50^{\mathrm{r}}$

Uiolencia Gwalt gewalt $\quad$ Nasyle

$46^{r}$

\begin{tabular}{|c|c|c|}
\hline Uippera & En Nater & Had Zad (!) ${ }^{\text {a }}$ \\
\hline Uir & En Man Ein Man & Muz \\
\hline Uirgo & En Juncfrau Ein iu(n)ckfraw & Panna \\
\hline Uiridis & Grine Grün & Zeleny Zelen \\
\hline Uirtus & Tugent & Mocz, cztnost \\
\hline Uis & kraft krafft & Mocz \\
\hline Uiscera & Gederme dérme & Strzewa \\
\hline Uisitare & haymsuchen ${ }^{\mathrm{b}}$ & Nawssczewiti ${ }^{c}$ \\
\hline Uita & leben & Ziwot ${ }^{\mathrm{d}}$ \\
\hline Uitare $^{e}$ & Huten meyden & Warowatise \\
\hline Uitulus & Einkalp ${ }^{f}$ & Tele \\
\hline Uituperare & Schelden & lati \\
\hline Uitrum & Glaz Glas & Sklo \\
\hline Uiuit & lebt & ziwgest \\
\hline Uix & Kaum & Gedwa \\
\hline Uicio & Rechung Rech(n)ung & Pomsta \\
\hline Ulna & En ele ellen & loket \\
\hline Ululare & Hulen & Wyti \\
\hline Ultimus & leczt & Posledni \\
\hline $\begin{array}{l}\text { B: vgl. S. } 48 \\
\text { A: deutsche } \\
\text { AB: in deut } \\
\text { B: davor } Z u \\
\text { recte Euitar } \\
\text { B: } b \text { zu } p \text { ko }\end{array}$ & $\begin{array}{l}\text { fehlt B: kursiver Nachtrag des Kor } \\
\text { he } \\
\text { brikator getilgt. Von ihm Ziwot (als g }\end{array}$ & $\begin{array}{l}\text { in tschechischer Kolumne } \\
\text { unterstrichen }\end{array}$ \\
\hline
\end{tabular}


$50^{\mathrm{v}}$

Umbilicus

Nabel Nappel

Pupek

$46^{v}$

$\begin{array}{ll}\text { Unde } & \text { Wanne wan her a } \\ \text { Undique } & \text { Úberol Vberál(l) }^{\text {b }} \\ \text { Undecim } & \text { Einlef ainlef } \\ \text { Ungentum } & \text { Salb Salbn( } n) \\ \text { Ungere } & \text { Salben } \\ \text { Unicus } & \text { Einiger Ainiger } \\ \text { Unigenitus } & \text { Eingeborn Aingeporner } \\ \text { Unus } & \text { Einer Ainer } \\ \text { Unusquis(que) } & \text { Jezlicher } \\ \text { Uolat } & \text { Vluget } \\ \text { Uolucres } & \text { Vogel vogl(l) } \\ \text { Uolumtas Uoluntas } & \text { wille } \\ \text { Uoluptas } & \text { wolust } \\ \text { Uoluere } & \text { Vmkeren vmbkeren } \\ \text { Uos } & \text { Ir } \\ \text { Uobiscum } & \text { Mit euch Mit Ewch } \\ \text { Uotum } & \text { Gelub } \\ \text { Uox } & \text { Schtimme Stym } \\ \text { Urbs } & \text { Stat Statt }\end{array}$

Odkud

Wssady

Gedenaczt

Mast

5

Mazati

Gediny Gedeny

Gednorozený Ged(n)orozeny

Geden

Gedenkazdy

10

leti

Ptaczy ${ }^{\circ}$

Wule

Rozkoss

obratiti

Wy

Swamy

Slib

Hlas

Miesto

a B: Wannen getilgt, darüber vom Korrektor wan her

b B: Akzent fast wie ein Längsstrich

c B: $z$ eingefügt 
$51^{\mathrm{r}}$

Urceus

Eimmer

Wiedro

$4^{r}{ }^{r a}$

$\begin{array}{lll}\text { Urina } & \text { Zeich Seich } & \text { Mocz } \\ \text { Ursus } & \text { Enber } & \text { Nedwied } \\ \text { Urtica } & \text { Nessel } & \text { koprziwa } \\ \text { Usquequo } & \text { Wilank wielanck } & \text { Dokud } \\ \text { Usura } & \text { wucher } & \text { lichwa } \\ \text { Uterque } & \text { Beide pä̈de } & \text { Oba } \\ \text { Utilis } & \text { Nucze } & \text { Vziteczny Vzitecznÿ } \\ \text { Uua } & \text { Weinber } & \text { hrozen } \\ \text { Uulpis } & \text { Vochs fuchs } & \text { lisska } \\ \text { Uultus } & \text { Antlicz } & \text { Obliczieg } \\ \text { Uelter } & \text { Wind } & \text { Chrt } \\ \text { Uultur } & \text { Geier } & \text { Sup } \\ \text { Uulnus } & \text { Wunde } & \text { Rana } \\ \text { Uxor } & \text { husvraue haufraw (!) } & \text { Zena }\end{array}$

a Abb. 38

b hier endet die Handschrift B 
$51^{\mathrm{V}}$

$\begin{array}{lll}\text { Deus } & \text { Got } & \text { Buoh } \\ \text { Deitas } & \text { Gotheit } & \text { Bostwi } \\ \text { Celum }{ }^{a} & \text { Himel } & \text { Nebe } \\ \text { Terra } & \text { Erde } & \text { Zemie } \\ \text { Aer } & \text { luft } & \text { Powietrzi } \\ \text { Ignis } & \text { Feuer } & \text { Oheň } \\ \text { Aqua } & \text { Wasser } & \text { woda } \\ \text { Lux } & \text { licht } & \text { Swietlo } \\ \text { Nox } & \text { Nacht } & \text { Nocz } \\ \text { Tenebra } & \text { Vinsternis } & \text { Trna } \\ \text { Sol } & \text { Sunne } & \text { Sluncze } \\ \text { Luna } & \text { Mon }{ }^{b} & \text { Miesycz }{ }^{b} \\ \text { Stella } & \text { Schern }(!) & \text { Hwiezda } \\ \text { Iris } & \text { Reinboge } & \text { Duha } \\ \text { Nebula } & \text { Nebel } & \text { Mlha }{ }^{\text {c }} \\ \text { Homo } & \text { Mensch } & \text { Czlowiek } \\ \text { Corpus } & \text { leichnam } & \text { Tielo } \\ \text { Anima } & \text { zel } & \text { Dusse } \\ \text { Uita } & \text { leben } & \text { Ziwot } \\ \text { Mors } & \text { Tot } & \text { Smrt } \\ & & \\ \text { a c und l neben der Initiale eingeflickt } & \\ \text { b deutsches und tschechisches Lemma vertauscht } & \end{array}$


$52^{\mathrm{r}}$

\begin{tabular}{|c|c|c|}
\hline Caput a & Heubet & Hlawa \\
\hline Capillus & hor & wlas \\
\hline Vertex & Scheitel & wrch \\
\hline Sinciput & Vorhorbit (!) & kezicze \\
\hline Occiput & Nacke & Tyl \\
\hline Crinis & hor & wlas \\
\hline Frons & Schtirne & Czelo b \\
\hline Cerebrum & Hirn & Mozk \\
\hline Oculus & Auge & woko \\
\hline Nasus & Nase & Nos \\
\hline Nares & Naselech(er) & Chrzipi \\
\hline Palpebre & Augbron ${ }^{c}$ & Oboczi \\
\hline Maxilla & Wangen d & $\operatorname{luze}^{e}$ \\
\hline Facies & Antlicz & licze \\
\hline Mentum & hinne $^{f}$ & Podbradek \\
\hline Barba & Bart & Brada \\
\hline Oos, oris & Munt & Vsta \\
\hline Labia & lippe & Rtý \\
\hline Dens & Czon & Zub \\
\hline Fauces & Gumen & Dasnie \\
\hline
\end{tabular}


52 v

$\begin{array}{lll}\text { Lingwa } & \text { Czunge } & \text { Jazyk } \\ \text { Collum } & \text { Hals } & \text { Hrdlo } \\ \text { Gula } & \text { ffros } & \text { lakota } \\ \text { Guttur } & \text { Kele } & \text { Chrtan } \\ \text { Auris } & \text { Ore } & \text { Vcho } \\ \text { Scapula } & \text { Schulder } & \text { Plecze } \\ \text { Humerus } & \text { Aksel } & \text { Rameno } \\ \text { Pectus } & \text { Brust } & \text { Prsy } \\ \text { Cor } & \text { hercze } & \text { Srdcze } \\ \text { Iecur } & \text { leber } & \text { Jatry } \\ \text { Pulmo } & \text { Lunge } & \text { Plicze } \\ \text { Venter } & \text { Bauch } & \text { Brzicho } \\ \text { Stomachus } & \text { Mage } & \text { Zaludek } \\ \text { Fel } & \text { Gale } & \text { Zlucz } \\ \text { Splen } & \text { Milcz } & \text { Slezena } \\ \text { Viscus } & \text { Darm } & \text { Trzewo } \\ \text { Umbilicus } & \text { Nabel } & \text { Pupek } \\ \text { Sangwis } & \text { Bluth } & \text { Krew } \\ \text { Cruor } & \text { Idem } & \text { a } \\ \text { Costa } & \text { Bein } & \text { Zebro }\end{array}$

a tschechische Entsprechung fehlt, entspricht krew der vorangehenden Zeile 
$53^{\mathrm{r}}$

\begin{tabular}{lll} 
Os, ossis & Bein & Kost \\
Latus & Seite & Bok \\
Manus & hant & Ruka \\
Digitus & vinger & Prst \\
Unguis & Negel & Nehet \\
Articulus & Gelid & Czlanek \\
Pollex & Deume & Palecz \\
Index & Czeiger & Vkazatel \\
Medius & Mittelste & Prostrzedni \\
Cubitus & Elboge & loket \\
Brachium a & Arm & Rameno b \\
Vena & Ader & Zila \\
Pugnus & Fauest & Piest \\
Palma & Spanne & Dlan \\
Coxa & Dich & Stehno b \\
Genu & Knie & koleno \\
Poples & kniescheibe & Czesska \\
Crus & Schinpein & Hnat \\
Tibia & waden & litka \\
Pes & Füs & Noha \\
a getilgter m-Kürzungsstrich über u & \\
b nach dem Zeilenende ein Merkstrich & \\
\hline
\end{tabular}


$53^{\mathrm{v}}$

$\begin{array}{lll}\text { Planta } & \text { Phärs } & \text { Pata } \\ \text { Cutis } & \text { Haut } & \text { kuze } \\ \text { Renes } & \text { Niren } & \text { Ledwiny } \\ \text { Caro } & \text { Fleisch } & \text { Masso } \\ \text { Uir } & \text { Man } & \text { Muz } \\ \text { Femina } & \text { weibe } & \text { Zena } \\ \text { Uxor } & \text { hauzfraw } & \text { Zena } \\ \text { Uirgo } & \text { Juncfraw } & \text { Panna } \\ \text { Sponsa } & \text { Brüth } & \text { Newiesta } \\ \text { Sponsus } & \text { Breütigum } & \text { Zenich } \\ \text { Uidua } & \text { Witwe } & \text { Wdowa } \\ \text { Socer } & \text { Swehir } & \text { Sswagr } \\ \text { Socrus } & \text { Swiger } & \text { Sswekr } \\ \text { Auus } & \text { Anherre } & \text { Died } \\ \text { Auia } & \text { Anvraue } & \text { babka } \\ \text { Senex } & \text { Alt } & \text { Stary } \\ \text { Uetula } & \text { Altvraue } & \text { Baba } \\ \text { Pater } & \text { Voter } & \text { Otecz } \\ \text { Mater } & \text { Muter } & \text { Mati } \\ \text { Frater } & \text { Bruder } & \text { Bratŕ }\end{array}$


$54^{\mathrm{r}}$

$\begin{array}{lll}\text { Soror } & \text { Swester a } & \text { Sestra }{ }^{a} \\ \text { Uitricus } & \text { Schtiffater }^{\text {b }} & \text { Otczim } \\ \text { Nouerca } & \text { Schtiffmut(er) } & \text { Maczecha } \\ \text { Priuignus } & \text { Schtifsun } & \text { Pastorek } \\ \text { Priuigna } & \text { StifTochter } & \text { Pastorkynie } \\ \text { Patruus } & \text { vetir } & \text { Strycz } \\ \text { Auunculus } & \text { Ome } & \text { Vgecz } \\ \text { Amita } & \text { Mume } & \text { Teta } \\ \text { Matertera } & \text { Mume } & \text { Teta } \\ \text { Nepos } & \text { Enigkl } & \text { Wnuk } \\ \text { Neptis } & \text { Enigklin } & \text { Wnuczka } \\ \text { Sororinus } & \text { Swest(er)kind } & \text { Sestrzenecż } \\ \text { Compater } & \text { Geuater } & \text { kmotr }{ }^{c} \\ \text { Com(m)ater } & \text { Geuater (!) } & \text { kmotra } \\ \text { Uicinus } & \text { Nochgbure } & \text { Sused } \\ \text { Uicina } & \text { Nochgburin } & \text { Suseda } \\ \text { Amicus } & \text { Fru(n)t } & \text { Przitel } \\ \text { Amica } & \text { Frundin } & \text { Przitelnicze } \\ \text { Socius } & \text { Geselle } & \text { Towarziss } \\ \text { Socia } & \text { Gesellen (!) } & \text { Towarziska } \\ & & \\ \text { a deutsches und tschechisches } & \text { Lemma vertauscht } & \\ \text { b eingeflickt } & & \\ { }^{\circ} \text { Merkstrich am Zeilenende } & & \end{array}$


$54^{v}$

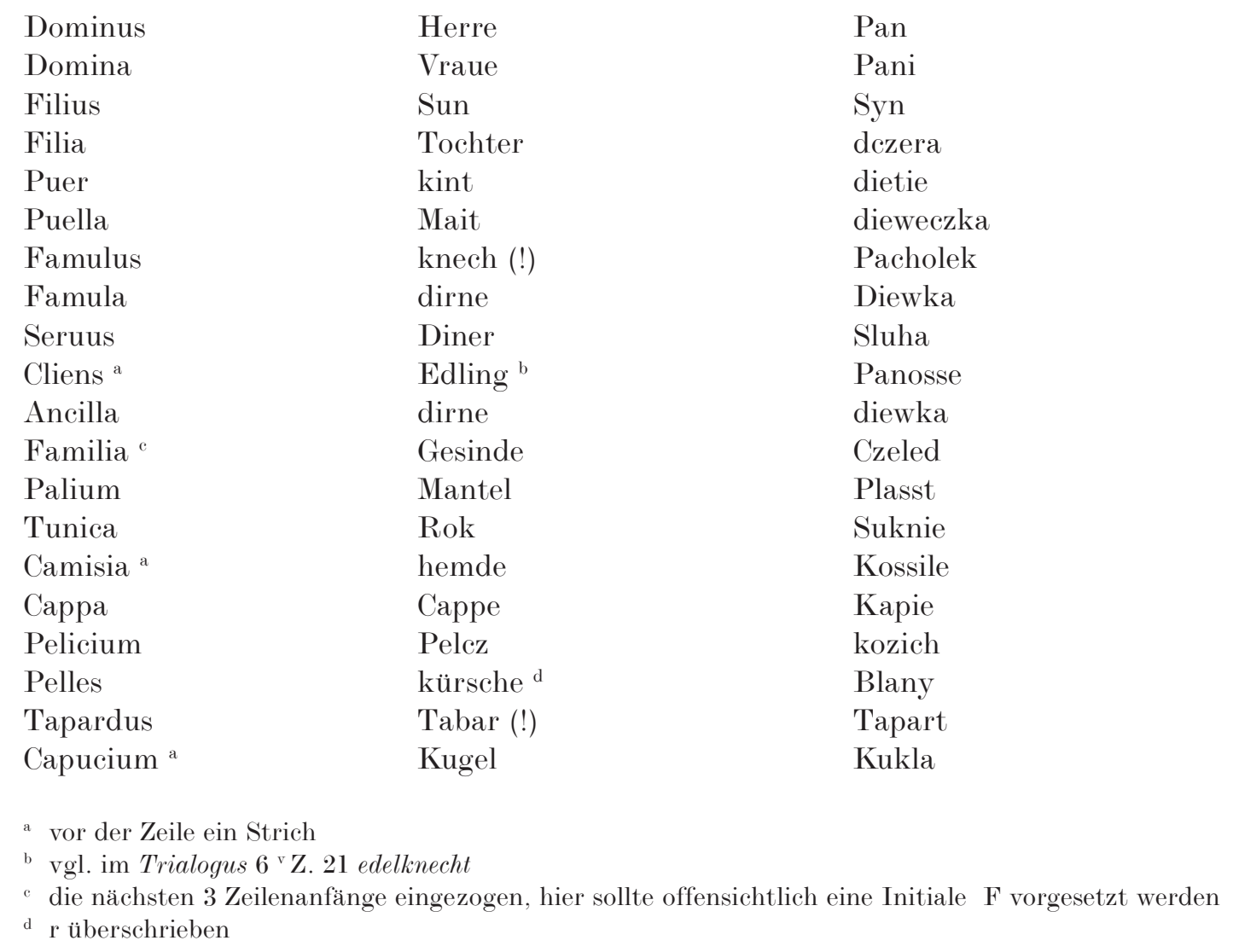


$55^{\mathrm{r}}$

\begin{tabular}{|c|c|c|}
\hline Pileum & Hut & Kobluk \\
\hline Mitra & Hübe & Czepicze \\
\hline Cingulus & Gurtel & Pas \\
\hline Bursa & Peicel a & Miessecz $^{b}$ \\
\hline Uagina & Scheide & Noznicze \\
\hline Cutellus & Messer & Nuz \\
\hline Manubrium & hefte & Trzen \\
\hline Cirorote & Hanczige $^{c}$ & Rukawicze $^{b}$ \\
\hline Manica & Ermel & Rukaw \\
\hline Braca & Bruch & hacze $^{\mathrm{d}}$ \\
\hline Bracale & Bruchgirtel & hacznik ${ }^{\mathrm{d}}$ \\
\hline Liga & Nestel & Stuha \\
\hline Superpeliciu(m) & korrecel (!) & komze \\
\hline Ocrea & Schtiuel & Sskornie \\
\hline Calcius & Schuch & Strzewicz \\
\hline Caliga & hose & Nohawicze \\
\hline Calcar & Schporn & Ostroha \\
\hline Antipedia & fürfus & Narti \\
\hline Subsolee ${ }^{\mathrm{e}}$ & Solen & Podesswy \\
\hline Sutor & Schuster & Sswecz \\
\hline \multicolumn{3}{|c|}{ 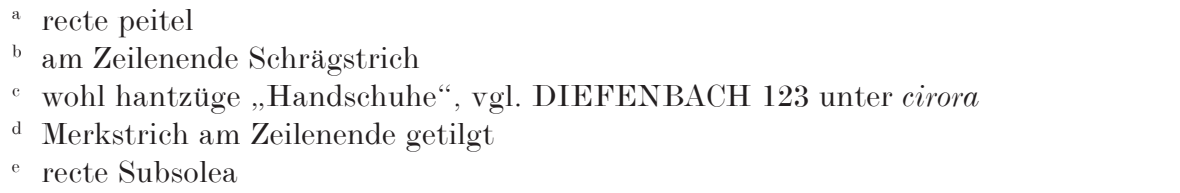 } \\
\hline
\end{tabular}


$5^{\mathrm{v}}$

$\begin{array}{lll}\text { Subula }{ }^{a} & \text { Ole } & \text { Ssidlo } \\ \text { Domus } & \text { hüse } & \text { Duom } \\ \text { Curia } & \text { hof } & \text { Dwur } \\ \text { Seps } & \text { Czeum } & \text { Plot } \\ \text { Horeum } & \text { Schewne } & \text { Stodola } \\ \text { Cumulus } & \text { Heuf } & \text { hromada } \\ \text { Area } & \text { Houeschtat } & \text { Miessczisstie } \\ \text { Porta } & \text { Pforte } & \text { Wrata } \\ \text { Stuba } & \text { Sstube } & \text { Gizba } \\ \text { Trabs } & \text { Enbol } & \text { Tram, brzewno } \\ \text { Paries } & \text { want } & \text { Stiena } \\ \text { Fenestra } & \text { venster } & \text { Okno } \\ \text { Scampnu(m) } & \text { Bank } & \text { Lawicze } \\ \text { Sedes } & \text { Schtul } & \text { Stolicze } \\ \text { Scabellum } & \text { Schemel } & \text { Stoliczka } \\ \text { Muscus } & \text { Moz } & \text { Mech } \\ \text { Hostium } & \text { Tür } & \text { Dwerzi } \\ \text { Limen } & \text { Swelle } & \text { Prah } \\ \text { Postis } & \text { Turschtudel } & \text { Podwoy } \\ \text { Cardo } & \text { Turangel } & \text { Steżege }\end{array}$

a die beiden nächsten Zeilen eingezogen. Hier sollte offenbar eine Initiale S vorgesetzt werden

${ }^{b}$ deutsches und tschechisches Lemma vertauscht 
$56^{\mathrm{r}}$

$\begin{array}{lll}\text { Palacium } & \text { Palas } & \text { Sýn } \\ \text { Camera } & \text { kamer } & \text { Komora } \\ \text { Tectum } & \text { Dach } & \text { Strzecha } \\ \text { Tegula } & \text { latte } & \text { lat } \\ \text { Celarium } & \text { keler } & \text { Piwnicze } \\ \text { Coquina } & \text { kuchen } & \text { Kuchenie } \\ \text { Cocus } & \text { koch } & \text { Kucharz } \\ \text { Colla } & \text { Topf } & \text { Hrnecz } \\ \text { Patella } & \text { Pfan } & \text { Panew } \\ \text { Cacabus } & \text { Sturcze } & \text { Pokliczka } \\ \text { Caldar } & \text { kessel } & \text { Kotel } \\ \text { Mortarium } & \text { Mörser } & \text { Mozdirz } \\ \text { Ueru } & \text { Schpis } & \text { Rozen } \\ \text { Tina } & \text { Czuber } & \text { Czber } \\ \text { Urna } & \text { Eymer } & \text { wiedro } \\ \text { Urcus } & \text { Idem } & \text { a } \\ \text { Scutella } & \text { Schussel } & \text { Misa } \\ \text { Discus } & \text { En Asch } & \text { okrzin } \\ \text { Peluis } & \text { Becken } & \text { Medenicze } \\ \text { Patera } & \text { Maser } & \\ & & \text { Rzepicze }\end{array}$

a vacat

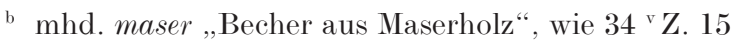




$\begin{array}{lll}\text { Ciphus } & \text { Koph } & \text { Koflik } \\ \text { Picarium } & \text { Becher } & \text { Czesse } \\ \text { Mensa } & \text { Tisch } & \text { Stul } \\ \text { Mensale } & \text { Tischtuch a } & \text { Vbrus } \\ \text { Manuterium } & \text { Hanttuch } & \text { Rucznik, vbrusecz } \\ \text { Coclear } & \text { lefel } & \text { lzicze } \\ \text { Dapifer } & \text { Truktessen }(!) & \text { Trogezes } \\ \text { Pincerna } & \text { Schenke } & \text { Ssenk } \\ \text { Tapetum } & \text { Tept } & \text { Koberzecz } \\ \text { Capisteriu }(m) & \text { Mulde } & \text { Neczky } \\ \text { Dolium } & \text { Butte } & \text { kad } \\ \text { Uas } & \text { vaz } & \text { Sud } \\ \text { Sera } & \text { Schlos } & \text { Zamek } \\ \text { Clauis } & \text { Schlissel } & \text { Klicz } \\ \text { Carbo } & \text { Cole } & \text { Vhel } \\ \text { Cinis } & \text { Asche } & \text { Popel } \\ \text { Scintilla } & \text { Funke } & \text { Giskra } \\ \text { Cista } & \text { Kaste } & \text { Truhla } \\ \text { Lectus } & \text { Bette } & \text { Loże }{ }^{b} \\ \text { Lectisterniu }(m) & \text { Bettegewant } & \text { Lożni rucho }{ }^{b} \\ \text { a deutsches und tschechisches Lemma vertauscht } & \\ { }^{b} \text { Pungierung unter dem z } & & \end{array}$


$57^{\mathrm{r}}$

\begin{tabular}{|c|c|c|}
\hline Culcitra & Kolter & Koltra \\
\hline Linteamen & leilach & Prostiradlo \\
\hline Cusinum & Kussen & Podusska \\
\hline Puluinar ${ }^{a}$ & Phul & Polsstarz \\
\hline Equus & Pfert & Kuon \\
\hline Equa & Pfertine ${ }^{b}$ & Kobila \\
\hline Spado & Hengst & Hinsst \\
\hline Ambulator & Celder & Mimochodnik \\
\hline Troctator & Draber & Klusawecz \\
\hline Elephas & Elephant & Slon \\
\hline Camelus & kamel & welblud \\
\hline Mulus & Murl (!) ${ }^{\mathrm{c}}$ & Mezek \\
\hline Asinus & Esel & wosel \\
\hline Bos & Ochs & wul \\
\hline Uacca & $\mathrm{Ku}$ & Krawa \\
\hline Taurus & Rint & Byk \\
\hline Iumentum & Fie & howado \\
\hline Uitulus & kalbe & Tele \\
\hline Ouis & Schof & Owcze \\
\hline Aries & Ster & Beran \\
\hline
\end{tabular}




$\begin{array}{lll}\begin{array}{l}\text { Agnus }{ }^{\text {a }} \\ \text { Agnellus a } \\ \text { Capra }\end{array} & \text { Schepcz } & \text { Skopecz } \\ \text { Hircus } & \text { Lam } & \text { Gehnie } \\ \text { Corcus } & \text { Bok } & \text { Koza } \\ \text { Porcellus } & \text { Vark } & \text { Kozel } \\ \text { Aper } & \text { varkelein } & \text { Prase } \\ \text { Scropha } & \text { Ber } & \text { Prasatko } \\ \text { Auca } & \text { Sü } & \text { Kanecz } \\ \text { Anser } & \text { Ganz } & \text { Swinie } \\ \text { Ala } & \text { Ganzer } & \text { Hus } \\ \text { Penna } & \text { Flugel } & \text { Hauser } \\ \text { Pilus } & \text { Feder } & \text { Krzidko } \\ \text { Pullus } & \text { har } & \text { Pero } \\ \text { Gallus } & \text { Hun } & \text { Srst } \\ \text { Galina } & \text { Hane } & \text { Kurze } \\ \text { Aneta } & \text { Henne } & \text { Kokot } \\ \text { Anetarius } & \text { Ente } & \text { Slepicze } \\ \text { Cignus } & \text { Enter } & \text { Kaczicze } \\ \text { Edus } & \text { Swan } & \text { Kaczer } \\ & \text { Czikkel } & \text { labut } \\ & & \text { Kozle }\end{array}$

a zwischen beiden Zeilen ein vorgesetzter Merkstrich 
$58^{\mathrm{r}}$

$\begin{array}{ll}\text { Craculus } & \text { Herr } \\ \text { Cuculus } & \text { Kuccuc } \\ \text { Conturnix } & \text { Hozelhün } \\ \text { Cordellus } & \text { Stigelicz } \\ \text { Alauda } & \text { Leriche } \\ \text { Merops } & \text { Specht } \\ \text { Ciconia } & \text { Schtorch } \\ \text { Grus } & \text { Kranch (!) } \\ \text { Aquilla } & \text { Ar } \\ \text { Uultur } & \text { Gire } \\ \text { Miluus } & \text { wie } \\ \text { Bubo } & \text { Huwe } \\ \text { Fasianus } & \text { Faysan } \\ \text { Accipiter } & \text { Habich } \\ \text { Nisus } & \text { Sperwer } \\ \text { Cornix } & \text { Kra } \\ \text { Coruus } & \text { Rob } \\ \text { Pica } & \text { Alester } \\ \text { Monedula } & \text { Tole } \\ \text { Passer } & \text { Schperlink } \\ & \\ \text { a hinter den ersten vier Zeilen je ein senkrechter Haarstrich } \\ \text { b durch Unterschreibung des ursprünglich initialen S mit z korrigiert } \\ \text { c ursprünglich wliha. i pungiert } \\ \text { d am Zeilenende ein senkrechter } \\ \text { Merkstrich }\end{array}$

Soyka ${ }^{a}$

zezhule $^{b}$

Rzerzabek

Stehlecz

Sskrziwanecz

wha ${ }^{\mathrm{c}}$

Czap

Rzerzab ${ }^{\mathrm{d}}$

Orlicze

Sup

10

Lunyak

wýr ${ }^{\mathrm{d}}$

Bazant d

Gestrzab

krahugecz

wrana

Hawran

Straka

Kawka

Wrabecz

20 
$58^{\mathrm{v}}$

\begin{tabular}{|c|c|c|}
\hline Catus $^{\text {a }}$ & Kacze & Koczka \\
\hline Murilegus & Kater & Koczur \\
\hline Mus & Meize (!) & Miss \\
\hline Talpa & Moltferf (!) & Krticze \\
\hline Uermis & Wurm & Czerw \\
\hline Musca & fflige & Mucha \\
\hline Culex & Mucke & komar \\
\hline Serpens & Slange & $\mathrm{Had}$ \\
\hline Rana & krote & Zaba \\
\hline Cicada ${ }^{b}$ & Heime & Swrczek \\
\hline Mustela ${ }^{b}$ & Wisel & Wlasycze \\
\hline Scorpio & Schkorp & Sstir \\
\hline Mons ${ }^{\mathrm{c}}$ & Berg & Hora \\
\hline Moneta $^{c}$ & Muncze & Raz \\
\hline Metallum & Erez & Ruda \\
\hline Plumbum & Blei & Olowo \\
\hline Cuprum & Kupfer & Mosaz \\
\hline $\mathrm{Es}$ & $\operatorname{Er}(!)$ & Mied \\
\hline Ferrum & Eysen & Zelezo \\
\hline Calibs & Stal & Oczel \\
\hline
\end{tabular}


$59^{\mathrm{r}}$

\begin{tabular}{lll} 
Aurum & Golt & Zlatto \\
Argentum & Silber & Strzibro \\
Denarius & Pfenning & Peniez \\
Obulus & Heller & Halerz \\
Babatum & Huweisen & Podkowa \\
Tenaces & Czange & klesscze \\
Forceps & Scher & Nuoze \\
Folles & Blasbalk & Miechy \\
Blesus & Lispener & Sseplawy a \\
Mancus & Anhant & Bezruky \\
Cecus & Blinder & Slepy \\
Surdus & Toep (!) & Hluchy \\
Leprosus & Auzzeczic & Malomoczny \\
Malus & Boze & Zly a \\
Bonus & Gut & Dobry \\
Pomus & Eppfelböm & Jabllön \\
Pomum & Eppfel & Jablko \\
Persicus & Pfirche (!) & Brzeskwie \\
Prinella & Pfleumen & Sliwy, Trnky \\
Cerosa & kirschen & Trzessnie \\
& & \\
a am Zeilenende Merkstrich & & \\
s Nachtrag, davor Wissnie durch Punktation gelöscht, vgl. S. 33 & \\
\hline
\end{tabular}


$59^{\mathrm{v}}$

$\begin{array}{lll}\text { Merosa } & \text { Weiksl } & \text { Wisnie } \\ \text { Corulus }{ }^{a} & \text { Hasel } & \text { Leska } \\ \text { Labrusca } & \text { Kalingen } & \text { Kalina } \\ \text { Fraga } & \text { Beren } & \text { Jahoda } \\ \text { Taxus } & \text { Knivore }{ }^{b} & \text { Tis } \\ \text { Quercus } & \text { Eyche } & \text { Dub } \\ \text { Platanus } & \text { Ahorn } & \text { Jawor } \\ \text { Tilia } & \text { Linde } & \text { Lipa } \\ \text { Bedula } & \text { Birken } & \text { Brzeza } \\ \text { Abies }{ }^{a} & \text { Tanne } & \text { Gedle } \\ \text { Salix } & \text { weiden } & \text { Wrba } \\ \text { Spina } & \text { Dorn } & \text { Trn } \\ \text { Tribulus } & \text { Distel } & \text { Bodlak } \\ \text { Uirga a } & \text { Rut } & \text { Metla } \\ \text { Scopa } & \text { Besem } & \text { Chwossczisscze } \\ \text { Nemus } & \text { Pusch } & \text { Hay } \\ \text { Silua } & \text { walt } & \text { Les } \\ \text { Lignum } & \text { Holcz } & \text { Drzewo } \\ \text { Pomerium } & \text { Baumgarte } & \text { Sad } \\ \text { Pomum } & \text { Appfel } & \text { Jablko } \\ & & \\ \text { a vor Zeile Merkstrich } & & \\ \text { b vermutlich Kompositum aus } & \text { mhd. }{ }^{\circ} \text { knie }+ \text { vorhe } & \end{array}$


$60^{\mathrm{r}}$

$\begin{array}{ll}\text { Pirum } & \text { Birrn } \\ \text { Uinea } & \text { Weingart } \\ \text { Uinum } & \text { Wein } \\ \text { Uua } & \text { weinber } \\ \text { Botrus } & \text { weinber } \\ \text { Ceruisia } & \text { Bir } \\ \text { Medo } & \text { mede } \\ \text { Cera } & \text { Wachs } \\ \text { Candela } & \text { kercze } \\ \text { Licmen a } & \text { knot } \\ \text { Sona } & \text { Schtrik } \\ \text { Sepum } & \text { Vnczlit } \\ \text { Lucibulum } & \text { Lichtschirbe } \\ \text { Lumen } & \text { Licht } \\ \text { Ortus } & \text { Garte } \\ \text { Ortulanus } & \text { Gartnar } \\ \text { Caulis, olus } & \text { Kreut b } \\ \text { Pepo } & \text { Pluczer } \\ \text { Rappa } & \text { Rübe } \\ \text { Raphanus } & \text { Retich } \\ \text { a recte Ligamen } & \\ \text { b r eingeflickt } & \\ \end{array}$

Hrusska

winicze

wino

Hrozen

Hrozen

Piwo

Med

wosk

Swicze

Knot

Prowaz

Loy

Kahanecz

Swielo (!)

Zahrada

15

Zahradnik

Zele

Dinie

Rzipa

Rzedkew

20 
60

$\begin{array}{ll}\begin{array}{ll}\text { Aleum } \\ \text { Cepe }\end{array} & \begin{array}{l}\text { Knobleich } \\ \text { Czwippolle } \\ \text { Sinapum }\end{array} \\ \text { Senf } \\ \text { Papauer } & \text { Mon } \\ \text { Faba } & \text { Bon } \\ \text { Saluia } & \text { Salbey } \\ \text { Petruselinu(m) } & \text { Petrsilie (!) } \\ \text { Campus } & \text { Velt } \\ \text { Ager } & \text { Acker } \\ \text { Sulcus } & \text { Furch } \\ \text { Semina } & \text { Samen } \\ \text { Triticum } & \text { weise (!) } \\ \text { Frumentu(m) } & \text { Getred } \\ \text { Siligo } & \text { Korn } \\ \text { Ordeum } & \text { Gerste } \\ \text { Auena } & \text { Hauer } \\ \text { Pisa } & \text { Erweis } \\ \text { Canapum } & \text { Hanf } \\ \text { Stramen } & \text { Schtro } \\ \text { Manipulus } & \text { Garbe } \\ & \\ \text { a davor Si getilgt } & \end{array}$

Czesnek

Czibule

Horczicze

Mak

Bob

Ssalwie

Petruzel

Pole

Role

Zahon

Semena

Pssenicze

Obile

Zito ${ }^{a}$

Geczmen

Owes

Hrach

Semenecz

Slama

Snop 
$61^{\mathrm{r}}$

$\begin{array}{ll}\text { Tritulator } & \text { Drescher } \\ \text { Nessor }{ }^{\text {a }} & \text { Sniczer } \\ \text { Falcator } & \text { Meder } \\ \text { Pratum } & \text { Wise } \\ \text { Gramina } & \text { Gras } \\ \text { Fenum } & \text { Hew } \\ \text { Palea } & \text { Spruy (!) } \\ \text { Pabulum }{ }^{\text {c }} & \text { Futer } \\ \text { Glossus } & \text { Scheup } \\ \text { Spica } & \text { Eher } \\ \text { Stipula } & \text { Stupfl } \\ \text { Rastrum } & \text { Eyde } \\ \text { Furca } & \text { Gabel } \\ \text { Annona } & \text { Getreide } \\ \text { Farina } & \text { Mel } \\ \text { Simula } & \text { Semel } \\ \text { Furfures } & \text { kleien } \\ \text { Siliques } & \text { Treber } \\ \text { Trica } & \text { Czopf } \\ \text { Exul } & \text { Elende } \\ & \\ \text { a recte Messor } & \\ \text { b recte Snitter } & \text { a aus p korrigiert } \\ \text { d am Zeilenende Merkstrich } & \\ & \\ & \\ & \end{array}$

Mlatecz

Zenecz

Senoseczecz

Luca

Trawa

Seno

Plewa

Obrok

Doch ${ }^{\mathrm{d}}$

klas

10

Strnisscze

Hrabie

widly

Obile

Muka

Zemle

Otruby

Mlato

Vplet

Wypowiedieny

20 


\begin{tabular}{|c|c|c|}
\hline Fur & Diep & Zlodiey \\
\hline Ecclesia & Kirche & Kostel \\
\hline Claustrum & kloster & Klasster \\
\hline Turris & Turm & wieze \\
\hline Campana ${ }^{a}$ & Glocke & Zwon \\
\hline Campanile a & Glockehuz & Zwonicze \\
\hline Campanator ${ }^{a}$ & Glockner & Zwonik \\
\hline Camerarius ${ }^{\text {a }}$ & Kemerer & Komornik \\
\hline Sacerdos & Prister & kniez \\
\hline Dyaconus & Dyaken & Jahen \\
\hline Clericus & Schuler & Zak \\
\hline Fcolaris ${ }^{b}$ & Idem & Tez \\
\hline Magister & Meister ${ }^{c}$ & Mistr ${ }^{c}$ \\
\hline Discipulus & Junger & Vezedlnik \\
\hline Ydiota & vngelert & Nedouka \\
\hline Papa & Pobest & Papez \\
\hline Imperator & Keiser & Czysarz \\
\hline Rex & Kunig & Kral \\
\hline Regina & Konigin & Kralowna \\
\hline Regulus & Cleinkunig & Kralik \\
\hline
\end{tabular}


$62^{\mathrm{r}}$

$\begin{array}{ll}\text { Dux } & \text { Herczoge } \\ \text { Ducissa } & \text { Herczogin } \\ \text { Princeps } & \text { Furste } \\ \text { Regnum } & \text { Kunigreiche } \\ \text { Sceptrum } & \text { Cepter } \\ \text { Episcopus } & \text { Bischof } \\ \text { Prepositus } & \text { Probost } \\ \text { Decanus } & \text { Techan } \\ \text { Archidiacon(us) } & \text { Erczepryster } \\ \text { Canonicus } & \text { Tumherre } \\ \text { Obediencia } & \text { Gehorsomkeit } \\ \text { Patria } & \text { Lant } \\ \text { Hereditas } & \text { Erbe } \\ \text { Uilla } & \text { Dorf } \\ \text { Comes } & \text { Groue } \\ \text { Comitissa } & \text { Grouinne } \\ \text { Miles } & \text { Rytter } \\ \text { Clipeus } & \text { Schilt } \\ \text { Custicus }{ }^{b} & \text { Gebeuer } \\ \text { Merces } & \text { lon } \\ \text { a Merkstrich nach Zeilenende } & \\ \text { b der Rubrikator setzte irrtümlich C statt R }\end{array}$

Wewoda

Wewodina

Knize

Kralowstwie

Berla

Biskup

Probosst

Diekan

Arczyprzist ${ }^{\text {a }}$

Kanownik

10

Posslussenstwie

wlast

Diedicztwie

Wes

Hrabie $^{a}$

Hrabinka ${ }^{a}$

Rytierz

Sstit

Sedlak

Mzda

20 
62

$\begin{array}{ll}\text { Uillicus } & \text { Anwalder } \\ \text { Gladius } & \text { Schwert } \\ \text { Galea } & \text { helm } \\ \text { Lorica } & \text { Panczer } \\ \text { Torax } & \text { Plate } \\ \text { Frenum } & \text { Czoum } \\ \text { Hasta } & \text { Sper } \\ \text { Faretra } & \text { kecher } \\ \text { Arcus a } & \text { Boge } \\ \text { Balista } & \text { Armbrust } \\ \text { Sagitta } & \text { Geschos } \\ \text { Telum } & \text { Pfayl } \\ \text { Cuspis } & \text { Schpis } \\ \text { Arma } & \text { Woppen } \\ \text { Iopa } & \text { Joppe } \\ \text { Securis } & \text { Aks } \\ \text { Dolabrum } & \text { Mesel } \\ \text { Terebellum } & \text { Newiger } \\ \text { Serra } & \text { Zage } \\ \text { Maleus } & \text { Hammer }\end{array}$

Wladarz

Mecz

Helm

Panczyrz

Platy

Vzda

Kopi

Tul

Luczisstie

Samostrzil

Strzela

Ssip

Sudlicze

Odieni

Kabat

Sekera

Dlato

Nebozyz

Pila

Kladiwo

a Merkstrich vor Zeilenbeginn 
$63^{\mathrm{r}}$

$\begin{array}{lll}\text { Carpentarius } & \text { Czimmerma(n) } & \text { Tesarz } \\ \text { Lac } & \text { Millich }{ }^{\text {a }} & \text { Mleko }{ }^{a} \\ \text { Caseus } & \text { Kese } & \text { Syr } \\ \text { Formodium } & \text { Twark } & \text { Twaroh } \\ \text { Formatica } & \text { Smetan } & \text { Smetana } \\ \text { Butirum } & \text { Buttr } & \text { Maslo } \\ \text { Polenta } & \text { Keizlicz } & \text { Kyselicze } \\ \text { Panis } & \text { Brot } & \text { Chleb } \\ \text { Placenta } & \text { Mazancz } & \text { Mazanecz } \\ \text { Clibanus } & \text { Backouen } & \text { Pecz } \\ \text { Caminus } & \text { Feuwermaur } & \text { kominus } \\ \text { Fornax } & \text { Owen } & \text { Kamana (!) } \\ \text { Lapis } & \text { Schtein } & \text { Kamen } \\ \text { Petra } & \text { Schten (!) } & \text { Skala } \\ \text { Stabulum } & \text { Stal } & \text { Chlew } \\ \text { Presepe } & \text { krippe } & \text { Gesle } \\ \text { Ceruus } & \text { Hirzz } & \text { Gelen } \\ \text { Ursus } & \text { Ber } & \text { Nedwied } \\ \text { Bubalus } & \text { Aurochse } & \text { Buwol }{ }^{b} \\ \text { Lupus } & \text { Wolf } & \text { Wlk } \\ \text { a deutsches und tschechisches } & \text { Lemma vertauscht } & \\ \text { b Merkstrich nach Zeilenende } & & \\ & & \end{array}$


$63^{\mathrm{v}}$

\begin{tabular}{|c|c|c|}
\hline Lepus & Hase & Zagicz \\
\hline Wulpis & Fuchs & lisska \\
\hline Symea & Affe & Opicze \\
\hline Capriollus ${ }^{\text {a }}$ & Rech & Srna \\
\hline Capricornus & Einhorn & Gednorozecz \\
\hline Erinacius & Igel & Gezek \\
\hline Asperiollus a & Eichorn & Wewerzicze \\
\hline Auis & Vogel & Ptak \\
\hline Grifo & Greiff & Noh \\
\hline Strucio & Straus & Sstros \\
\hline Passer & Sperlink & wrabecz \\
\hline Oocticorax ${ }^{b}$ & Nachtrabe & Sicz, kalus \\
\hline Uespertilio & Fledermaus & Netopyrz \\
\hline Lacerta & Aüdaxe & Jessczerka \\
\hline Bufo & Crot & Zaba \\
\hline Columbus & Teub ${ }^{c}$ & holub \\
\hline Columba & Teube & Holubicze \\
\hline Irund d & Swalwe & Wlastowicze \\
\hline Turtur & Turtelteube & Hrdliczka \\
\hline Perdix & Rebhun & Kuroptwa \\
\hline
\end{tabular}


$64^{\mathrm{r}}$

$\begin{array}{lll}\text { Qviscula } & \text { Wachtel } & \text { Krzepelicze } \\ \text { Filomena } & \text { Nachtigal } & \text { Slawik } \\ \text { Mare } & \text { Mer } & \text { Morze } \\ \text { Infernus } & \text { Helle } & \text { Peklo } \\ \text { Lacus } & \text { Ze } & \text { Gezero } \\ \text { Draco } & \text { Trache } & \text { Drak } \\ \text { Dyabulus } & \text { Teuuel } & \text { Diabel } \\ \text { Tonitru (!) } & \text { Dorne (!) a } & \text { Hrom } \\ \text { Luuia } & \text { Regen } & \text { Desst } \\ \text { Nix } & \text { Sne } & \text { Snih } \\ \text { Gelu } & \text { Frost } & \text { Mraz } \\ \text { Glacies } & \text { Eys }{ }^{b} & \text { led } \\ \text { Frigus } & \text { Kelde } & \text { Zima } \\ \text { Uentus } & \text { wint }{ }^{b} & \text { witr } \\ \text { Nauis } & \text { Schif } & \text { Lodi } \\ \text { Nauigium } & \text { Schifunge } & \text { Prziwoz } \\ \text { Littus } & \text { Vber } & \text { Brzeh } \\ \text { Remus } & \text { Ruder } & \text { weslo } \\ \text { Flumen } & \text { Bach } & \text { Rzeka } \\ \text { Fluuius } & \text { Flus } & \text { Potok } \\ \text { a recte Donner } & & \\ \text { b Zierpunkte fehlen } & & \\ & & \end{array}$


64

$\begin{array}{lll}\text { FOns } & \text { Brun } & \text { Studnicze } \\ \text { Diluuium } & \text { Sintflut } & \text { Potopa } \\ \text { Piscis } & \text { Fischs (!) } & \text { Ryba } \\ \text { Cetus } & \text { walfisch } & \text { Welryb } \\ \text { Usio } & \text { Hüse } & \text { Wyzyna } \\ \text { Salmo } & \text { Salm, Lachs } & \text { Losos } \\ \text { Luceus }{ }^{a} & \text { Hecht } & \text { Sstika } \\ \text { Angwilla } & \text { Ol } & \text { Vhorz } \\ \text { Truta } & \text { vore }{ }^{b} & \text { Pstruh } \\ \text { Allec } & \text { Herink } & \text { herynk } \\ \text { Cancer } & \text { Crebs } & \text { Rak } \\ \text { Caluus } & \text { Cal } & \text { Lysy b } \\ \text { Claudus } & \text { Lam } & \text { Kulhawý } \\ \text { Scabiosus } & \text { Grindechter } & \text { Prassiwy } \\ \text { Mutus } & \text { Stum(m)er } & \text { Niemý } \\ \text { Luscus } & \text { Schilinder } & \text { Ssilhawý } \\ \text { Crispus } & \text { Crusper } & \text { Kaderzawý } \\ \text { Niger } & \text { Schwarcz } & \text { Czrný } \\ \text { Albus } & \text { weys }{ }^{b} & \text { Bilý } \\ \text { Rubeus } & \text { Rot } & \text { Czrwený }\end{array}$

a zweites $\mathrm{u}$ aus i korrigiert

b Zierpunkte fehlen 
$65^{\mathrm{r}}$

$\begin{array}{ll}\text { Mendicus } & \text { Beteler } \\ \text { Pauper } & \text { Armer } \\ \text { Diues } & \text { Reich } \\ \text { Usura } & \text { wucher } \\ \text { Usurarius } & \text { wuch(e)rer } \\ \text { Mercator } & \text { koufman } \\ \text { Largus } & \text { Milde } \\ \text { Parcus } & \text { karg } \\ \text { Pius } & \text { Gütlich } \\ \text { Benignus } & \text { Idem } \\ \text { Mitis } & \text { Semfte } \\ \text { Misericors } & \text { Barmherczik } \\ \text { Humilis } & \text { Dimittik } \\ \text { Paciens } & \text { Geduldic } \\ \text { Superbus } & \text { Hochfertik } \\ \text { Iracundus } & \text { Czorniger } \\ \text { Flagellum } & \text { Geizel } \\ \text { Flabellum } & \text { wedel } \\ \text { Abbas } & \text { Abt } \\ \text { Monachus } & \text { Minnich }\end{array}$

Zebrak

Chudý

Bohatý

Lichwa

lichewnik

Kupecz

Ssczedry

Skupy

Milostiwy

Dobrotiwy

Tichy

Milosrdny

Pokorny

Trpeliwy (!)

Hrdý

Hniewiwy

Bicz

wohanka ${ }^{a}$

Opat ${ }^{a}$

Mnich

20

a Merkstrich am Zeilenende 
$65^{\mathrm{v} a}$

$\begin{array}{lll}\text { Monialis } & \text { Nunne } & \text { Jebczisska } \\ \text { Uerteca } & \text { wurcze } & \text { Bradawicze } \\ \text { Statua } & \text { Süle } & \text { Socha } \\ \text { Colus } & \text { Rocke } & \text { Przeslicze } \\ \text { Fusum } & \text { Spille } & \text { Potacz } \\ \text { Sigillum } & \text { Garnrocke } & \text { Kolowrat } \\ \text { Glomicellu(m) } & \text { Glauwen } & \text { Klubko } \\ \text { Merdare }{ }^{\text {b }} & \text { Scheysen } & \text { Sraty } \\ \text { Comedere } & \text { Essen } & \text { Gisty } \\ \text { Permerdare } & \text { Bescheysen } & \text { Zesraty } \\ \text { Lingere } & \text { Lekchen } & \text { Lyzati } \\ \text { Merda } & \text { Drekh } & \text { howno } \\ \text { Culus } & \text { Ars } & \text { Rzyt } \\ \text { Testiculi } & \text { Chuoden }{ }^{\text {c }} & \text { Muodye } \\ \text { a vgl. Abb. 8 } & & \\ \text { b die restlichen Zeilen vom Schreiber C nachgetragen, vgl. S. 33 und Abb. 18. Keine rubrizierten Initialen } \\ \text { oder Zierpunkte. Vgl. S. 18 und Abb. 8 }\end{array}$

